Article

\title{
An Integrated Method Combining Remote Sensing Data and Local Knowledge for the Large-Scale Estimation of Seismic Loss Risks to Buildings in the Context of Rapid Socioeconomic Growth: A Case Study in Tangshan, China
}

\section{Guiwu Su ${ }^{1, *}$, Wenhua Qi ${ }^{1}$, Suling Zhang ${ }^{2}$, Timothy Sim ${ }^{3}$, Xinsheng Liu ${ }^{4,5}$, Rui Sun ${ }^{4,5}$, Lei Sun ${ }^{1}$ and Yifan Jin ${ }^{1}$}

1 Institute of Geology, China Earthquake Administration, Beijing 100029, China;

E-Mails: xiamen1985@163.com (W.Q.); sunleiyanshan_2008@126.com (L.S.); jinyifan518@gmail.com (Y.J.)

2 China Earthquake Networks Center, China Earthquake Administration, Beijing 100045, China; E-Mail: zs1@seis.ac.cn

3 Department of Applied Social Sciences, Faculty of Health and Social Sciences, The Hong Kong Polytechnic University, Hong Kong 999077, China;

E-Mail: timothy.sim@polyu.edu.hk

4 School of Geography, Beijing Normal University, Beijing 100875, China; E-Mails: sinsonglew@mail.bnu.edu.cn (X.L.); sunrui@bnu.edu.cn (R.S.)

5 State Key Laboratory of Remote Sensing Science, Co-Sponsored by Beijing Normal University and RADI, Beijing 100875, China

* Author to whom correspondence should be addressed; E-Mail: suguiwu@ies.ac.cn; Tel.: +86-10-6200-9075.

Academic Editors: George P. Petropoulos and Prasad S. Thenkabail

Received: 25 August 2014 / Accepted: 17 February 2015 / Published: 4 March 2015

\begin{abstract}
Rapid socioeconomic development in earthquake-prone areas can cause rapid changes in seismic loss risks. These changes make it difficult to ensure that risk reduction strategies are realistic, practical and effective over time. To overcome this difficulty, ongoing changes in risk should be captured timely, definitively, and accurately and then specific and well-timed adjustments of the relevant strategies should be made. However, methods for rapidly characterizing such seismic disaster risks over a large area have not been sufficiently developed. By focusing on building loss risks, this paper presents the development of an integrated method that combines remote sensing data and local
\end{abstract}


knowledge to resolve this problem. This method includes two key interdependent steps. (1) To extract the heights and footprint areas of a large number of buildings accurately and quickly from single high-resolution optical remote sensing images; (2) To estimate the floor areas, identify structural types, develop damage probability matrixes, and determine economic parameters for calculating monetary losses due to seismic damage to the buildings by reviewing building-relevant local knowledge based on these two parameters (i.e., the building heights and footprint areas). This method is demonstrated in the Tangshan area of China. Based on the integrated method, the total floor area of the residential and public office buildings in central Tangshan in 2009 was $3.99 \%$ lower than the corresponding area number obtained by a conventional earthquake loss estimation project. Our field-based verification indicated that the mean relative error of the method for estimating the floor areas of the assessed buildings was $2.99 \%$. A simulation of the impacts of the 1976 Ms 7.8 Tangshan earthquake using this method indicated that the total damaged floor area of the residential and public office buildings and the associated direct monetary loses in the study area could have been 8.00 and 28.73 times greater, respectively, than in 1976 if this earthquake had recurred in 2009, which is a strong warning to the local people regarding the increasing challenges they may face.

Keywords: rapid socioeconomic growth; high-resolution optical remote sensing image (Hr-ORSI); building-relevant local knowledge (Br-LK); large-scale estimation of risk; seismic loss risk to buildings; Tangshan; China; simulation of the impacts of the $1976 \mathrm{Ms}$ 7.8 Tangshan earthquake

\section{Introduction}

Sound knowledge of seismic disaster risk is a prerequisite for ensuring the effectiveness and efficiency of seismic hazard and disaster mitigation strategies, preparedness measures, and emergency response plans. Seismic disaster risks are constantly and significantly changing in earthquake-prone areas where rapid socioeconomic development is occurring (including many parts of China). One such area is Tangshan, China, which is located in the "Chinese Capital Region". This area experienced severe impacts from the Ms 7.8 earthquake that occurred in 1976 and significant population and economic expansion following 1976. From 1985 to 2010, the population of this administrative region increased from 1.38 to 3.07 million, with the GDP increasing from 0.61 to 67.48 billion USD, urbanization increasing from $24.6 \%$ to $53.4 \%$, and urban built-up areas expanding from 100 to $209 \mathrm{~km}^{2}$ [1]. These increases inevitably caused significant changes in the seismic vulnerabilities and risks from year to year [2-4]. The continual, rapid, and accelerating changes and/or growths in vulnerability and risk have made it difficult to ensure that the area's earthquake disaster risk reduction strategies have remained fact-based, practical and effective over time. Certain strategies may become irrelevant after a short period. To prevent such strategies from becoming irrelevant, associated changes in risks must be captured quickly and accurately to perform timely, specific, and pertinent adjustments. 
In the fields of hazard and disaster research, disaster risk is commonly defined as "the potential disaster losses in lives, health status, livelihoods, assets and services, which could occur to a particular community or a society over some specified future time period" [5]. The classical expression of disaster risk is widely formulated as follows [6]:

$$
R=H \times E \times V
$$

where $R$ is the disaster risk, $H$ is the hazard, $E$ and $V$ represent the elements and vulnerabilities of the elements, respectively, exposed to the hazard.

The oldest and most developed approach for evaluating large scale seismic disaster risks is the conventional and mainstream "earthquake loss estimation" approach. This approach has served as the focus or base of various studies, such as ATC-13 [7], ATC-25 [8], EMS98 [9-11], RADIUS [12], and HAZUS [13-15]. In these studies, the value of $H$ in Equation (1) has typically been expressed as the intensity of the seismic ground motion (e.g., the modified Mercalli intensity (MMI)). The element of $E$ in Equation (1) primarily included buildings, lifelines, other man-made facilities, and the residents themselves, and $V$ was typically expressed in terms of the loss ratio curves (LRCs) or the damaged probability matrixes (DPMs) of the exposed elements $(E)$ induced by seismic ground motion. Assessing the $H$ values with certain reliable specific occurrence probabilities for large areas is extremely difficult; thus, researchers have generally applied deterministic methods (e.g., the scenario earthquake method) to realistically and practically specify, establish and determine the value of $H$ using in Equation (1). These specific previous studies were based on establishing various LRCs or DPMs. One primary advantage of these LRC or DPM-based methods is that they yield definite, accurate results that are usually expressed in terms of the specific numbers of buildings damaged, human casualties, or monetary losses. However, these methods require the preparation of large amounts of detailed data for $E$ in Equation (1) (e.g., building inventories). In most cases, acquiring these data requires significant labor, time and money. When assessing seismic loss risks over a considerably large area with rapid socioeconomic development, applying this type of method may be difficult or impossible. It is highly likely that the large amount of data collection required to target a large area of this type through conventional data preparation cannot keep pace with rapid socioeconomic development and evolving risks. This difficulty is likely greater on the Chinese mainland than elsewhere due to China's current breakneck speed of socioeconomic development.

There are other approaches that are capable of characterizing large-scale seismic disaster risk potentials, including the approaches given by Cutter et al. [16,17], Su et al. [2,3], Carreño et al. [18], and Cardona and Carreño [19]. Unlike the LRC and DPM-based methods, the specific methods of these approaches do not usually address all three elements $(H, E$, and $V$ in Equation (1)) that contribute to risk. Specifically, these previous approaches only addressed the $E$ and $V$ or $V$ elements. However, these $E$ and $V$ or $V$-focused studies can still reveal the seismic risk potentials of a place (to a certain extent) because the exposure of more elements at a certain place and/or the greater vulnerabilities of these elements generally correspond with more risk under conditions with the same seismic intensity impacts. Due to the extreme difficulties that can occur when obtaining seismic intensities with reliable occurrence probabilities for a large area, this general perception and/or understanding of seismic risks or risk potentials is justified and understandable. Thus, this risk perception manner has often been adopted in the field of earthquake disaster research. The first step in these approaches is to establish a 
set of $E$ and $V$ indexes or $V$ indexes with primary components that are derived from various public data sources (e.g., statistical yearbooks). Next, methods of this type are used to synthesize one or several man-made $E$ and $V$ or $V$ composite indexes with values that vary within a certain index range (e.g., from 0 to 1 ) to broadly and comprehensively characterize the disaster risk potentials of a given location. Subsequently, with updated data that can be more easily realized than updating the data required by the LRC or DPM-based methods, the temporal variations of the risk potentials at such locations during various periods can be conveniently observed. Because readily available public data are mainly used as input data, these $E$ and $V$ or $V$ composite index-focused methods possess several advantages over LRC- or DPM-based methods. Specifically, index-focused methods are more comprehensive, save more labor and money, easily cover large areas, and are easier to use when examining potential risk variations (even periodically, such as once every few years). However, conventional and mainstream LRC and DPM-based methods can yield explicit, specific results in terms of specific amounts of building damage, human deaths, and economic losses, whereas the $E$ and $V$ or $V$ composite index-focused methods can only provide general and relative results regarding statistical and inter-place contrast when considering if a location has risks and if the level of a risk at one given location may be greater than another. It is not always easy to determine what elements on earth at a given location are at risk and how serious the hidden problems on earth are when considering results represented as a highly composite index. Moreover, if the basic geographic or spatial unit of analysis for a large scale study is too small (such as the sub-county levels, e.g., the village level or town/township level), the $E$ and $V$ or $V$ composite index-focused methods frequently involve nearly the same levels of difficulty regarding data collection (e.g., the percentage of aged people, per capita income, and mean education level of each village or town/township) as the LRC and DPM-based methods. For example, a distinct lack of public data sources or similar databases exists regarding data at the sub-county scales at the contemporary Chinese mainland. Thus, it is difficult to apply this type of method on a large scale to assess seismic risk potentials at high spatial resolutions.

In addition to the two types of approaches mentioned above that are capable of characterizing seismic disaster risks or risk potentials over large areas, some other studies are also helpful for understanding or estimating seismic disaster risks of an area. Several researchers have developed GDP and population data-based models to broadly estimate the seismic vulnerability and risk of an area [20-23]. However, the risk implications of the results of these studies are not specific or detailed relative to those of conventional and mainstream LRC and DPM-based methods. From the standpoint of timeliness requirements that are crucial for capturing and reducing seismic disaster risks in the context of rapid socioeconomic development, the seismic disaster risk studies that are relevant to the field of remote sensing are particularly valuable. Because remote sensing images, especially those with high resolutions, may be the only currently practical and reliable tools that are capable of providing full, clear and detailed coverage of large areas when labor resources and work times are limited, this information is urgently needed. Recently, apart from applications in post-earthquake impact assessments [24-31], many studies have addressed the application of high-resolution remote sensing technology to pre-earthquake exposure, vulnerability, and risk. In these pre-earthquake studies, the $E$ and/or $V$-relevant issues (see Equation (1)) of various buildings were widely discussed, including various optical imagery-based specific analyses (Table 1) [32-50], some attempts at fusing optical imagery and LiDAR or SAR data [51-53] to help extract the heights of buildings, and several comprehensive reviews [54-57]. 
Table 1. Brief summary of studies that applied high resolution optical RS to determine the seismic loss risks of buildings (excluding reviews).

\begin{tabular}{|c|c|c|c|c|}
\hline Author & Data & $\begin{array}{c}\text { The Main Topics Addressed } \\
\text { (Topics Can Be Categorized as Building Stock/Exposure Focused, Building } \\
\text { Vulnerability Focused, and Specific Building Loss Estimates) }\end{array}$ & $\begin{array}{l}\text { Number of } \\
\text { Buildings or the } \\
\text { Study Area Covered }\end{array}$ & Accuracy or Reliability \\
\hline Dutta et al. [32] & QuickBird & $\begin{array}{l}\text { (1) Developing an automatic method for estimating the number of buildings. } \\
\text { (2) Combining RS-derived roof material information, field data and existing } \\
\text { database data to compile building inventories. The buildings were classified as } \\
\text { low-, mid-, or high-rise reinforced or non-reinforced concrete buildings. } \\
\text { (3) Using the fragility curves of HAZUS and the scenario earthquake method to } \\
\text { estimate the building damage numbers. }\end{array}$ & $\begin{array}{l}52 \mathrm{~km}^{2} \text { (suburban area } \\
\text { of Bangkok, Thailand) }\end{array}$ & Not mentioned. \\
\hline Ehrlich et al. [33] & QuickBird & $\begin{array}{l}\text { Developing automatic methods for extracting building footprint-related urban } \\
\text { built-up areas and building heights. }\end{array}$ & $\begin{array}{l}48 \mathrm{~km}^{2} \text { (urban area of } \\
\text { Sana'a, Yemen) }\end{array}$ & $\begin{array}{l}\text { The MRE of the extraction } \\
\text { of relevant built-up area } \\
\text { was } 78.86 \% \text {. }\end{array}$ \\
\hline Geiß et al. [34] & $\begin{array}{l}\text { IKONOS; } \\
\text { Multi-temporal TM } \\
\text { and ETM; nDSM }\end{array}$ & $\begin{array}{l}\text { Exploring the method and extent by which the seismic vulnerabilities of the } \\
\text { buildings may be examined and assessed directly using various RS-derived } \\
\text { building features and their environments. The in situ assessed vulnerabilities of } \\
\text { the buildings were based on an expert scoring and EMS- } 98 \text { scheme. }\end{array}$ & $\begin{array}{l}434 \text { buildings for } \\
\text { method development }\end{array}$ & $\begin{array}{l}\text { Compared with expert } \\
\text { scoring, the MAPE of the } \\
\text { method was } 10.6 \% \text {. } \\
\text { Compared with EMS- } 98 \text {, } \\
\text { the overall accuracy of the } \\
\text { method was } 65.4 \% \text {. }\end{array}$ \\
\hline Gei $\beta$ et al. [35] & $\begin{array}{l}\text { IKONOS; } \\
\text { Multi-temporal TM } \\
\text { and ETM; nDSM }\end{array}$ & $\begin{array}{l}\text { (1) Examining the correlations of the seismic building structural types } \\
\text { (SBSTs) with the buildings and environmental features derived from remote } \\
\text { sensing data. The in situ determined SBSTs were based on the relevant logic } \\
\text { of HAZUS. } \\
\text { (2) Local LRCs and the scenario intensity-based earthquake loss estimates. }\end{array}$ & $\begin{array}{l}573 \text { buildings for } \\
\text { method development. } \\
\text { Padang, Indonesia } \\
\text { for application }\end{array}$ & $\begin{array}{l}\text { The overall accuracy of the } \\
\text { estimation of SBSTs based } \\
\text { on RS-derived data } \\
\text { was } 84 \% \text {. }\end{array}$ \\
\hline Li and Zhai [36] & $\begin{array}{l}\text { Meter/sub-meter } \\
\text { resolution } \\
\text { satellite images }\end{array}$ & $\begin{array}{l}\text { Developing a semi-automatic method for extracting the building height and floor } \\
\text { number and manually measuring the building footprint. }\end{array}$ & 56 buildings & $\begin{array}{l}\text { The RMSE of floor } \\
\text { number estimate was } 0.467 \\
\text { The MRE of the footprint } \\
\text { estimate was less than } 10 \% \text {. }\end{array}$ \\
\hline
\end{tabular}


Table 1. Cont.

\begin{tabular}{|c|c|c|c|c|}
\hline Author & Data & $\begin{array}{c}\text { The Main Topics Addressed } \\
\text { (Topics Can Be Categorized as Building Stock/Exposure Focused, Building } \\
\text { Vulnerability Focused, and Specific Building Loss Estimates) }\end{array}$ & $\begin{array}{c}\text { Number of } \\
\text { Buildings or the } \\
\text { Study Area Covered }\end{array}$ & Accuracy or Reliability \\
\hline $\begin{array}{l}\text { Miura et al. [37]; } \\
\text { Miura and } \\
\text { Midorikawa [38] }\end{array}$ & IKONOS & $\begin{array}{l}\text { (1) Developing the RS-based method for updating existing GIS building } \\
\text { inventories. The focus of this method was used to automatically detect new } \\
\text { buildings using high-resolution optical images. } \\
\text { (2) Using existing logic for classifying the seismic vulnerabilities of local } \\
\text { buildings to characterize the seismic vulnerability features of the changed } \\
\text { building stock. } \\
\text { (3) Using the fragility curves of local buildings and the scenario earthquake } \\
\text { method to estimate building damage numbers. }\end{array}$ & $\begin{array}{l}\text { Approximately } \\
300 \mathrm{~km}^{2} \text { (Metro } \\
\text { Manila, Philippines) }\end{array}$ & $\begin{array}{l}\text { Nearly } 90 \% \text { of the new mid } \\
\text { and high-rise buildings can be } \\
\text { detected successfully. }\end{array}$ \\
\hline Mück et al. [39] & QuickBird; DEM & $\begin{array}{l}\text { Exploring the method and extent by which the seismic vulnerabilities of buildings } \\
\text { may be evaluated directly using the building features (size, shape, orientation, } \\
\text { regularity, height, and accessibility) derived from RS data. The in-situ building } \\
\text { vulnerability measurements were based on the expert scoring method. }\end{array}$ & $\begin{array}{l}500 \text { buildings for } \\
\text { method development }\end{array}$ & $\begin{array}{l}\text { Compared with expert } \\
\text { scoring-based vulnerability } \\
\text { measurements, the overall } \\
\text { accuracy of the method } \\
\text { was } 81 \% \text {. }\end{array}$ \\
\hline $\begin{array}{l}\text { Panagiota et al. } \\
\text { [40]; Panagiota } \\
\text { et al. }[41]\end{array}$ & $\begin{array}{l}\text { Airborne high } \\
\text { resolution data; } \\
\text { DEM }\end{array}$ & $\begin{array}{l}\text { Exploring a method by which the seismic vulnerabilities of buildings may be } \\
\text { directly evaluated using the building roof types and heights derived from RS data. } \\
\text { The in-situ vulnerability assessments of buildings were based on EMS-98. }\end{array}$ & $\begin{array}{l}402 \text { buildings for } \\
\text { method development }\end{array}$ & $\begin{array}{l}\text { Compared with } \\
\text { EMS98-based vulnerability } \\
\text { assessment, the overall } \\
\text { accuracy of the best model of } \\
\text { the method was } 62.5 \% \text {. }\end{array}$ \\
\hline $\begin{array}{l}\text { Pittore and } \\
\text { Wieland [42]; } \\
\text { Wieland et al. [43] }\end{array}$ & $\begin{array}{l}\text { Multi-temporal } \\
\text { TM and MSS; } \\
\text { High resolution } \\
\text { optical images; } \\
\text { OpenStreetMap; } \\
\text { Omni-directional } \\
\text { images }\end{array}$ & $\begin{array}{l}\text { (1) Developing the method using high-resolution optical RS images and } \\
\text { OpenStreetMap to collect footprints. Developing the method using } \\
\text { Omni-directional images to measure the building heights and floor numbers. } \\
\text { (2) Exploring the method by which the seismic vulnerabilities of buildings } \\
\text { may be directly evaluated by integrating step-by-step building and block's } \\
\text { features derived from multi-source images. These features include } \\
\text { land-use/coverage and the ages of built-up areas of blocks, construction types, } \\
\text { footprints, areas, shapes, heights, floor numbers, ages, and building uses. } \\
\text { The seismic vulnerabilities of buildings were characterized using EMS-98. }\end{array}$ & $\begin{array}{l}\text { Bishkek, Kyrgyzstan } \\
\text { (case study area) }\end{array}$ & Not mentioned \\
\hline
\end{tabular}


Table 1. Cont.

\begin{tabular}{|c|c|c|c|c|}
\hline Author & Data & $\begin{array}{c}\text { The Main Topics Addressed } \\
\text { (Topics Can Be Categorized as Building Stock/Exposure Focused, Building } \\
\text { Vulnerability Focused, and Specific Building Loss Estimates) }\end{array}$ & $\begin{array}{l}\text { Number of } \\
\text { Buildings or the } \\
\text { Study Area Covered }\end{array}$ & Accuracy or Reliability \\
\hline $\begin{array}{l}\text { Sarabandi and } \\
\text { Kiremidjian [44] }\end{array}$ & $\begin{array}{l}\text { High-resolution } \\
\text { optical imagery }\end{array}$ & $\begin{array}{l}\text { Exploring this method by combining building features that were derived from RS } \\
\text { (footprint, height, shape, roof material, and roof type) and ancillary information } \\
\text { to estimate types of seismic building structures (SBSTs). The SBSTs were } \\
\text { determined based on the relevant logic of HAZUS. }\end{array}$ & $\begin{array}{l}1947 \text { buildings for } \\
\text { method development }\end{array}$ & $\begin{array}{l}\text { The error of the best SBSTs } \\
\text { estimation model that based } \\
\text { on RS data and ancillary } \\
\text { information was } 13.46 \% \text {. }\end{array}$ \\
\hline Wu et al. [45] & WorldView-2 & $\begin{array}{l}\text { Relating the heights, structural types, and uses of buildings and the local geologic } \\
\text { conditions with the seismic damage grades of buildings under one specific } \\
\text { seismic intensity (intensity VII). Building heights were derived from RS images } \\
\text { using an existing method; the structural type and uses of the buildings and the } \\
\text { local geologic conditions were obtained using in-situ surveys. The damage grades } \\
\text { were characterized according to EMS-98. }\end{array}$ & $\begin{array}{l}35 \text { training buildings, } \\
48 \text { assessed buildings. }\end{array}$ & $\begin{array}{l}\text { Not mentioned (refers to the } \\
\text { reliabilities of the considered } \\
\text { specific relationships) }\end{array}$ \\
\hline Yuan and Wang [46] & IKONOS & $\begin{array}{l}\text { Exploring the possibility of broadly examining the structural information of a } \\
\text { building by observing the overall appearances of groups of buildings in RS } \\
\text { images that can be visibly interpreted. }\end{array}$ & $\begin{array}{l}\text { Dehra Dun city, India. } \\
\text { (addressed place) }\end{array}$ & Not mentioned \\
\hline $\begin{array}{l}\text { Zhang et al. }[47] \text {; } \\
\text { Zhang et al. }[48]\end{array}$ & QuickBird & $\begin{array}{l}\text { (1) Developing automatic methods for extracting the building heights, } \\
\text { footprints, and floor areas. } \\
\text { (2) Referring to Yin's DPM study [49] to address the buildings' vulnerabilities. } \\
\text { (3) Using Yin's method [49] to calculate damaged floor areas and monetary losses. }\end{array}$ & $\begin{array}{l}41 \text { buildings for } \\
\text { developing the } \\
\text { methods. } 100 \mathrm{~km}^{2} \\
\text { (suburban area of } \\
\text { Shanghai, China) } \\
\text { for application. }\end{array}$ & $\begin{array}{l}\text { The MAE of the height } \\
\text { estimate was } 3.29 \mathrm{~m} . \\
\text { The MRE of the footprint } \\
\text { assessment was } 12 \% \text {. }\end{array}$ \\
\hline Zhao et al. [50] & QuickBird & $\begin{array}{l}\text { (1) Developing an automatic method for extracting the building floor } \\
\text { numbers. Manually measuring the footprint. } \\
\text { (2) Referring to Yin's DPMs [49] to address the vulnerabilities of the buildings. } \\
\text { (3) Using Yin's method [49] to calculate the damaged floor area. }\end{array}$ & 35 buildings & $\begin{array}{l}\text { The MRE of the footprint } \\
\text { assessment was less than } 10 \% \text {. }\end{array}$ \\
\hline
\end{tabular}

Note: (1) The topic(s) presented in bold text in the "The main topics addressed" column indicate the focuses of each relevant study that had multiple main topics.

(2) MAE represents the mean absolute error; MRE represents the mean relative error; RMSE is root mean square error; and MAPE is the mean absolute percentage error. 
These remote sensing-based $E$ and/or $V$ studies showed that remote sensing technologies have great potential for overcoming timeliness and coverage problems relative to LRC or DPM-based approaches and $E$ and $V$ or $V$ composite index-focused methods for addressing seismic loss risks in the context of rapid socioeconomic growth. However, when accurately assessing the seismic loss risks of a large area determinately and in detail, remote sensing technologies still face several challenges that may be difficult or impossible to overcome when exclusively using this technology. (1) Currently, it is still difficult to use remote sensing data and technology alone to directly produce some types of information that are essential for quantitatively calculating specific seismic loss risks, especially core data or information, such as building structural types and DPMs. Several previous studies have broadly addressed the associations between the seismic vulnerabilities of buildings and the building heights, shapes, roof/surface materials, and other properties that can be observed, measured, and/or detected from remote sensing images $[33,36,46]$. However, these association discussions are far from the implications of the LRCs and DPMs of buildings, which are classical expressions of seismic building vulnerabilities and were summarized based on earthquake engineering knowledge and actual earthquake damages. Some recent studies have carefully explored how remote sensing may contribute to examining and assessing the seismic structure type and/or vulnerability of a building [34,35,39-45], which are the technical cores of the mainstream quantitative approaches used to determine seismic loss risks of buildings. However, uncertainties remain that require further validation. For example, Wu et al. [45] used several tens of sample buildings in an interesting attempt to relate heights, structural types, and uses of buildings and the local geologic environments with the building damage grades under one specific seismic intensity (intensity VII). However, it is worth further exploring what or how much do these relationships imply relative to classical connotation and conventional expressions of seismic vulnerability of a building? In addition, how reliable are such relationships when they were derived from 35 buildings (for example, relative to the commonly accepted DPMs on the Chinese mainland that were summarized based on experiences from multiple actual earthquakes and innumerable affected buildings)? Geiß et al. [34], Mück et al. [39], Panagiota et al. [40,41], Wieland et al. [43], and Pittore and Wieland [42] attempted to directly link the seismic vulnerabilities of buildings with the features of buildings and the buildings' environments derived from remote sensing data. These attempts attempted to bypass the critical but frequently hard tasks (esp. when facing a large number of buildings) of conventional earthquake engineering methods for characterizing the seismic structural vulnerabilities of buildings. Thus, the methods of this kind were quick, capable of easily covering a large number of buildings, and universally transferable. However, the applicabilities of these new and enlightening alternatives for characterizing the seismic vulnerabilities of buildings (relative to conventional earthquake engineering-based methods), may require extensive and careful discussion and validation by experienced earthquake engineers and associated remote sensing-focused scientists. In addition, the diverse actualities of different places and the actual earthquake damages that were not sufficiently discussed in the context of these previous studies may also require careful considerations. Geiß et al. [34] stated that an open dialogue should be triggered. Given the needs and difficulties of large-scale estimations of seismic loss risks in the context of rapid socioeconomic growth, such dialogue is particularly worthwhile, urgent and expected; (2) Remote sensing imagery with high resolution contains important and specific information (e.g., footprint areas of buildings) that can be used to characterize specific seismic loss risks in detail. However, the techniques for extracting this 
information have not been sufficiently developed. When addressing a large number of objects (e.g., a large number of buildings) over a limited amount of time, it is difficult to extract highly accurate and specific information (e.g., the total floor areas of a building) from remote sensing imagery. Although Li and Zhai [36] and Zhao et al. [50] developed relatively accurate information, their studies only involved a very small number of buildings. This may be one important reason why existing remote sensing studies relevant to pre-earthquake disaster risks have mainly focused on developing various technological methods and have rarely presented applications of them in relatively or considerably large places with relatively or considerably large numbers of buildings. In summary, several large gaps exist between what remote sensing images and technology can currently provide and what conventional and mainstream large-scale seismic loss risk estimates specifically require. Bridging such gaps is important for promoting deep and actual practice-aimed applications of remote sensing data and technology in broad seismic loss risk reduction battlefields.

A method that rapidly and precisely captures seismic disaster risks and their changing scenarios over large areas with rapid socioeconomic growth has not been sufficiently developed to date. The purpose of this study was to propose an integrated or hybridized method that combines high-resolution remote sensing imagery with local knowledge to solve this issue. To accomplish this task, we introduced local knowledge reviews to bridge the gaps between the remote sensing and technical cores of conventional quantitative approach for determining seismic loss risks. We focused on building loss risks to demonstrate the development and use of this integrated method. Extensive and large-scale building development has been one of the most visible and significant aspects of China's rapid socioeconomic expansion within the last several decades [58-62]. No surveys of Chinese mainland buildings have been reported in the literature since 1985 when a nationwide building survey was performed. Such building-focused studies are urgently needed to cope with seismic disaster risks on the Chinese mainland.

In this building-focused study conducted in 2010, the term local knowledge was not used in the purely social science sense. Instead, the term building-relevant local knowledge (Br-LK) was used to refer to various sources of information regarding the buildings in a specific area. This knowledge included local building codes, local dwelling traditions and culture, and local building construction planning and policies. The Br-LK also included local building information contained in almanacs, statistical yearbooks, the chorography of local chronicles, building construction archives, urban and land-use planning reports, volunteered geographic information [63-66], academic books and papers, and scientific and social service research reports. The high-resolution remote sensing imagery used in this study was high-resolution optical remote sensing images (Hr-ORSIs) that were either satellite or airborne-based with visible primary image characteristics from ground objects that could be manually examined. By fully combining the advantages of these two sources (Br-LK and Hr-ORSIs), the definitiveness, accuracy and timeliness were all enhanced when estimating the earthquake-induced building loss risks across a large area with rapid socioeconomic growth.

The paper begins with the overall framework of the proposed integrated method. Next, it demonstrates how the heights and the footprint areas of a large number of buildings may be accurately and rapidly extracted from a single Hr-ORSI. Then, the bridging process is described by reviewing Br-LKs to help accurately and rapidly determine the various core parameters required to specifically calculate the building loss risks, including the building structural types, total and sub-total floor areas, DPMs, 
and economic parameters for calculating monetary losses due to seismic damage to buildings. Next, two methods are presented for verifying the accuracy of the method. In a specific application of this method, a simulation of the impacts of the Ms 7.8 Tangshan earthquake of 1976 is presented in the context of urban development as of 2009. In the penultimate section of the paper, a series of discussions are presented regarding the advantages, limitations, application prospects, and future extendibility or scalable directions of the method. Finally, the paper ends with several final remarks of this study.

\section{Overall Framework of the Proposed Method}

Within the last several decades, earthquake engineers in China have performed extensive conventional LRC- and/or DPM-based earthquake loss estimation work [67-71], often based on the methodologies developed by the Applied Technology Council of the USA (ATC). In this study, we followed the basic logic of the ATC and its Chinese variations to explore a novel integrated method for the timely, accurate, and large-scale characterization of seismic loss risks in areas of rapid socioeconomic growth. Specifically, (1) we directly established the seismic hazard parameter $(H)$ in Equation (1) in terms of certain specific hypothetical or scenario intensity values based on the Chinese Seismic Intensity Scale [72]. As in the Modified Mercalli Intensity (MMI) scale used in the USA and the European Macroseismic Scale (EMS), this seismic intensity scale included twelve degrees designated by Roman Numerals I through XII. The ground motion and associated macro damage implications are generally equal to one another among the three scales at the same degree [73-75]. The empirical and statistical conversion/transform relationships between the intensities of the Chinese Seismic Intensity Scale and Peak Ground Accelerations (PGA) are shown in Table 2 [76]. In actual seismic loss assessment practices either before or after earthquakes on the Chinese mainland, currently available DPMs are still based on seismic intensity, such as the baseline DPMs for different regions developed by Yin [49]. No PGA-based DPMs are currently available that can be used to analyze seismic losses of buildings in groups on the Chinese mainland. Thus, we also used intensity as a seismic hazard parameter. Next, (2) we selected buildings as representative exposed elements for this study. After these selections, the integrated method was used to rapidly and accurately determine the required parameters for estimating the seismic loss risks of the buildings, including their structural types, DPMs, total and sub-total floor areas, and economic parameters for calculating the monetary losses due to seismic damage.

Table 2. Empirical and statistical conversion correspondences between the intensities on the Chinese Seismic Intensity Scale and the Peak Ground Accelerations (PGA) [76].

\begin{tabular}{cccccc}
\hline PGA & $0.04 \mathrm{~g} \leq \mathrm{a}_{\max }<0.09 \mathrm{~g}$ & $\mathbf{0 . 0 9} \mathrm{g} \leq \mathrm{a}_{\max }<0.19 \mathrm{~g}$ & $0.19 \leq \mathrm{a}_{\max }<0.38 \mathrm{~g}$ & $0.38 \leq \mathrm{a}_{\max }<0.75 \mathrm{~g}$ & $\geq 0.75 \mathrm{~g}$ \\
\hline Intensity & VI & VII & VIII & IX & X \\
\hline
\end{tabular}

Note: (1) $\mathrm{a}_{\max }$ indicates the maximal acceleration (i.e., the peak ground acceleration (PGA)); (2) $\mathrm{g}$ refers to the gravitational acceleration, which is commonly defined as $1 \mathrm{~g}=9.81 \mathrm{~m} / \mathrm{s}^{2}$.

The overall framework of this integrated method is illustrated in Figure 1. Specifically, the method consists of the following main interdependent parts: (1) estimating the height and the footprint area of each individual building from a single Hr-ORSI accurately and quickly by improving and/or using 
existing application-oriented techniques; (2) using Br-LK reviews as a bridging tool to determine the total and sub-total floor areas, structural types, DPMs, and key economic parameters for calculating monetary losses associated with each type of building that are required by conventional LRC- and/or DPM-based earthquake loss estimates as quickly, reliably, and accurately as possible based on the building's height and footprint area; (3) assigning various specific hypothetical intensity values to the relevant equations to assess the building loss risks under various seismic hazard scenarios.

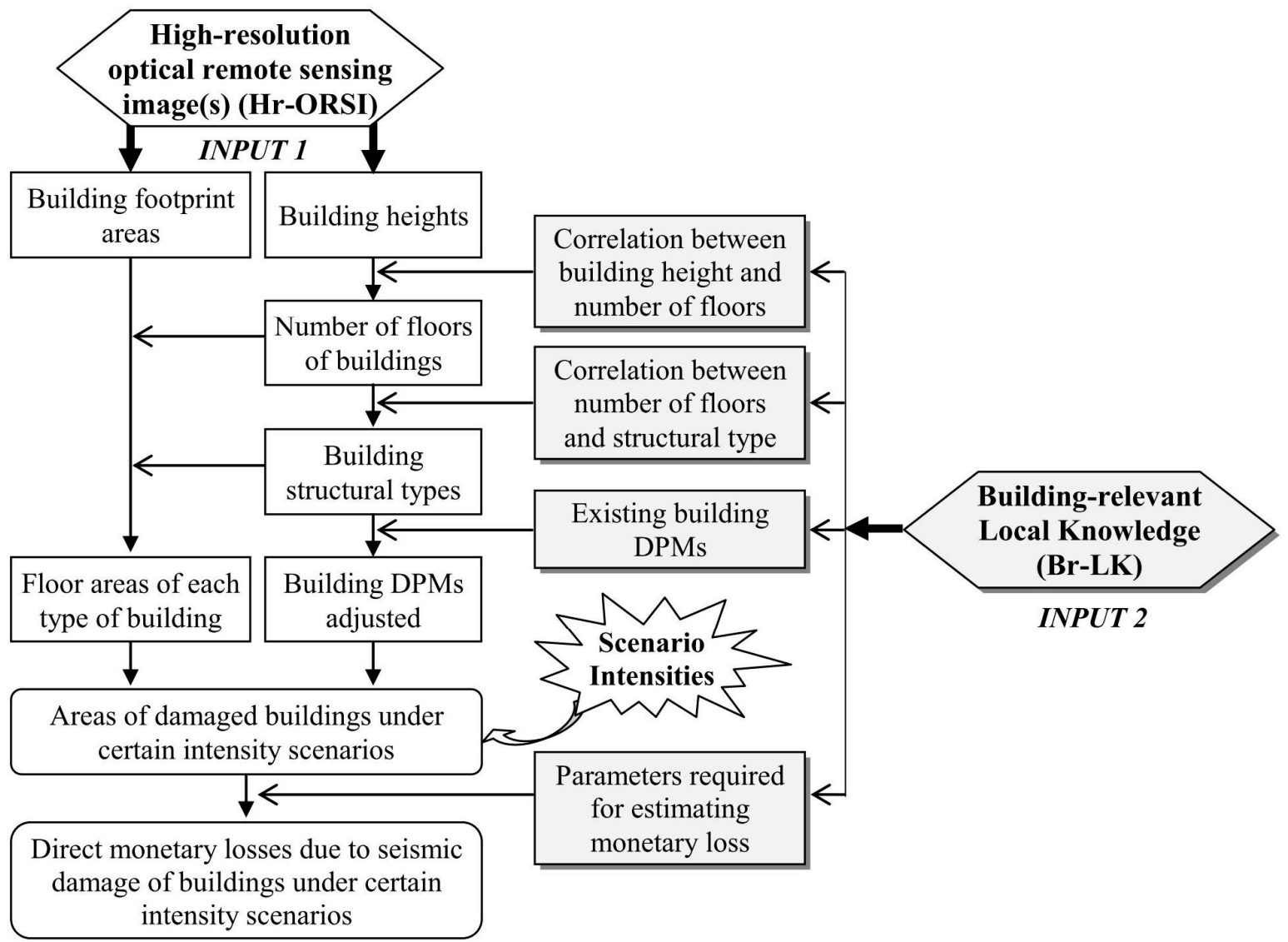

Figure 1. Overall framework of the proposed integrated method.
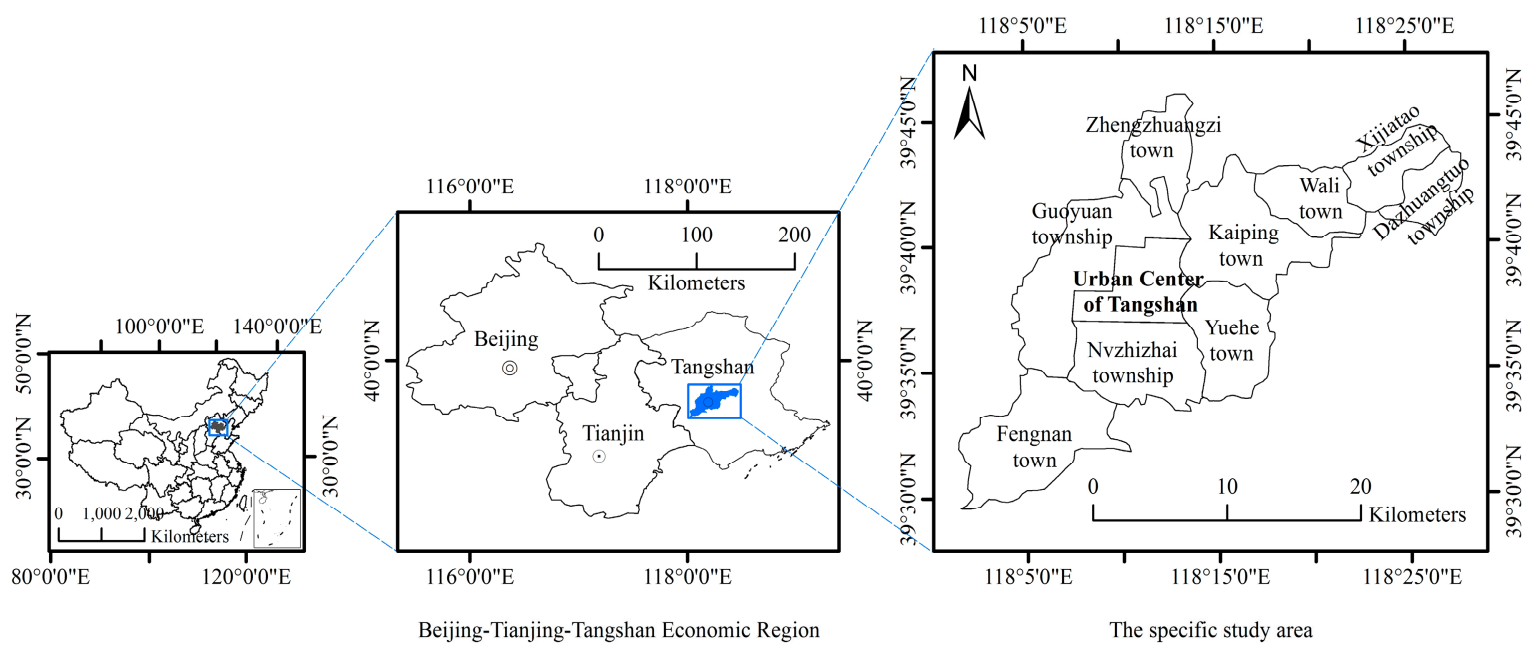

Figure 2. Location of the study area. 
The use of this integrated method and its verifications were demonstrated in the central part of Tangshan, China (Figure 2), an area where our associated studies were based for several years [2-4,77,78]. As shown in Figure 2, the specific target region includes the entire urban district of Tangshan, its periurban fringes, and a few of its suburban and rural towns and townships. This target region is flat in terrain, the entire study area measures $456 \mathrm{~km}^{2}$, and the area had a population of 698,596 in 2009. The population density in this area in 2009 was 1532 persons per square kilometer, which was 12 times greater than the average population density of China in 2009. The region's GDP was 6.61 billion USD in 2009 with a GDP per capita of 9463 USD, which was approximately 3.5 times the national average of China in 2009 [79].

\section{Developing the Parameters Required for Estimating Building Loss Risk Using Single Hr-ORSIs}

In Sections 3 and 4 of the paper, we explain how the core parameters that were required for calculating the potential seismic building loss risks were determined by combining the Hr-ORSI and Br-LK data. These parameters included the building structural types, DPMs, total floor areas, and economic metrics that were necessary for calculating monetary losses. These parameters cannot be obtained directly from remote sensing images, regardless of the spatial resolutions of the images, because only the roofs and parts of the outside walls of buildings are visible (even in Hr-ORSIs). However, the heights and the footprint areas of the buildings can be directly estimated from an Hr-ORSI, and these two parameters are important for determining many of the required core parameters. We used GeoEye-1 images in 2009 to explore the ways in which these two beginning and basic parameters can be accurately and rapidly estimated.

\subsection{Determining Building Heights}

According to the literature, there are two primary approaches for estimating building heights using an Hr-ORSI. One method is to use stereo Hr-ORSI pairs [80-85], and the other method is to use the shadows of buildings from a single Hr-ORSI [33,37,86-88]. Earlier studies have shown that using stereo Hr-ORSI pairs results in more accurate height estimates. However, it is often difficult to acquire the needed stereo Hr-ORSI pairs. There are two ways to obtain Hr-ORSI pairs. The first is to purchase existing pairs. However, few Hr-ORSI pairs exist that cover the Chinese mainland. For example, the Tangshan area is one of the few areas in China that has been extensively covered by various Hr-ORSIs. However, existing stereo pairs of Hr-ORSIs remain rare. The second method is to trust a relevant company to produce new stereo Hr-ORSI pairs. Existing Hr-ORSI data are expensive; the custom production of new Hr-ORSI pairs is even more expensive. Therefore, the financial cost of using stereo Hr-ORSI pairs may substantially increase when addressing a considerably large area.

For the purpose of broader applications, the proposed integrated method began by using single existing Hr-ORSIs to determine building heights. Researchers have developed two primary types of single Hr-ORSI-based methods for this task. Some researchers have estimated a building's height by measuring the entire length of the building's shadow [37,87-89]. This type of method is theoretically and mathematically the easiest and was developed first. Other methods have been used to estimate building heights by measuring two other building imaging parameters, the building azimuth and shadow length normal to building strike/trend $[47,50,86,90,91]$. However, it is difficult and often impractical to 
apply these two types of methods to large areas containing a large number of buildings. The first type of method is not capable of resolving incomplete or overlapping shadow issues due to various interferences from neighboring buildings or other surrounding ground objects. The methods of the second type can overcome these challenges, but require many complex measurements that are labor and time intensive for areas that contain large numbers of buildings (details are presented below).

We developed an algorithm that only requires deriving the same imaging point distance (SIPD) from a single Hr-ORSI to estimate building heights. The SIPD is the distance between the imaging position of a certain point on a building's roof edge and the imaging position of that point's shadow on a single Hr-ORSI. The imaging geometry of a building and that of its SIPD are illustrated in Figure 3. In this figure, the gray bar represents a building, $T$ denotes a point on the building's roof edge, $B$ is the vertical projection of point $T$ on the ground, $H$ is the building's height, and $P$ and $S$ denote the imaging positions of point $T$ and its shadow, respectively, in a Hr-ORSI. The distance between imaging points $P$ and $S$ is the SIPD, which is denoted by $L_{s p}$ in Figure 3.

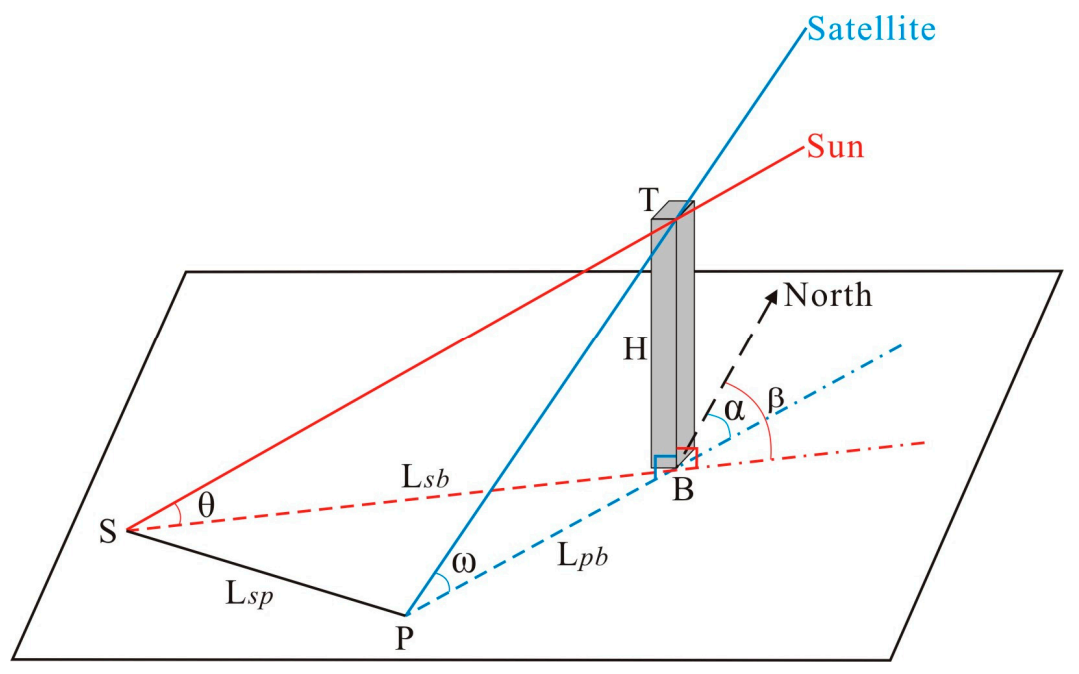

Figure 3. The imaging geometry of a building and that of its same imaging point distance (SIPD).

Using Figure 3 and referring to the basic geometry principles of triangles, we first obtained the following rudimentary expressions:

$$
\begin{gathered}
H=\tan \theta \times L_{s b} \\
H=\tan \omega \times L_{p b} \\
L_{s p}{ }^{2}=L_{s b}{ }^{2}+L_{p b}{ }^{2}-2 L_{s b} L_{p b} \cos (\beta-\alpha)
\end{gathered}
$$

where $H$ is the building's height; $L_{s p}$ is the SIPD; $\omega$ and $\alpha$ are the elevation and azimuth angles of the satellite, respectively; and $\theta$ and $\beta$ are the elevation and azimuth angles of the sun, respectively.

Based on these three basic formulas, we obtained the following expression:

$$
H=L_{s p} \times \frac{\tan \theta \tan \omega}{\sqrt{\tan ^{2} \theta+\tan ^{2} \omega-2 \tan \theta \tan \omega \cos (\beta-\alpha)}}
$$

For simplification, we introduced the coefficient $\varphi$ to simplify Equation (5) as follows:

$$
H=L_{s p} \times \varphi
$$




$$
\varphi=\frac{\tan \theta \tan \omega}{\sqrt{\tan ^{2} \theta+\tan ^{2} \omega-2 \tan \theta \tan \omega \cos (\beta-\alpha)}}
$$

The coefficient $\varphi$, as shown in Equation (7), is determined using the imaging mechanism and parameters of the Hr-ORSI. To obtain $H$ (the building's height), the only task left is to measure the SIPD, namely $L_{s p}$, in Equation (6).

The existing single Hr-ORSI-based methods explained above must be based on either measuring the entire length of a building's shadow or on measuring a building's azimuth and its shadow length normal to its strike/trend. When applied to a large number of buildings over a large area with rapid socioeconomic development, the algorithm we developed is easier, quicker, and more accurate, feasible and practical than the two types of existing methods. (1) The SIPD method does not consider the entire length of a building's shadow (i.e., it does not consider point $B$ in Figure 3). Therefore, the SIPD method allows one to avoid extreme difficulties in identifying this point, which can result from various shading effects or from possible high gray-tone similarities between this point and its surroundings; (2) The two imaging points $P$ and $S$ shown in Figure 3 originate from the same reference point (i.e., the same point of a building's roof edge). To serve as a reference, we always selected a distinct point, such as a building's roof edge corner. This selection made the identification of points $P$ and $S$ much easier. Moreover, using a point on a building's roof edge as a reference was not the only option. All of these advantages of this algorithm allow one to avoid various shading or gray-tone similarity interferences when identifying points $P$ and $S$; (3) Compared with using a building's azimuth and its shadow length normal to the building's strike/trend to determine a building's height, the SIPD-based method only removes one required parameter in theory. However, this new measurement saves significant time and labor by avoiding the complex process of tracking and determining each building's azimuths, normal, and strike/trends separately. Saving time and labor is critical when targeting a large area with a high number of buildings fueled by rapid socioeconomic growth.

We used ArcGIS 9.3 to calculate the building heights. During this process, two key steps were performed. First, the SIPDs were manually identified and vectorized using ArcGIS 9.3. This step was neither difficult nor particularly time or labor consuming. For example, all of the densely packed buildings (approximately 1200 individuals) in a $50-\mathrm{km}^{2}$ zone in the study area were vectorized within 4 to $5 \mathrm{~h}$ by a single skilled person. The second step was to calculate all of the SIPDs, $L_{s p}$ in Equation (6) using the software's Calculate Geometry and Field Calculator modules. This calculation was simple and rapid.

\subsection{Estimating Building Footprint Areas}

We based the estimate of a building's footprint area on the outline information of the building's roof provided by the Hr-ORSI. To date, experts have developed several automatic and semiautomatic procedures to rapidly delineate a building's roof outline [33,39,45,92-98]. However, it is still difficult to apply these technically advanced procedures to irregularly shaped buildings and to identify and eliminate shading, interferences, and high gray-tone similarity effects resulting from either the buildings themselves or from the buildings' environments. To ensure accuracy, a great deal of post-processing work must be performed. When addressing a large area with a large number of buildings, applying these automatic or semiautomatic procedures remains difficult. 
To achieve the good accuracy that is required (and essential in fact) for seismic loss risk reduction practices, this study included manual vectorization to estimate the buildings' footprint areas. Using GIS, the roof outlines of buildings were manually digitized and the footprint areas were estimated accordingly. Indeed, the manual vectorization technique for determining the outlines of building roofs using ArcGIS 9.3 is easy and not very time or labor intensive. Specifically, the required time and labor essentially equaled that required to manually digitize the buildings' SIPDs.

\section{Developing the Required Parameters for Building Loss Risk Estimations by Reviewing Various Sources of Br-LK}

In China, the most established and commonly used system for classifying the seismic vulnerabilities of buildings is the system first developed by Yin [68]. In this system, buildings are assigned to the following five categories: (1) earth/wood buildings (E/W buildings); (2) single-story brick buildings (S/B buildings); (3) brick and concrete buildings (B/C buildings); (4) reinforced concrete buildings ( $\mathrm{R} / \mathrm{C}$ buildings); and (5) specially structured buildings. However, not all of these building categories were addressed in this study. We concentrated on the first four categories of Yin's classification system by focusing on residential buildings and public service offices (For clarity, we use the following phrases/expressions: addressed buildings, assessed buildings, buildings for residential and public office usages, or buildings of interest as needed in the associated statements/sentences of the article to indicate this concentration/focus.). This focus was selected due to China's high population density, with residential buildings representing the vast majority of its total building stock. Furthermore, during the recent decades of rapid socioeconomic development in Mainland China, the growth in residential and public service buildings has constituted the most significant change in its total building stock [60-62,99-101].

\subsection{Estimating the Number of Floors}

In our integrated method, the number of floors in a building must be accurately estimated because the structural types, total floor areas and DPMs of certain groups of buildings are estimated directly or indirectly from the estimated number of floors. We estimated the number of floors/stories in a residential and public office building using a correlation with the building's height because the height of a single-floor residential and public office building and the height of each floor in a multi-floor residential and public office building are considerably regular in a certain area. This regularity results from the integrated impacts of long standing dwelling traditions and architectural cultures and modern building codes and urban planning practices of/in a particular local area.

Tangshan, China, is a typical development in North China. The buildings of interest there, such as those in rural and suburban areas, typically follow the North China architectural style [102-105]. In addition, this area is industrialized and modernized. Therefore, its buildings, particularly those in urban centers, meet modern building construction standards and regulations. To develop general correlations between the heights and numbers of floors of residential and public office buildings in this area, we referred to the Br-LK, which included (but was not limited to) archives, yearbooks, building codes, and urban planning reports. Next, we carefully reviewed and confirmed these correlations during a field investigation that spanned 3 days. 
For this fieldwork, we first selected sample building sites based on our reviews or observations of the general features of the assessed buildings regarding their structural types, heights or high/low-rise appearances, and spatial distributions (e.g., the differences between urban and nonurban buildings or areas). These reviews were based on either relevant Br-LKs (such as urban planning materials and building codes) or on the Hr-ORSIs. Overall, our selection resulted in 82 sample sites. These sites were assigned to two categories, urban and nonurban. Next, one or more typical buildings within each site were selected as sample buildings for analysis (Figure 4). Overall, 235 buildings were selected based on this stratified sampling method. The height of each sample building was measured using a handheld laser rangefinder, and the number of floors and structural type of each building were recorded using a handheld GPS instrument. Based on these data, we developed a correlation between the numbers of floors and the heights of the residential and public office buildings in the study area.

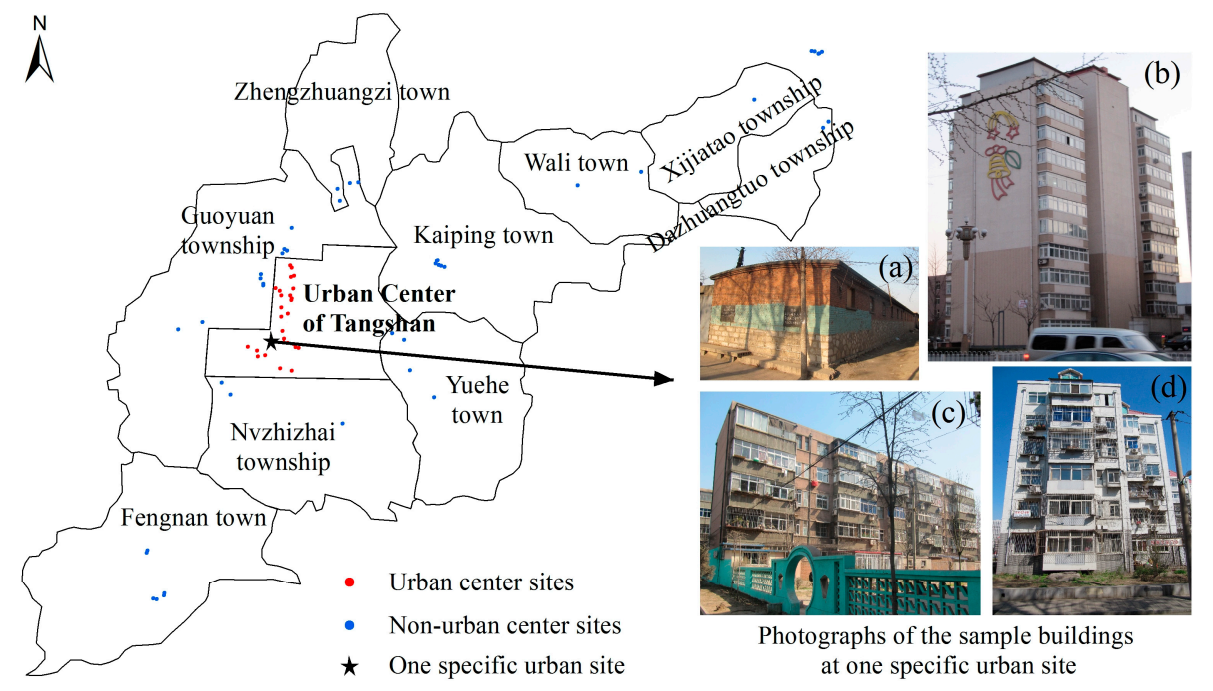

Figure 4. Locations of the sample building sites in the study area and photographs of several specific sample buildings. (a) S/B building $3.1 \mathrm{~m}$ tall; (b) R/C building $32.4 \mathrm{~m}$ tall with 11 floors; (c) B/C building $14.5 \mathrm{~m}$ tall with five floors; (d) B/C building $18.2 \mathrm{~m}$ tall with six floors.

An analysis of the arithmetical means indicated that the mean floor height of all sample buildings was $2.94 \mathrm{~m}$. The sample data showed that the total heights (from ground to roof) of single-floor sample buildings and the ground to ceiling heights of the first floor in multi-floor sample buildings were between 3 to $4 \mathrm{~m}$, with most closer to $4 \mathrm{~m}$ because the buildings in this area are generally built approximately $1 \mathrm{~m}$ above the ground. The box-plots and the means of the total heights of the sample buildings with different numbers of floors showed that the maximum, minimum, and the mean total heights of the single-floor sample buildings were $4.1 \mathrm{~m}, 2.9 \mathrm{~m}$, and $3.3 \mathrm{~m}$, respectively, and those of the buildings with two floors were $6.8 \mathrm{~m}, 6.2 \mathrm{~m}$, and $6.4 \mathrm{~m}$, respectively (Figure 5), and so forth. The regression analysis showed that a good linear relationship existed between the total heights and the numbers of floors in the sample buildings (Figure 6). This linear correlation is more defined than that observed by Wurm et al. [106] because the buildings in their study included all types of buildings in their study area. In contrast, the buildings in our study only included those for residential and public 
office usages. The floor heights of the residential or public office buildings within a given area are generally similar, consistent, and stabile.

Thus, we made the following general rules to rapidly estimate the numbers of floors of residential or public use buildings based on their estimated heights in the study area: buildings with an estimated height of approximately 3 to $4 \mathrm{~m}$ have one floor, buildings with estimated heights of approximately 6 to $7 \mathrm{~m}$ have two floors, buildings with estimated heights of approximately 9 to $10 \mathrm{~m}$ have three floors, and so forth. Using these rules and the building heights that were estimated in Section 3.1, the numbers of floors were rapidly determined for all of the assessed buildings in the study area.

Based on the numbers of floors described above and on the estimated footprint areas as described in Section 3.2, the total floor area of a given addressed building was calculated using the field calculator function in the GIS instrument.

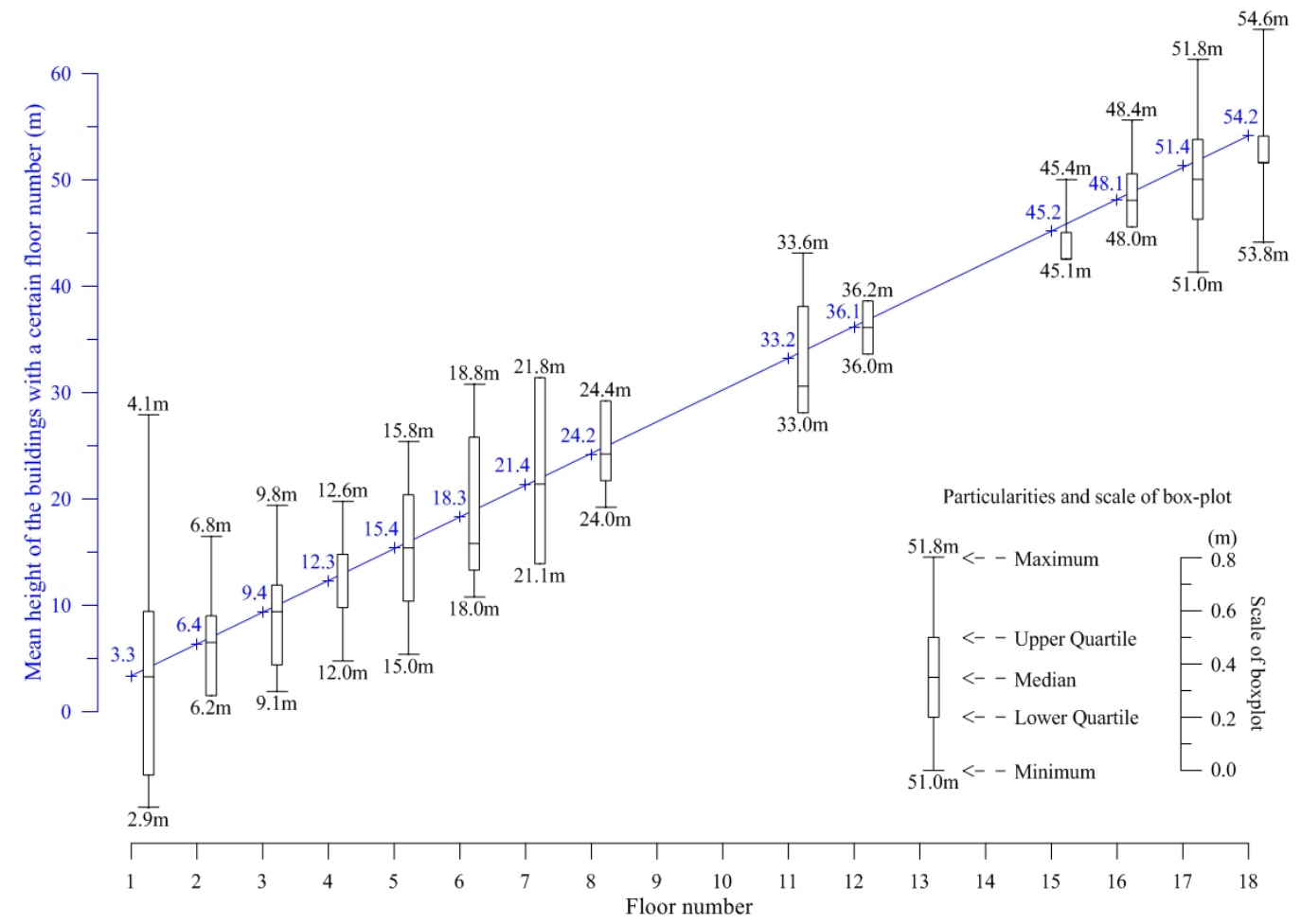

Figure 5. Box-plots and means of the total heights of the sample buildings with different numbers of floors. Note: (1) This figure contains two layers of information that use the same X-axis. One layer is the mean heights of the sample buildings with different numbers of floors and is represented by blue crosses indicating mean height points, blue numerals indicating height values, and the blue line fit to the height points. The other layer is the height variances of the sample buildings with different numbers of floors, which are illustrated by box-plots (in black color); (2) All of the box-plots are plotted using one length scale (see the lower right of the Figure); thus, the total height variance features of the sample buildings with different floor numbers depicted in different box-plots are comparable with one another in this figure. For example, the total height variance ranges represented by the entire lengths of the box-plots are comparable. Thus, one can easily observe that buildings with a certain number of floors possess larger or smaller total height variance ranges. 


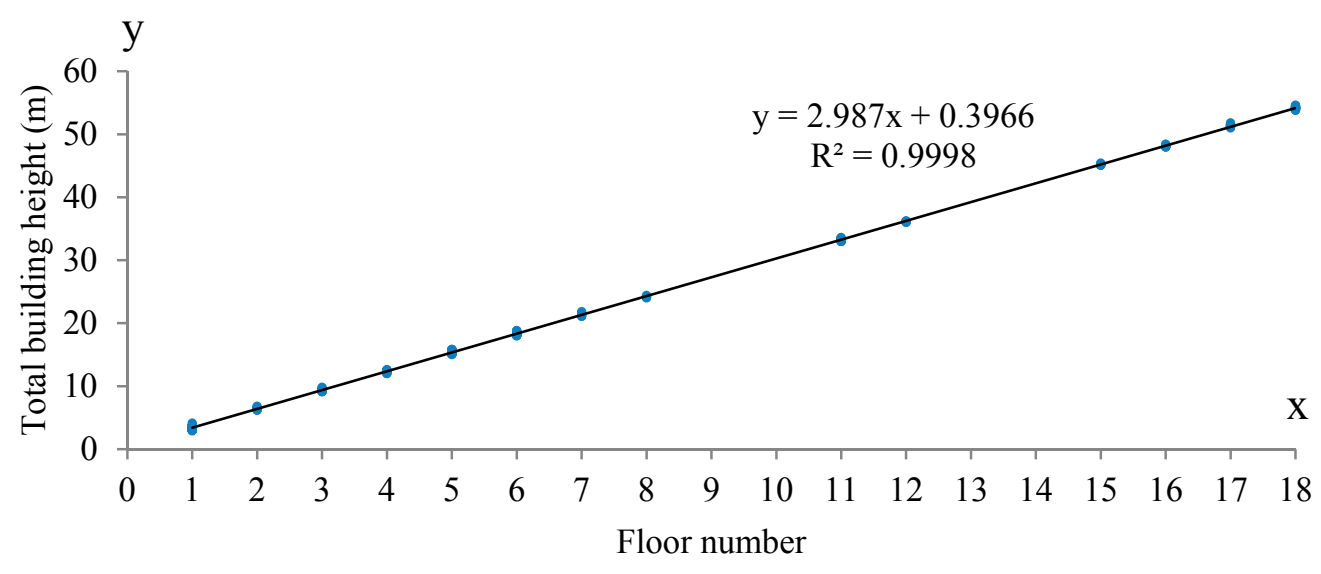

Figure 6. Regression between total building height and number of building floors.

\subsection{Assessing Structural Types}

We used the numbers of floors obtained in the last step as a starting point for determining the structural types of the buildings $[31,33,48,50,107]$. The height or number of floors of a residential and/or public office use building in a specific area usually presented a certain type of empirical correspondence with the building's structure type. This correspondence is the combined product of various local contexts, including a long tradition of dwelling and architectural cultures, current and historical economic development levels, building code requirements, building construction policies, and land-use and urban planning practices.

To assess how structural types may be correlated with the numbers of floors in residential and public office buildings in Tangshan, various sources of Br-LKs were first carefully reviewed, including archives, reports, books, almanacs, statistical yearbooks, local chronicles, building codes, online data, and journals [108-121]. In this way, important findings were obtained.

(1) Because of the overall synchronized and systematic post-disaster reconstruction of Tangshan after the 1976 earthquake, earth/wood buildings (E/W buildings) nearly disappeared in this area [111,113,114]. Among all of the buildings, apart from a relatively small number of specially structured buildings (belonging to the fifth type of Yin's classification system), only three primary types of buildings were identified in the area following the 1976 earthquake, single-story brick buildings (S/B buildings), brick and concrete buildings (B/C buildings), and reinforced concrete buildings ( $\mathrm{R} / \mathrm{C}$ buildings).

(2) Codes for the seismic design of buildings in China, including TJ11-74 [122], TJ11-78 [123], GBJ 11-89 [124], GB 50011-2001 [125], and GB 50011-2010 [126], clearly regulate the maximum number of floors for buildings of various structural types based on certain seismic design requirements. For example, based on the associated construction requirements, the maximum height of B/C buildings in the zones where the seismic fortification intensity is VIII (on the Chinese Seismic Intensity Scale) on the Chinese mainland is six floors. Buildings with more than six floors must be of R/C type. Tangshan experienced a terrible Ms 7.8 earthquake in 1976. Intensity VIII specifies the seismic design intensity/criterion in this area following this large earthquake. Because Tangshan is a relatively economically developed area on the Chinese mainland, relevant building codes have been adhered to well since the 1976 earthquake. Consequently, the maximum number of floors (i.e., six floors) in B/C type residential and public office buildings is well defined in this area. Currently, all residential and 
public office buildings with more than six floors in Tangshan are R/C type, except for a few very old buildings.

(3) The building uses, ages, spatial distributions and aggregation patterns can serve as a reference for judging the structural types of buildings. In particular, the spatial distributions and aggregate appearances are generally clearly visible in the Hr-ORSIs. This observation is one important reason for our use of these types of images as the basis of our integrated method. Figure 7 displays examples of the 2009 GeoEye-I panchromatic images of the buildings in the Tangshan area. Specifically, Figure 7a shows a group of S/B houses, each measuring 8-9 $\mathrm{m}$ on a side with a yard and standing in regular rows. These S/B houses were primarily constructed between 1976 and 1986 [112,114] and are widely distributed across the rural regions of the study area. Figure $7 \mathrm{~b}$ shows a remote sensing image of a group of slab-type and tower-like buildings. These buildings are rectangular, spaced approximately 20 to $25 \mathrm{~m}$ apart, and regularly clustered together. Buildings of this type all consist of two to six floors. Large sections occupied by such buildings were also constructed from 1976 to 1986 [112,114]. These buildings are essentially $\mathrm{B} / \mathrm{C}$ buildings and are usually used for urban residences. Figure $7 \mathrm{c}$ shows various high-rise buildings, most of which are used for residential purposes with some being used as public service offices. Small portions of the first floors of these buildings are used for commercial purposes. These buildings all belong to the $\mathrm{R} / \mathrm{C}$ category. Most of these $\mathrm{R} / \mathrm{C}$ buildings were constructed after 2000, are typically 10 floors or taller and are situated in periurban areas or along main urban or periurban roads. A few R/C buildings were built before 2000, are seven or eight stories tall and are located in or near the urban center [112,114].
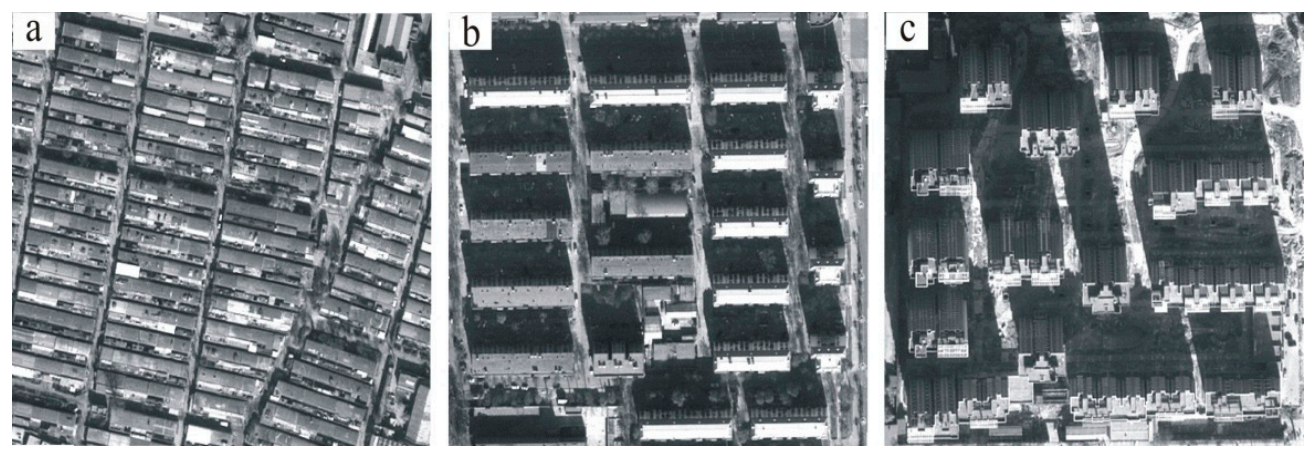

Figure 7. Examples of building distributions visible in the GeoEye-1 panchromatic images.

(a) S/B buildings; (b) B/C buildings; (c) R/C buildings.

To further investigate and summarize the correlations between the numbers of floors and the structural types of the residential and public office buildings in the study area, we confirmed the structural types of all sample buildings and their correlations with the numbers of floors during the 3-day field investigation mentioned in Section 4.1 (Figure 4). The following pre-assumptions were made for this analysis: all single-floor buildings are S/B type, all of the buildings with two through six floors are B/C type, and all the buildings with seven or more floors are $\mathrm{R} / \mathrm{C}$ type, and vice versa. The confusion matrix of the sample data showed that the overall accuracy of these pre-assumptions was $97.02 \%$, with a kappa coefficient of 0.95 (Table 3), which agreed well with our preceding findings presented immediately above from carefully and comprehensively reviewing various Br-LKs and observing the associated Hr-ORSIs (e.g., based on the relevant seismic building codes, 
the maximum height of the $\mathrm{B} / \mathrm{C}$ buildings in this area is six floors tall). In fact, it was these preceding findings (esp. those from various Br-LKs) that formed the foundation and boundary conditions of our pre-assumptions.

Table 3. Confusion matrix of the correspondences between the actual numbers of floors and the actual structure types of the sample buildings.

\begin{tabular}{|c|c|c|c|c|c|c|}
\hline & & \multicolumn{3}{|c|}{$\begin{array}{l}\text { Numbers of Buildings with } \\
\text { Different Structural Types }\end{array}$} & \multirow{2}{*}{$\begin{array}{l}\text { Total Number } \\
\text { of Buildings }\end{array}$} & \multirow{2}{*}{$\begin{array}{c}\text { Accuracy of the Preset/Estimated } \\
\text { Structure Type Based on the } \\
\text { Number of Floors (\%) }\end{array}$} \\
\hline & & S/B & $\mathbf{B} / \mathbf{C}$ & $\mathbf{R} / \mathbf{C}$ & & \\
\hline Numbers of & 1 & 28 & 0 & 0 & 28 & 100.00 \\
\hline buildings with & $2 \sim 6$ & 0 & 121 & 6 & 127 & 95.28 \\
\hline different floors & $\geq 7$ & 0 & 1 & 79 & 80 & 98.75 \\
\hline \multicolumn{2}{|c|}{ Total number of buildings } & 28 & 122 & 85 & 235 & \\
\hline \multirow{2}{*}{\multicolumn{2}{|c|}{$\begin{array}{c}\text { Accuracy of the preset/estimate } \\
\text { number of floors based on } \\
\text { structure type }(\%)\end{array}$}} & 100.00 & 99.18 & 92.94 & & \\
\hline & & \multicolumn{5}{|c|}{ Overall accuracy: $97.02 \%$, kappa coefficient: 0.95.} \\
\hline
\end{tabular}

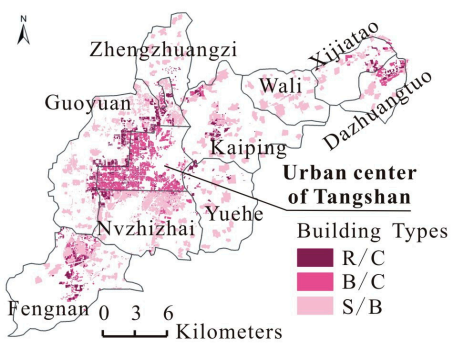

a

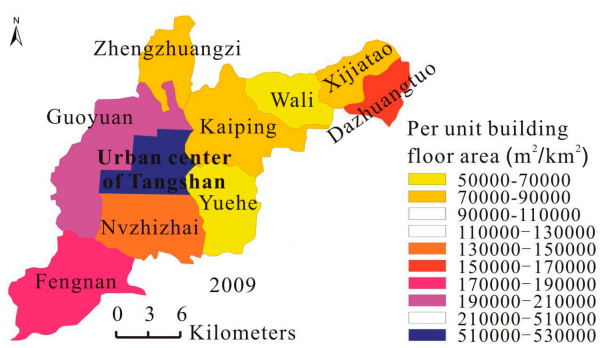

b

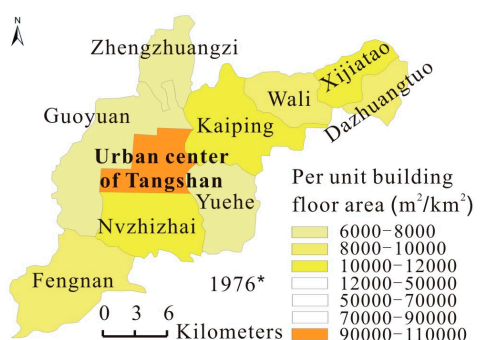

C

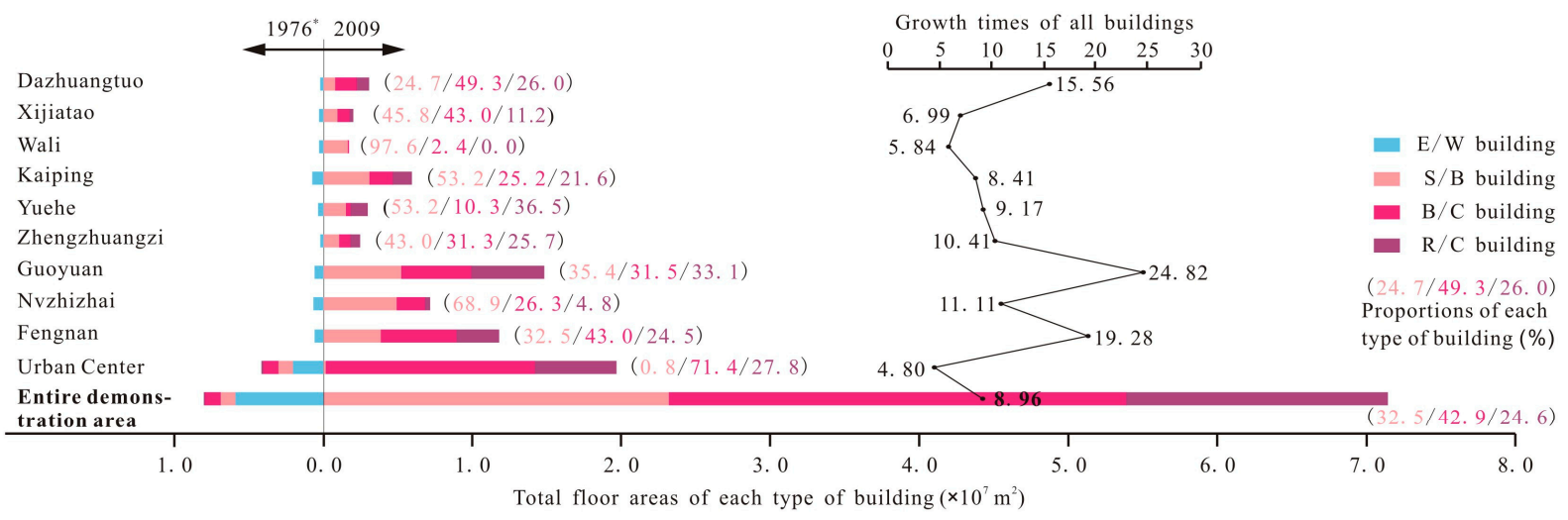

d

Figure 8. Building stock growth and changes in the study area from 1976 (shortly before the Ms 7.8 Tangshan earthquake) to 2009. (a) The distributions of various types of buildings in 2009; (b) The per-unit building floor areas in 2009; (c) The per-unit building floor areas in 1976; (d) Building growths by area and type from 1976 to 2009; * The numbers of each type of building in 1976 (shortly before the Ms 7.8 Tangshan earthquake) were obtained by reviewing the relevant literature [108,111]. 
Based on these findings, we adopted the following general rules to rapidly identify the structural types of all of the residential and public use buildings in the study area: buildings with one estimated floor are $\mathrm{S} / \mathrm{B}$, buildings with two to six estimated floors are $\mathrm{B} / \mathrm{C}$, and buildings with seven or more estimated floors are $\mathrm{R} / \mathrm{C}$. The results indicated that the buildings with relatively good seismic performance in 2009 , including the $\mathrm{R} / \mathrm{C}$ and $\mathrm{B} / \mathrm{C}$ buildings, were primarily distributed in the urban center, western urban outskirts, and at a few additional locations (including north of the towns of Fengnan and Dazhuangtuo). The S/B buildings were distributed across the rural and suburban regions (Figure $8 \mathrm{a}$ ). This distribution indicated large structural vulnerability variations from place to place. The most potentially resilient area in 2009 was the urban center, where S/B buildings were rare. The most seismically vulnerable location was the town of Wali, where very few R/C buildings existed at that time (Figure 8a).

Based on the total floor area of each building estimated in Section 4.1 and on its structural type judged here, we rapidly obtained the general total floor areas of each type of building $(\mathrm{S} / \mathrm{B}, \mathrm{B} / \mathrm{C}$, and R/C buildings) within the entire study area in 2009 (see bars extending to the right in Figure 8d). A comparison of the building stock in the study area in 2009 and in 1976 indicated that very significant growth and changes occurred during the previous decades. For instance, the E/W buildings completely disappeared and the total floor area of all residential and public office buildings in the study area was 8.96 times greater in 2009 than the total floor area of the same buildings in 1976 (shortly before the Ms 7.8 Tangshan earthquake). In addition, the total floor area of all residential and public office buildings in the township of Guoyuan increased by an astonishing factor of 24.82 (Figure 8a-d).

\subsection{Defining Building Damage Probability Matrixes (DPMs)}

The DPMs used in this study were developed in three steps. (1) Yin [49] developed a set of baseline DPMs for Chinese mainland buildings that consisted of several sub-sets based on buildings in various parts of China. In his DPM set, a sub-set was included that was primarily based on the experiences of the 1976 Tangshan earthquake and was specific to the middle region of northern China. Therefore, we first based our DPMs of seismic intensities VI through X (Unless otherwise stated, these intensities and intensity XI discussed in this paragraph and those mentioned throughout the paper all correspond with the Chinese Seismic Intensity Scale.) on this sub-set; (2) Because no matrix with an intensity of XI was included in Yin's matrix set, we used observations of the building damages in the zone subjected to an intensity of XI during the 2008 Wenchuan earthquake [127]. No discussion of the matrix of intensity XI was conducted for the Chinese mainland before this large earthquake, mainly because an insufficient number of the sample buildings that were damaged by this very high intensity; (3) To update our DPMs and make them more consistent with local current conditions, we performed several additional adjustments to the matrixes obtained in the previous two steps. These adjustments were primarily based on relevant findings from several recent earthquake loss estimation studies in cities in the middle region of northern China, including Nanyang, Henan province [128], Handan, Hebei province [129], and urban Tangshan, Hebei province [130]. Our final DPMs are presented in Table 4.

Based on previous results, including the total constructed/floor areas of each type of building for residential and public office usages in the study area in 2009 and their DPMs, we calculated the 
damage potential of one specific type of building in this area in 2009 under a specific intensity scenario using Equation (8) [49].

$$
A_{s}=B_{s} \times \sum_{j} P\left[D_{j} \mid I\right]
$$

where $A_{S}$ refers to the damage area of $S$-type buildings under a specific intensity scenario $I$; $B_{S}$ represents the total constructed/floor area of the $S$-type buildings; $P\left[D_{j} \mid I\right]$ are the buildings' DPMs; $S$ represents the specific structural types of the buildings, including the $\mathrm{S} / \mathrm{B}, \mathrm{B} / \mathrm{C}$ and $\mathrm{R} / \mathrm{C}$ types; and $j$ denotes a building's degree of damage, which is usually assigned to slight damage, moderate damage, major damage, or total collapse in China [131].

Table 4. Damage probability matrix (DPM) of each type of building.

\begin{tabular}{ccccccc}
\hline $\begin{array}{c}\text { Structural } \\
\text { Type }\end{array}$ & Intensity & $\begin{array}{c}\text { No } \\
\text { Damage (\%) }\end{array}$ & $\begin{array}{c}\text { Slight } \\
\text { Damage (\%) }\end{array}$ & $\begin{array}{c}\text { Moderate } \\
\text { Damage (\%) }\end{array}$ & $\begin{array}{c}\text { Major } \\
\text { Damage (\%) }\end{array}$ & $\begin{array}{c}\text { Collapse } \\
\text { (\%) }\end{array}$ \\
\hline \multirow{6}{*}{ S/B } & VI & 49.00 & 24.15 & 13.05 & 11.98 & 1.82 \\
& VII & 28.00 & 21.29 & 22.08 & 20.27 & 8.36 \\
& VIII & 12.00 & 16.33 & 23.09 & 30.30 & 18.28 \\
& IX & 8.00 & 10.53 & 17.66 & 26.14 & 37.67 \\
& X & 2.20 & 4.81 & 11.90 & 17.25 & 63.84 \\
& XI & 0.00 & 0.00 & 0.00 & 5.00 & 95.00 \\
\hline \multirow{6}{*}{ B/C } & VI & 76.73 & 19.54 & 2.98 & 0.67 & 0.08 \\
& VII & 77.54 & 15.64 & 4.64 & 1.72 & 0.46 \\
& VIII & 68.35 & 17.21 & 9.00 & 3.98 & 1.46 \\
& IX & 53.18 & 19.10 & 15.24 & 8.22 & 4.26 \\
& X & 28.00 & 19.52 & 21.95 & 17.64 & 12.89 \\
& XI & 0.30 & 1.50 & 4.70 & 11.70 & 81.80 \\
\hline \multirow{5}{*}{ R/C } & VI & 90.00 & 10.00 & 0.00 & 0.00 & 0.00 \\
& VII & 85.00 & 14.00 & 1.00 & 0.00 & 0.00 \\
& VIII & 70.00 & 25.00 & 5.00 & 0.00 & 0.00 \\
& IX & 50.00 & 31.50 & 14.50 & 3.50 & 0.50 \\
& X & 20.00 & 30.00 & 35.00 & 10.50 & 4.50 \\
& XI & 1.69 & 3.38 & 10.02 & 34.91 & 50.00 \\
\hline
\end{tabular}

Note: These DPMs were adapted from Yin [49], CNCDR [127], Zhang et al. [128], Zhang et al. [129], and Li et al. [130].

Using the result from Equation (8), the value of $A$ in the following Equation (9) can be derived accordingly. This equation expresses the total potential damage to all of the addressed types of buildings in the study area in 2009 under certain specific intensity scenarios. Example calculations are presented in the Appendix of this paper.

$$
A=\sum_{S} A_{s}
$$

\subsection{Developing Parameters for Calculating Monetary Losses}

The direct losses in monetary terms due to building damage are usually assigned to two categories: structural damage to the buildings themselves and damage to the contents of the buildings $[7,70,132]$. 
From this standpoint, the expression widely adopted in mainland China for calculating total direct monetary losses is

$$
L(I)=\sum_{s} \sum_{j} P\left[D_{j} \mid I\right] \times B_{s} \times b_{s} \times \varepsilon_{b j}+\sum_{s} \sum_{j} P\left[D_{j} \mid I\right] \times B_{s} \times a_{s} \times \varepsilon_{a j},
$$

where $L(I)$ represents the total direct monetary losses that resulted from seismic damage to buildings under a specific intensity of $I ; b_{S}$ is the replacement cost per unit floor area of the $S$-type buildings expressed in RMB or USD per square meter; $\varepsilon_{b j}$ denotes the loss ratio of $S$-type buildings with the degree of damage of $j ; a_{s}$ is the average/mean monetary value of the building contents per unit floor area of the $S$-type buildings, which is usually expressed in RMB or USD per square meter; and $\varepsilon_{a j}$ indicates the loss ratio of the building contents with a degree of damage of $j$.

Of the parameters in Equation (10), $P\left[D_{j} \mid I\right]$ and $B_{S}$ were obtained in earlier steps. Therefore, estimating the direct monetary losses due to building damage requires proper determinations of other parameters in the expression, including $a_{s}, b_{s}, \varepsilon_{a j}$, and $\varepsilon_{b j}$. We determined the values of these parameters by primarily reviewing the Br-LK that was relevant to the study area in 2009. Moreover, to render these parameters more appropriate and reliable, during the 3-day field investigation (Figure 4), we performed small-scale interviews involving a number of local households, public service departments, and building construction companies.

To determine $a_{s}$, we primarily referred to 2009 data from the local Economic Statistical, local Price, and local Construction Statistical Yearbooks and used the records of interviews of local households and public service departments. In the published data alone (e.g., yearbooks), abundant records and information exist regarding parameter $a_{s}$. For example, this information includes the average/mean amount of major indoor durable goods owned per 100 households, the values of these goods, and the average/mean living space per capita for the various types of buildings addressed. Based on the same rationale, we assigned a value to parameter $b_{s}$ by primarily reviewing the local Construction Statistical Yearbook, the local Price Yearbook and consultations with local building construction companies. The values of parameters $\varepsilon_{b j}$ and $\varepsilon_{a j}$ were based on the comprehensive analysis of relevant data in the available loss assessment reports of numerous past earthquakes nationwide [133-135], in relevant research books [136], and in available earthquake loss estimation project reports [128-130,137].

After assigning values to the variables in Equation (10) based on estimates or calculations following the above steps and after selecting various specific intensity scenarios, the potential direct monetary losses due to residential and public office building damage in the study area in 2009 can be displayed. Please see Appendix of this paper for an example calculation.

\section{Verifications}

\subsection{Field-Based Verifications}

From previous sections, the reliability and accuracy of the integrated method developed in the study is primarily determined by the following: (1) the accuracies of the estimated building heights and footprint areas and (2) the reliabilities of the estimated correlations between the building height and 
number of floors and between the number of floors and structural type in the study area. To test the accuracy and reliability of our estimates, a careful field sampling investigation was conducted.

The first step of this field sampling investigation was to select an adequate set of sample buildings using a mixed sampling method. First, we delineated various sample sub-areas by cluster sampling. As explained earlier, the accuracies of estimated building heights and footprint areas depend on the accuracies of the SIPDs measurements and the roof outlines in the Hr-ORSIs. The primary factors that influence the clear identification and accurate measurement of these two parameters include the following: (1) various shading or interference effects in the images of a building's shadow or roof that stem from the building's surroundings (e.g., trees); (2) high gray-tone similarities between the images of a building's shadow or roof and its background (e.g., water bodies); and (3) a building's irregular or unique shape (relevant to measuring roof outlines only). Based on the significance of these three aspects regarding their combined effects on image interpretation, we divided the GeoEye-1 images spanning the entire study area into three clusters. (1) A low-effect cluster, namely a low-effect sub-area, was characterized by low building densities with very little or no effects from trees or other ground objects. Building-occupied land in the low-effect cluster comprised approximately $30 \%$ of the total building-occupied land in the study area; (2) A moderate-effect cluster (i.e., moderate-effect sub-area) was characterized by a moderate building density. A few or several of the buildings' shadows and/or roof outlines were shaded or interfered with, but the distinct roof edge points that were used for determining the SIPDs, such as the corner of a building's roof edge, were always clearly visible. The land occupied by buildings in this sub-area accounted for approximately $55 \%$ of the total land occupied by buildings in the study area; (3) A high-effect cluster (i.e., high-effect sub-area) of land occupied by buildings accounted for approximately $15 \%$ of the total land occupied by buildings in the study area. This sub-area always had a very high building density and significant shadowing and roof shading or interference effects. The rooftop edge points in this sub-area for determining the SIPDs frequently cannot be easily identified. In some cases, irregular-shaped buildings may be included. Next, we selected specific sample sites and selected a site size by using the stratified sampling concept, which involved two steps. (1) We determined the total size of the specific sample site(s) of each cluster (sub-area). In this case, the building-occupied lands of the low, moderate, and high-effect clusters (sub-areas) comprised approximately $30 \%, 55 \%$ and $15 \%$, respectively, of the total building-occupied land in the study area. To ensure that the building sample is adequate for testing the overall accuracy of the estimated heights and footprint areas of all of the assessed buildings in the study area, we concluded that the total sizes of the specific sample site(s) with low, moderate and high effects should be $2 \mathrm{~km}^{2}, 3.6 \mathrm{~km}^{2}$, and $1 \mathrm{~km}^{2}$, respectively; (2) Next, we selected the locations of these specific sites. The determining factor was the representativeness of the sites regarding the above-mentioned interference effects, gray-tone similarities, and the number of irregular-shaped buildings. Finally, we designated all of the individual residential and public office buildings in these specific sites as our final sample buildings for analysis, which numbered 954.

The second step was to perform verification through fieldwork. For this step, we used a handheld laser rangefinder to measure the true floor height, total building height and footprint area of each sample building. In addition, we used a handheld GPS to locate the exact spatial positions of the sample buildings and to record their structural types and numbers of floors. The accuracy or reliability of the integrated method developed in this study was evaluated using these data. 


\subsubsection{Accuracy of the Building Height Estimates}

After comparing the true heights of the buildings measured in the field with the estimated heights of the same buildings obtained using the method we proposed in this study, we concluded that the overall accuracy of the building height estimation algorithm we developed was satisfactory (Figures 9-11; Table 5). Overall, a good linear relationship was observed between the measured/true heights obtained from the fieldwork and the estimated heights that were derived from the images (Figure 9). The mean measured height of the sample buildings was $19.72 \mathrm{~m}$, and the mean estimated height of these same buildings was $19.39 \mathrm{~m}$. Furthermore, the mean absolute error (MAE) between the estimated and measured heights was $0.55 \mathrm{~m}$, and the mean absolute percentage error (MAPE) was $3.23 \%$ (Table 5). The mean measured floor height of the sample buildings was $3.09 \mathrm{~m}$, which closely matched our earlier estimated height. In terms of estimation error differences in the buildings with different actual floor numbers, Figure 10 shows that larger errors mainly occurred when estimating the heights of the buildings that were 4 through 6 and 11,12, 17 and 18 floors in height. Regarding the differences between the measured and the estimated height of each individual sample building, only 27 buildings had absolute differences that were near or greater than $3 \mathrm{~m}$, including only $2.83 \%$ of the 954 sample buildings (Table 5) and occurring at the moderate and high effect sites (Table 5; Figure 11). In this integrated method, the height of a building is an important reference by which a building's floor number is judged. The large differences between the buildings' mean height $(19.72 \mathrm{~m})$ and/or mean floor height $(3.09 \mathrm{~m})$ that were measured in the field and the estimating errors (e.g., MAE of $0.55 \mathrm{~m}$ ) indicated that these estimation errors did not significantly influence the reliability of using these estimated heights to judge the number of floors in a building, except in a few extreme cases. Such an accuracy level is high enough to produce reliable estimates of the number of floors in a building by using the estimated building heights.

Figure 12 provides several examples of measured vs. estimated height differences that were much larger than $3 \mathrm{~m}$, which could yield an incorrect estimate of number of floors. The building with the largest absolute height estimation error was building No. 189 at the high effect site. Figure 12a shows that most of its shadow was blocked by a building in the front, which significantly distorted its shadow, made it difficult to identify a reliable SIPD and yielded a large height estimation error $(15.75 \mathrm{~m})$. Figure $12 \mathrm{~b}$ shows the cases in which large portions of the buildings' shadows were projected onto surrounding trees, which rendered the shadows of the upper potions of the buildings nearly indiscernible. This type of interference can also produce serious estimation errors. However, these extreme instances of shading or interferences were rare across the study area and were primarily observed in high-effect sub-area (Figure 11) in which the land occupied by buildings only accounted for approximately $15 \%$ of the total land occupied by buildings in the study area. 


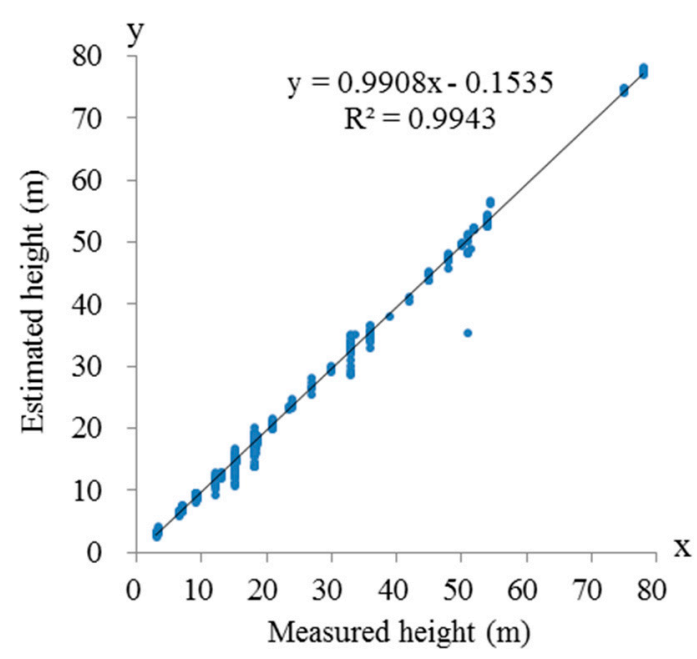

Figure 9. Scatter plot of the estimated and measured building heights.
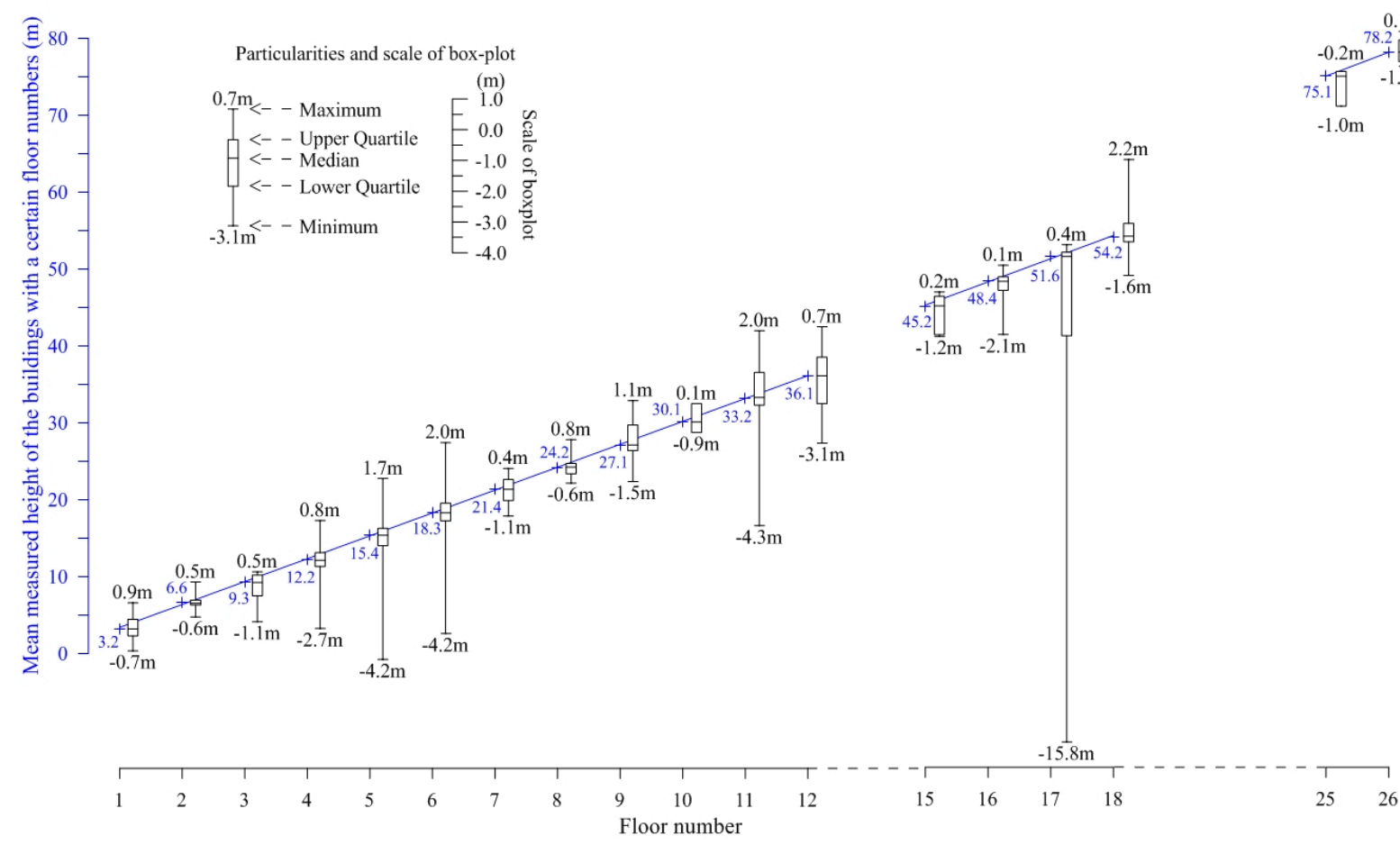

Figure 10. Mean measured heights and box-plots of the absolute errors of the estimated heights of buildings with different actual floor numbers. Note: (1) This figure contains two layers of information that use one X-axis. One layer is the mean measured heights of the sample buildings with different numbers of floors and is represented by blue crosses indicating height points, blue numerals indicating height values, and the blue lines fit to the data. The other layer is the absolute errors of the estimated heights, which are illustrated by box-plots that are colored in black; (2) All of the box-plots are plotted using one length scale (see the upper left of the Figure); thus, all of the error features of the height estimates of the buildings with different actual floor numbers depicted in these box-plots are comparable with one another, including the height estimate error ranges displayed by the entire lengths of the box-plots in this figure. In this way, one can easily observe that the buildings with a number of floors possess a type of error. 


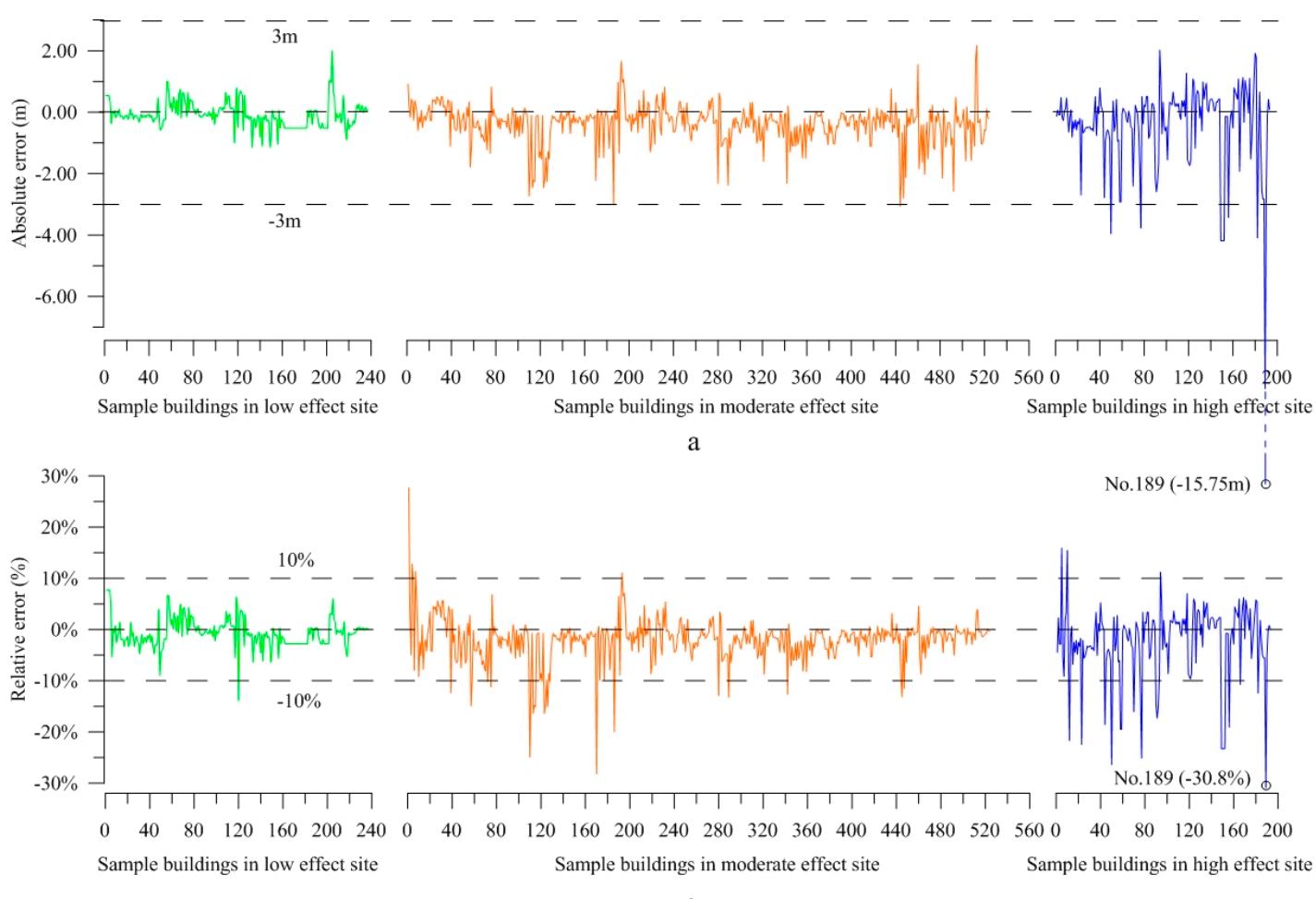

$\mathrm{b}$

Figure 11. Absolute and relative differences between the measured and estimated heights of the sample buildings. (a) Absolute differences; (b) Relative differences. Note: (1) On all $\mathrm{x}$-axes, the sample buildings at each site were sorted based on their height. Specifically, the buildings were arranged from low to high, with larger building (serial) numbers corresponding with larger actual/measured building heights; (2) Relative errors were obtained by subtracting the measured heights from their estimated counterparts. Thus, one can observe that a systematical under-estimation occurred in the building height estimations in this study, especially at the moderate and high effect sites.

Table 5. Summary of the building height estimation errors.

\begin{tabular}{|c|c|c|c|c|c|c|c|}
\hline \multirow[t]{2}{*}{ Sample Buildings } & \multirow[t]{2}{*}{ MAE } & \multirow[t]{2}{*}{ MAPE } & \multirow[t]{2}{*}{$r$} & \multirow[t]{2}{*}{ RMSE } & \multirow{2}{*}{$\begin{array}{c}\text { Total } \\
\text { Building Number }\end{array}$} & \multicolumn{2}{|c|}{$\begin{array}{c}\text { Buildings with Absolute Error } \\
\text { Near or Greater than } \pm \mathbf{3} \mathbf{~ m}\end{array}$} \\
\hline & & & & & & Number & Percentage \\
\hline Whole sample & 0.55 & $3.23 \%$ & 0.997 & 0.99 & 954 & 27 & $2.83 \%$ \\
\hline In low effect site & 0.35 & $2.14 \%$ & 0.999 & 0.49 & 237 & 0 & $0.00 \%$ \\
\hline In moderate effect site & 0.53 & $3.08 \%$ & 0.999 & 0.80 & 524 & 8 & $1.53 \%$ \\
\hline In high effect site & 0.88 & $4.98 \%$ & 0.983 & 1.67 & 193 & 19 & $9.84 \%$ \\
\hline
\end{tabular}

Note: MAE represents the mean absolute error; MAPE represents the mean absolute percentage error; $r$ is the

Pearson's product-moment correlation coefficient; and RMSE is the root mean square error.

\subsubsection{Accuracy of the Building Footprint Area Estimates}

The overall accuracies of the buildings' estimated footprint areas were satisfactory (Figures 13 and 14; Table 6). Overall, a good linear relationship was observed between the measured/true footprint areas obtained in the field and the estimated footprint areas derived from images (Figure 13). The average measured/true footprint area of the sample buildings was $622.77 \mathrm{~m}^{2}$, and the average estimated 
footprint area was $623.55 \mathrm{~m}^{2}$. The MAE between these measured and estimated areas was $16.54 \mathrm{~m}^{2}$, and the MAPE was 2.99\% (Table 6). Regarding the differences between the measured and the estimated areas of each individual sample building, the buildings that had relative differences of less than $2.99 \%$ accounted for $63.94 \%$ of the total sample buildings. Only 43 buildings had relative differences that exceeded $10 \%$, which accounted for $4.51 \%$ of all of the sample buildings (Table 6 ). The larger errors nearly all occurred at the moderate and high effect sites (Table 6; Figure 14).
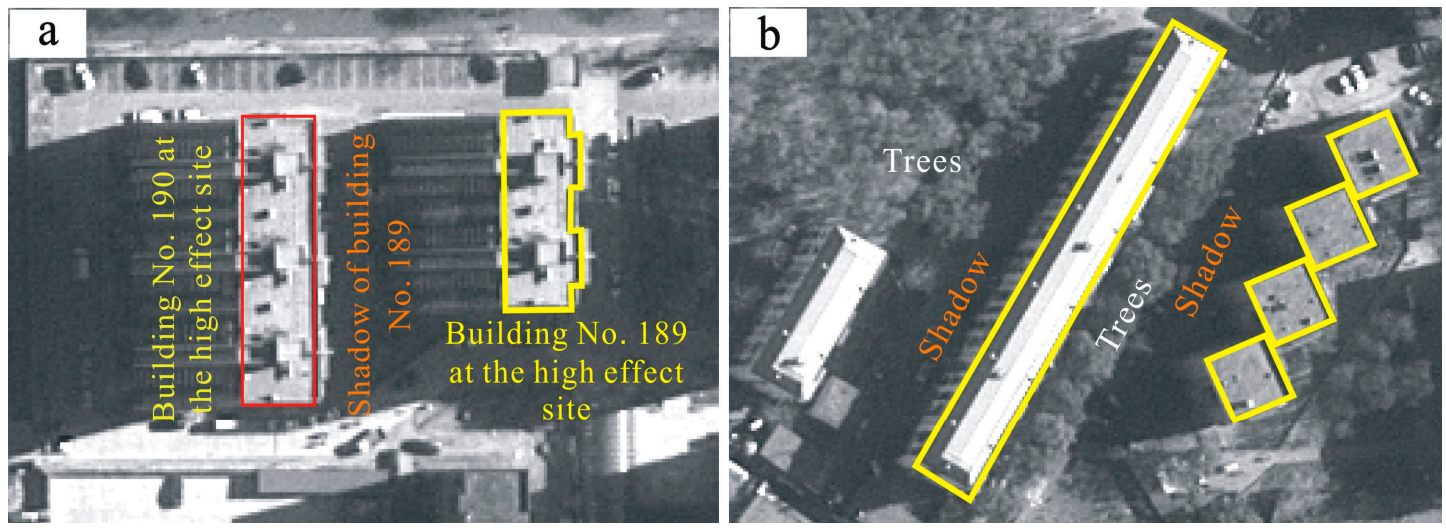

Figure 12. Images of the selected buildings with large height estimation errors.

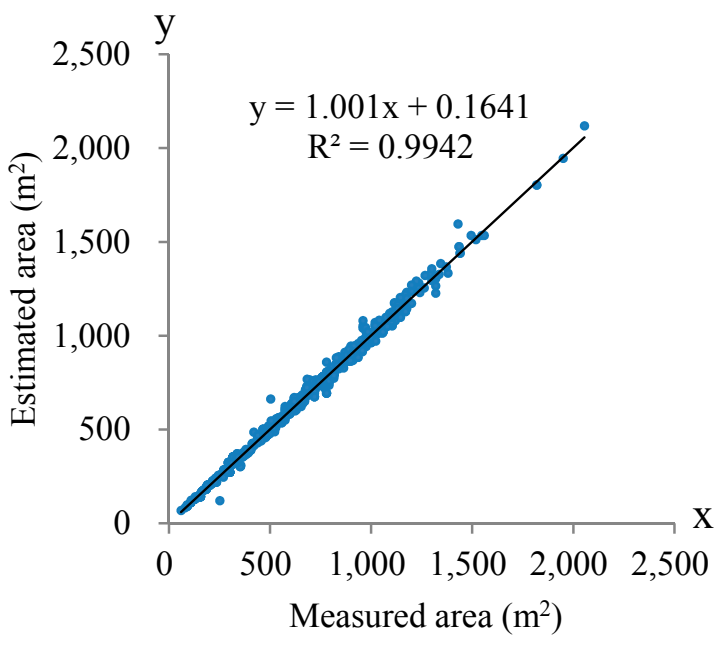

Figure 13. Scatter plot of the estimated and measured building footprint areas.

Figure 15 shows several examples of large measured vs. estimated differences. Building No. 37 at the high effect site had the largest relative error of $52.7 \%$ (Figure 14), which mainly occurred because the roof of the building was in the shadow of a building in front of it (No. 13) (Figure 15a). Apart from image shading, interference, or the high gray-tone similarity effects, the irregular shape of a building's roof was another source of error when estimating building footprint areas. Figure 15b shows examples of this error for two rows of uniquely shaped buildings. It was not easy to precisely digitize these irregular roof outlines, which means that certain errors were inevitable. However, the occurrence of such extreme errors when estimating building footprint areas were rare, as were the extreme errors that occurred when estimating the building heights as discussed above. 


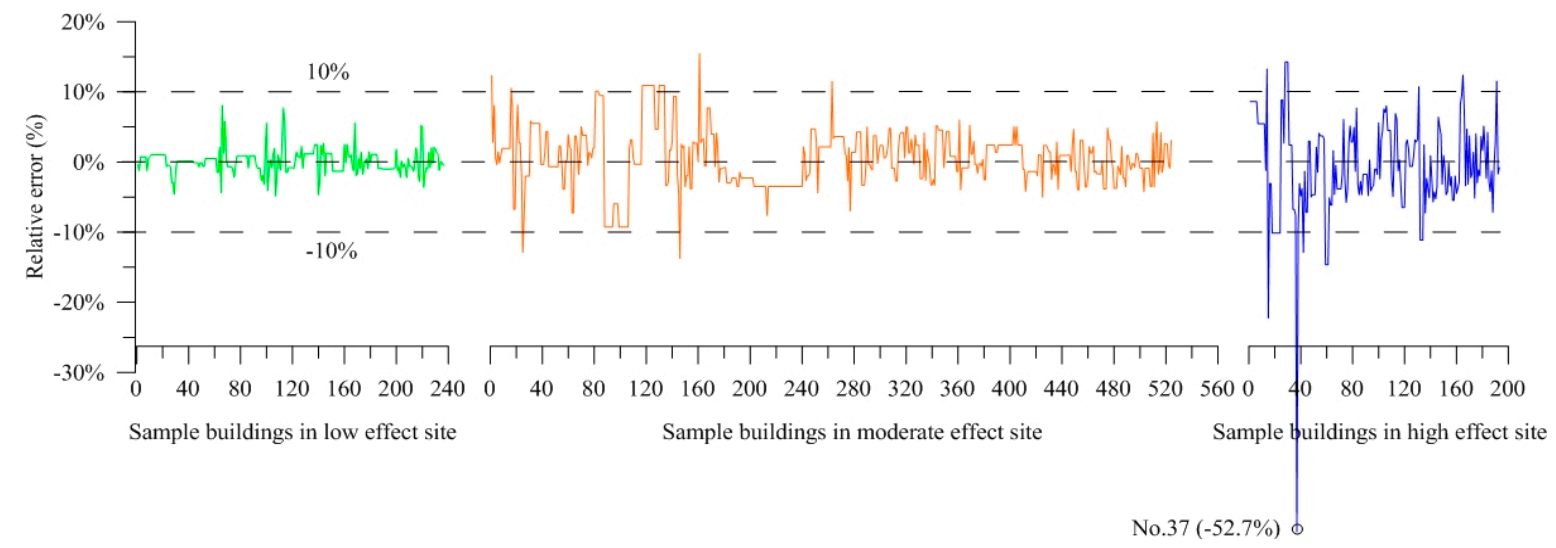

Figure 14. Relative differences between the measured and estimated footprint areas of the sample buildings. Note: (1) On all x-axes, the sample buildings at each effect site were arranged by footprint size, with larger (serial) numbers of buildings corresponding with larger building footprint areas; (2) Relative errors were obtained by subtracting the measured footprint areas from their estimated footprints.

Table 6. Summary of the building footprint area estimation errors.

\begin{tabular}{|c|c|c|c|c|c|c|c|}
\hline \multirow[t]{2}{*}{ Sample Buildings } & \multirow[t]{2}{*}{ MAE } & \multirow[t]{2}{*}{ MAPE } & \multirow[t]{2}{*}{$\boldsymbol{r}$} & \multirow[t]{2}{*}{ RMSE } & \multirow{2}{*}{$\begin{array}{l}\text { Total Number } \\
\text { of Buildings }\end{array}$} & \multicolumn{2}{|c|}{$\begin{array}{l}\text { Buildings with Relative } \\
\text { Errors Exceeded } 10 \%\end{array}$} \\
\hline & & & & & & Number & Percentage \\
\hline Entire sample & 16.54 & $2.99 \%$ & 0.997 & 23.47 & 954 & 43 & $4.51 \%$ \\
\hline Low effect site & 13.68 & $1.73 \%$ & 0.997 & 19.35 & 237 & 1 & $0.42 \%$ \\
\hline Moderate effect site & 15.90 & $3.26 \%$ & 0.998 & 20.57 & 524 & 26 & $4.96 \%$ \\
\hline High effect site & 21.84 & $3.78 \%$ & 0.996 & 33.40 & 193 & 16 & $8.29 \%$ \\
\hline
\end{tabular}

Note: MAE is the mean absolute error; MAPE is the mean absolute percentage error; $r$ is the Pearson's product-moment correlation coefficient; and RMSE is the root mean square error.
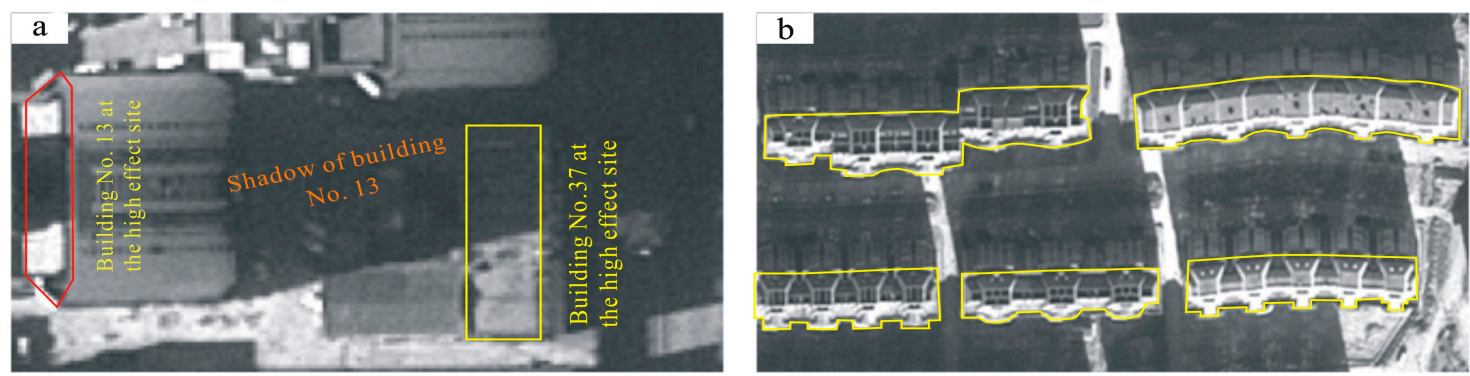

Figure 15. Images of buildings with large footprint area estimation errors.

\subsubsection{Reliabilities of the Estimated Correlations between Building Height, Number of Floors and} Structural Type

In this study, we established two sets of general rules using the proposed integrated method composed of a series of estimated or prescribed correlations regarding building height, the number of floors and structural type (Sections 4.1 and 4.2) to rapidly and generally determine the floor numbers and structure types of all residential and public office buildings in the study area. The data obtained in the field can also serve to test the reliabilities of these general rules or estimated/prescribed correlations. 
In terms of this specific test, the 954 buildings used for field-based verification are actually a simple random sample.

The field data from these sample buildings showed that all of the single-floor sample buildings were between 3.00 and $3.90 \mathrm{~m}$ tall, all of the buildings with two floors were 6.4 to $6.8 \mathrm{~m}$ tall, and so forth. After comparing these actual relationships between the number of floors and the building height with our pre-set rules or estimated/prescribed correlations (e.g., buildings with an estimated height of approximately 3 to $4 \mathrm{~m}$ have one floor), it was found that these pre-set or pre-assumed rules agreed well with the corresponding actual relationships. The confusion matrix showed that the overall agreement between our pre-set rules/estimated correlations and the actual relationships was 91.61\%, with a kappa coefficient of 0.89 (Table 7).

The field data of the sample showed that all of the single-floor sample buildings were of S/B type; $95.16 \%$ of the sample buildings with two to six floors were B/C type, and $4.84 \%$ of the sample buildings with two to six floors were $\mathrm{R} / \mathrm{C}$ type (Table 8). In addition, all of the sample buildings with seven or more floors were $\mathrm{R} / \mathrm{C}$ type, except very few special cases of buildings taller than seven floors that were constructed before 2000, which were B/C type (Table 8). By comparing these facts with our estimated/pre-set correlations (i.e., the residential and public office buildings with one estimated floor are all S/B type structures, the buildings with two to six estimated floors are all B/C type, and with seven or more estimated floors are all $\mathrm{R} / \mathrm{C}$ type), we found that the overall agreement between our general and rapid building structural type estimate rules and the corresponding facts was $95.81 \%$, with a kappa coefficient of 0.88 (Table 8). This value was slightly higher than that regarding the rapid estimation of the buildings' floor numbers. The errors in this estimation primarily occurred when estimating the structure type of the building with six or fewer floors. This estimated bias occurred because some of the relatively lower buildings are also $\mathrm{R} / \mathrm{C}$ type structures in the study area due to recent economy development.

Table 7. Summary of the confusion matrix between the actual floor numbers of the sample buildings and those estimated by our pre-set rules.

\begin{tabular}{|c|c|c|c|c|c|c|c|c|c|c|}
\hline Actual Number of Floors & 1 & 2 & 3 & 4 & 5 & 6 & 7 & 8 & 9 & 10 \\
\hline Total number of buildings with certain numbers of floors & 20 & 61 & 31 & 47 & 289 & 337 & 16 & 11 & 6 & 4 \\
\hline Number of buildings with correct floor estimations & 20 & 57 & 31 & 45 & 266 & 320 & 16 & 11 & 5 & 4 \\
\hline Number of buildings over-estimated by one floor & & 4 & & & 1 & 1 & & & & \\
\hline Number of buildings under-estimated by one floor & & & & 2 & 22 & 16 & & & 1 & \\
\hline \multicolumn{11}{|l|}{ Number of buildings with other estimation errors } \\
\hline Actual Number of Floors & 11 & 12 & 13 & 14 & 15 & 16 & 17 & 18 & 25 & 26 \\
\hline Total number of buildings with certain numbers of floors & 35 & 14 & 1 & 2 & 8 & 19 & 21 & 21 & 4 & 7 \\
\hline Number of buildings with correct floor estimations & 26 & 8 & 1 & 1 & 8 & 12 & 15 & 17 & 4 & 7 \\
\hline Number of buildings over-estimated by one floor & 4 & & & & & 6 & & 2 & & \\
\hline Number of buildings under-estimated by one floor & 5 & 6 & & 1 & & 1 & 5 & 2 & & \\
\hline Number of buildings with other estimation errors & & & & & & & $1 *$ & & & \\
\hline
\end{tabular}

Overall accuracy: $91.61 \%$, kappa coefficient: 0.89 .

* All errors resulted from misestimating one floor, except for one 17-floor building (No. 189 at the high effect site) that was wrongly estimated to have 12 floors. 
Table 8. Confusion matrix between the actual structure types of the sample buildings and those estimated by our pre-set rules.

\begin{tabular}{|c|c|c|c|c|c|c|}
\hline & & \multicolumn{3}{|c|}{$\begin{array}{c}\text { Number of Buildings with Each } \\
\text { Estimated Structure Type } \\
\end{array}$} & \multirow{2}{*}{$\begin{array}{c}\text { Total } \\
\text { Building } \\
\text { Number }\end{array}$} & \multirow{2}{*}{$\begin{array}{c}\text { User Accuracy (Correctly } \\
\text { Estimated Percentage of } \\
\text { Buildings with Each Actual } \\
\text { Structural Type) (\%) } \\
\end{array}$} \\
\hline & & $\mathbf{S} / \mathbf{B}$ * & $\mathrm{B} / \mathrm{C} *$ & $\mathbf{R} / \mathbf{C} *$ & & \\
\hline Number of buildings & $\mathrm{S} / \mathrm{B}$ & 20 & 0 & 0 & 20 & 100.00 \\
\hline with each actual & $\mathrm{B} / \mathrm{C}$ & 0 & 727 & 3 & 730 & 99.59 \\
\hline structure type & $\mathrm{R} / \mathrm{C}$ & 0 & 37 & 167 & 204 & 81.86 \\
\hline \multicolumn{2}{|c|}{ Total building number } & 20 & 764 & 170 & 954 & \\
\hline \multicolumn{2}{|c|}{$\begin{array}{l}\text { Produce accuracy (Correct percentage } \\
\text { of pre-set rules used to estimate the } \\
\text { structural types of buildings) }(\%)\end{array}$} & 100.00 & 95.16 & 98.24 & & \\
\hline
\end{tabular}

* These structural types were estimated based on our pre-set rules (i.e., buildings with one estimated floor based on the estimated building height are S/B; buildings with two to six estimated floors are B/C, and buildings with seven or more estimated floors are R/C.)

\subsection{Actual Earthquake Loss Estimation Project-Based Verification}

In 2009, an actual earthquake loss estimation project that used the conventional data collection method was launched in the study area [130]. This project is one important reason for our selection of 2009 as the year to develop our integrated method. The target area of this project was the central part of Tangshan (i.e., its most urbanized area). This area overlapped with the area of the present study but was much smaller. This project not only included the building types that we addressed in our study, specifically the $\mathrm{R} / \mathrm{C}, \mathrm{B} / \mathrm{C}$, and $\mathrm{S} / \mathrm{B}$ buildings, but also involved special and less prevalent structures, including steel buildings, single-floor plants, single-floor spacious buildings (e.g., cinemas), and temporary buildings. This project spanned more than three years and was completed in late 2012.

This verification method focused on comparing the constructed/floor areas of the $\mathrm{R} / \mathrm{C}, \mathrm{B} / \mathrm{C}$, and $\mathrm{S} / \mathrm{B}$ buildings that were established by Li et al. with the corresponding measurements that were estimated in this study. We found that the relative difference between these two studies regarding the total floor area of all three types of buildings was small (i.e., $-3.996 \%$ ). The relative differences in the $\mathrm{R} / \mathrm{C}$ and $\mathrm{B} / \mathrm{C}$ buildings were larger, reaching $-16.667 \%$ and $12.029 \%$, respectively (Table 9 ). These two larger differences were observed because a small number of newly constructed buildings with six or fewer floors were assigned to the $\mathrm{R} / \mathrm{C}$ category in the work of $\mathrm{Li}$ et al. but were generally classified as $\mathrm{B} / \mathrm{C}$ structures in our study.

Given this particular verification, the accuracy and reliability of the integrated method proposed in this study for rapid and large scale estimations of seismic risk to the residential and public office buildings are considered satisfactory and can attain the accuracy levels provided by conventional data collection methods. 
Table 9. Comparisons between the determined building floor areas of Li et al. [130] and the floor areas that were estimated in the current study.

\begin{tabular}{|c|c|c|c|c|}
\hline Description & $\mathrm{R} / \mathrm{C}$ & $\mathrm{B} / \mathrm{C}$ & $\mathbf{S} / \mathbf{B}$ & Total \\
\hline $\begin{array}{l}\text { Building areas determined by } \\
\text { Li et al. }\left(\mathrm{m}^{2}\right)\end{array}$ & $15,760,000$ & $15,460,000$ & $9,360,000$ & $40,580,000$ \\
\hline $\begin{array}{l}\text { Building areas estimated in } \\
\text { the current study }\left(\mathrm{m}^{2}\right)\end{array}$ & $13,133,316$ & $17,319,625$ & $\begin{array}{c}10,631,624 * \\
(8,505,299+2,126,325) \\
\end{array}$ & $\begin{array}{c}41,084,565 * \\
(38,958,240+2,126,325) \\
\end{array}$ \\
\hline $\begin{array}{l}\text { Absolute differences } \\
\text { between the values of } \\
\text { Li et al. and the } \\
\text { current study }\left(\mathrm{m}^{2}\right)\end{array}$ & $-2,626,684$ & $1,859,625$ & $-854,701$ & $-1,621,760$ \\
\hline $\begin{array}{l}\text { Relative differences between } \\
\text { the values observed by } \\
\text { Li et al. and in the current } \\
\text { study }(\%)\end{array}$ & -16.667 & 12.029 & -9.131 & -3.996 \\
\hline
\end{tabular}

* In China, particularly in its eastern half, many single-floor houses consist of two parts, the main house and its auxiliary structures. Among these houses, the main house is used as a living room, and the auxiliary structures are often used as kitchens, storerooms, and so forth. In general, the main rooms are taller and much larger than the auxiliary rooms. In actual pre-earthquake loss estimates in China based on conventional data collection, these auxiliary structures have often been neglected. This exclusion occurred in the research conducted by Li et al. [130]. This oversight is due to the much lower importance of these smaller auxiliary structures. More fundamentally and frequently, this omission is due to the difficulties that occur when gathering pertinent data using conventional methods. However, in our present study, these auxiliary structures were included and treated as S/B buildings. The total floor area of these auxiliary structures obtained using our integrated method was 2,126,325 $\mathrm{m}^{2}$. After evaluating these differences based on the floor area of the S/B buildings and on the total floor area of all of these three types of buildings, this value was excluded from our data when performing related comparisons to ensure that the findings of Li et al. could be compared with those of this study.

\section{Simulating the Impacts of the Ms 7.8 Tangshan Earthquake of 1976}

The Ms 7.8 Tangshan earthquake of 1976 claimed over 240,000 lives and caused over 0.82 billion USD (in constant 1990 valuations) in total property losses [110,113]. This earthquake is the deadliest earthquake in the history of modern China. In recent years since this earthquake, the following question has often been posed: What would occur if an earthquake of similar magnitude recurred in the 21 st century in the same place, where rapid, or even accelerated, socioeconomic growth and fixed assets accumulation have lasted for many years? However, there is no specific answer to this question because ample and detailed data, applicable methods, or even a basic understanding of this extremely difficult problem are lacking.

The integrated method developed in this study can contribute to solving this complex problem to a certain degree. Therefore, a simulation of the impacts from the recurrence of this large earthquake was performed. This simulation provided a basic understanding of what would occur if a strong earthquake were to occur in the same location today. In addition, this simulation offered an opportunity to apply the proposed new method. For this simulation, we assumed that a similarly strong earthquake recurred in 2009 at the same location as the 1976 earthquake. The location of this simulation corresponded 
exactly with the area of the current study (i.e., the central part of the disaster area associated with the Ms 7.8 Tangshan earthquake of 1976) (Figure 16). The scenario intensities were assumed to be the same as those experienced in the study area in 1976 (Figure 16). The affected objects of the simulation only consisted of R/C, B/C, and S/B buildings. Moreover, to fully use the results of this current study, we combined the data in Table 3 with similar data from Section 5.1. Based on this combination, we determined that all of the single-story residential and public office buildings addressed in the study area were S/B type. Of the buildings with two to six floors, we determined that $95.20 \%$ were $\mathrm{B} / \mathrm{C}$ type and $4.80 \%$ were $\mathrm{R} / \mathrm{C}$ type. Of the buildings with seven or more floors, we determined that $1.52 \%$ were $\mathrm{B} / \mathrm{C}$ type and $98.48 \%$ were $\mathrm{R} / \mathrm{C}$ type.

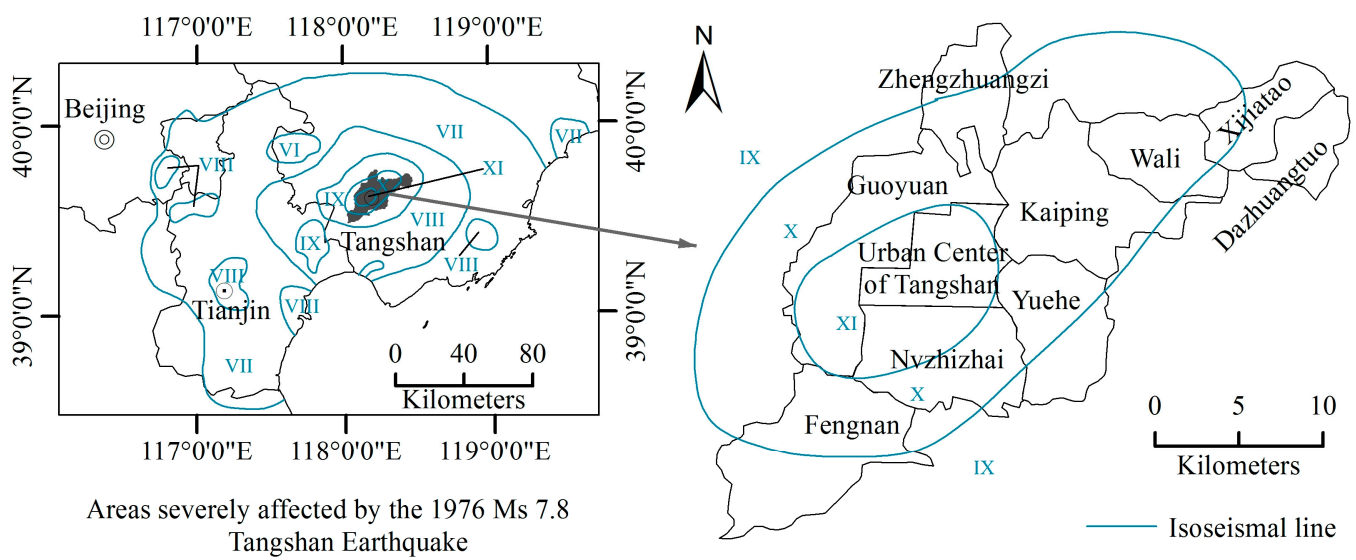

Figure 16. Seismic intensities in and near the study area during the Ms 7.8 Tangshan earthquake of 1976.

We developed certain impact simulation scenarios after assigning specific values (e.g., the total floor areas and DPMs of each type of building) that were obtained earlier in this study to the corresponding variables in Equations (8)-(10) and after considering the actual intensities that occurred in 1976. The results indicated that if the 1976 Tangshan earthquake had recurred in 2009, the total damage to the residential and public office buildings in the study area would have been 8.00 times greater than in 1976 (Figure 17a), despite the significant structural improvements that were made to these types of buildings since 1976 (Figure 8d).

The total direct economic losses due to damaged buildings for these two usages would have been 28.73 times greater in 2009 than in 1976 (Figure 17a). The spatial distributions of these simulated impact scenarios and their contrasts with the spatial differences of the actual losses in 1976 are shown in Figure 17b,c. The most notable difference was the large increase in the loss risk potential in the periurban area and in several "satellite" towns. For example, the simulated building damage and direct economic loss in the Guoyuan area in 2009 were 23.57 and 95.00 times greater than their respective values associated with the 1976 event (Figure 17a).

This particular simulation only addressed the increases in the seismic disaster risk potential due to building stock growth. To our knowledge, building damage is a beginning component and only one component of a complete earthquake disaster scenario. Therefore, these simulated risk increases only represent a first chapter and a portion of the area's rapid seismic disaster risk accumulations that have resulted from rapid socioeconomic development. For several decades, GDP growth has been a top 
priority in the study area. This building-focused simulation is a strong warning to the booming economy and the crowded residents in this area regarding the current and future challenges that they may face.
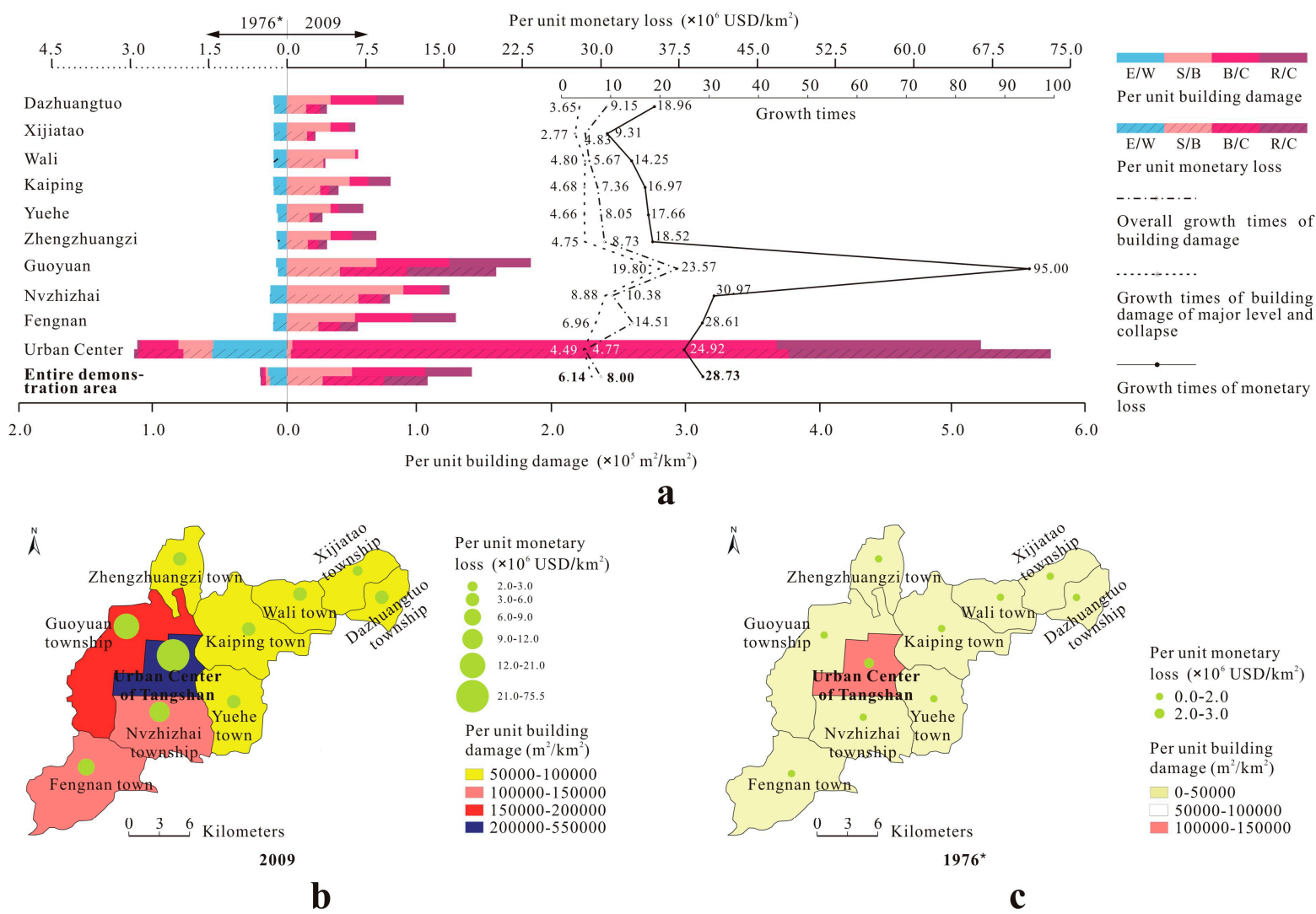

a

Figure 17. Actual building damage and monetary losses of the study area due to the Ms 7.8 Tangshan earthquake of 1976 and their corresponding values due to a simulated earthquake in 2009. (a) A breakdown, by area and building type, of the actual damage and losses in 1976 and the simulated scenarios in 2009; (b) Spatial distributions of building damage and monetary loss simulations in 2009; (c) Spatial distributions of actual building damage and monetary losses in 1976. * Actual building damage and monetary losses in the study area from the Ms 7.8 Tangshan Earthquake in 1976 were obtained from the relevant literature $[108,111,113]$.

\section{Discussion}

The previous sections of the paper described the development and application of the proposed integrated method. This section will discuss the general advantages, limitations, application prospects, and near-future extendible or scalable directions of the method.

\subsection{General Advantages}

The first advantage of this integrated method is its speed and labor savings compared with conventional LRC or DPM-based quantitative earthquake loss estimate methods. This advantage, particularly its speed, is highly critical for analyzing seismic loss risks in an area where socioeconomic 
growth is rapid. We based this study on the central Tangshan area, which contains densely packed buildings, to demonstrate the development and application of this method. The study area measured $456 \mathrm{~km}^{2}$, which greatly exceeded the areas considered in all other conventional earthquake loss estimation projects conducted in Mainland China that we reviewed [128-130,137-140]. After the Hr-ORSI and Br-LK sources were compiled, the potential seismic risks to the residential and public office buildings in this study area were calculated over approximately ten working days by two skilled individuals. In contrast with durations of several years (typically 2 to 3 years in mainland China) and the great deal of labor involved in conventional earthquake loss estimation projects, the speed and labor savings of this method stand out. This advantage is ensured by three aspects of the proposed integrated method. (1) The Hr-ORSIs sources are employed as a starting point to replace time and labor-intensive conventional methods of collecting building data and preparing building inventories; (2) Next, the Br-LK sources are reviewed to further accomplish this replacement. As is commonly known, large gaps exist between the information that Hr-ORSIs can directly provide and the specific parameters or data that specific seismic loss calculations for buildings require. Thus, a Br-LK review was proposed in this study to bridge these gaps. In other words, the Br-LK review was introduced to tightly link up remote sensing technologies with technical cores of mainstream quantitative seismic loss risk estimates. Our work, which employed the Br-LK review method to help determine the required parameters, is similar to the studies conducted during the previous decade that summarize baseline building DPMs for various regions or locations in China [71,141]. Among these studies, Yin and Yang [71] divided the entire Chinese mainland into three large regions and developed a set of baseline building DPMs for each of these regions. Hu et al. [141] attempted to sum the baseline building DPMs of much smaller and specific locations (e.g., various counties). The difference between these studies and our work is that we addressed, for example, the correlations between building heights and the number of floors and between the number of floors and the structural type in addition to developing location-specific DPMs. The current study indicates that this review is not a time- or labor-consuming task once the various Br-LK sources have been compiled; (3) The speed of the integrated method is also evident in our new algorithm for the large-scale estimation of building heights from single Hr-ORSIs. Although this algorithm involves manual work, it does not require substantial labor and time.

In addition to being rapid and saving labor, this integrated method provides an accuracy that is comparable with that of conventional quantitative earthquake loss estimation methods, as indicated by our relevant detailed verification presented earlier in this paper. This accuracy is primarily a function of the following two aspects of this integrated method: (1) The methods by which the heights and footprint areas of a large number of buildings of interest were estimated, including the new algorithm for extracting building heights and the old but realistic manual methods of obtaining building footprint areas that we adopted for the purpose of actual application; (2) The comprehensive and careful manner in which various Br-LKs were reviewed to obtain reliable correlations between the building height and the number of floors and between the number of floors and the structural types, reliable DPMs of the buildings, and reliable economic parameters for calculating monetary loss due to building damage specific to a certain area and a certain time context. Similarly to the location-specific baseline DPM summarization work in China that was conducted by the Chinese earthquake engineering experts mentioned above, this approach ensures that the reliabilities of these correlations and parameters are 
reasonable. Compared with the extreme difficulties of preparing and updating the building data and inventories of large areas with large numbers of buildings and rapid socioeconomic development using conventional methods, establishing and updating a small specialized database consisting of various $\mathrm{Br}-\mathrm{LK}$ s of such an area is much more practical and easier. By using such a database and increasingly available and advanced Hr-ORSIs, the correlations, metrics, and parameters of the buildings in the area (e.g., correlations between the number of floors and structural types) that are directly or indirectly required in conventional seismic building loss risk calculations can be conveniently updated. Therefore, if a comprehensive Br-LK database of certain areas can be developed and maintained properly, the proposed integrated method may be applied more conveniently in these areas in a timely and accurate manner.

In addition to offering noteworthy speed, substantial labor savings, and good accuracy, this integrated method is also less costly than conventional seismic loss estimation methods, although Hr-ORSIs are still expensive. In this study, we employed GeoEye-1 images with panchromatic and multispectral resolutions of $0.41 \mathrm{~m}$ and $1.65 \mathrm{~m}$, respectively, and with coverage spanning an area of $456 \mathrm{~km}^{2}$ to demonstrate how this method is developed and applied. The cost of these images was approximately $\$ 9000$, which accounted for nearly $90 \%$ of the total financial investment of this study. By comparing this current study with certain conventional earthquake loss estimation projects performed on the Chinese mainland [128-130,137,139,140], we noted that our study area was larger (in most cases, much larger) than the target areas considered in each of these conventional projects. However, the total financial investment of the integrated method addressed in this current study was less than one-tenth of the mean cost of these conventional method-based earthquake loss estimation projects.

\subsection{Application Prospects}

\subsubsection{Applicability to Other Locations}

The proposed integrated method begins with estimating the building heights by using Hr-ORSIs. After considering the availability and costs of these images, we developed an algorithm that is based on single images to accomplish this task. This algorithm is theoretically sound if it is assumed that the targeted buildings are located on a level site (i.e., a site with flat terrain). Otherwise, the height estimates would be biased. For example, if the imaging points of $S$ in Figure 3 were projected onto a hillside or a low-lying area, the SIPDs would be somewhat shortened or lengthened. Therefore, this building height estimation method is only applicable in locations that are relatively level/flat, including plains, the low-lying parts of basins, the flat parts of plateaus, and even certain locally flat locations in mountainous and hilly regions.

The specific correlations between the numbers of floors, building heights and structural types and the location-specific DPMs of the residential and public office buildings established in the context of the study area can be applied to the same building groups in other areas of Tangshan. In addition, these correlations and DPMs are probably reliable in some other parts of North China and in some of its neighboring areas, including the cities of Beijing and Tianjin, the south-central region of Inner Mongolia, and the provinces of Hebei, Shanxi, Henan, and Shandong. This trend occurs because the longstanding dwelling and architectural traditions and modern construction practices in these areas (as in the 
Tangshan area) all essentially belong to the North China architectural style [102-105]. This consistency was also used by Chinese earthquake engineering experts to develop baseline DPMs for these locations [71,141]. The probable and general reliabilities and applicabilities of these correlations and DPMs across these mentioned areas are also supported by several seismic loss estimation studies that have used conventional building inventory preparation methods in recent years in the southern parts of the North China Plain, such as Nanyang in Henan province [128] and Handan in Hebei province [129]. For example, the data from the Nanyang area indicated that $92.6 \%$ of the buildings with seven or more floors are R/C type buildings and $96.4 \%$ of the buildings with two to six floors are B/C type buildings, which is consistent with the correlations in Tangshan. Tangshan and its surrounding areas underwent a large-scale, unified, systematic reconstruction campaign after the 1976 earthquake; thus, the buildings in and around Tangshan are more uniform than those in other parts of North China and its neighboring locations. However, this uniformity does not necessarily mean that the correlations and DPMs from this region are not applicable to these other locations. First, the high uniformities in Tangshan are mainly manifested as consistencies or similarities regarding certain aspects of land-use and land coverage (e.g., certain lands used for housing) rather than, for example, as a correlation between building height and the number of floors. These land use/coverage-focused consistencies allow us to process building images in bulk (i.e., in location-specific building groups). Second, since the completion of the post-disaster reconstruction after the 1976 earthquake (middle to late 1980s), the buildings in Tangshan have undergone significant changes, particularly during the previous decade, as have experienced the buildings in many other regions of the Chinese mainland. These changes have altered these land use/coverage-focused uniformities (i.e., not as uniform as they were before). Some information regarding building stock changes in the study area was presented earlier in this paper.

Except in North China and in some of its neighboring areas, the specific correlations regarding the building heights, the numbers of floors, and structural types and the DPMs of residential and public office buildings established in the context of the study area most likely do not conform to the correlations of the buildings with the same usage designations at different other places on the Chinese mainland, especially in villages and small towns and particularly regarding height/floor number-structure type correlations and DPMs. This difference occurs because the long-existing dwelling and architectural traditions and modern construction practices in these other areas belong to other large architectural styles (i.e., Northeast China, Northwest China, East China, and Southwest China style) [102-105]. For example, thicker walls are used in cold northeast areas of China [142], clay is often used to make walls for public houses in the vast dry areas in northwestern China (esp. rural areas) [102,143], and hollow bricks are frequently used to build residential houses in many areas of the Qinghai-Tibet Plateau due to either the lack of natural resources (i.e., clay) for locally producing regular brick or because of the high costs of transporting in the bricks [144].

Furthermore, the height/floor number-structure type correlations and the DPMs of the residential and public office buildings (esp. the former) in many other mainland areas of China, especially in the western half, are likely not as clear or regular as those shown for Tangshan. Such a likely complex is associated with the more common co-existence of multi-cultural dwellings and architectural conventions, less developed land and urban planning practices [105,145], and/or other actualities in these western places. In view of more insufficient exploration than that conducted on DPMs (e.g., Yin and Yang [71] have summarized several baseline building DPMs for different large regions of the Chinese mainland; 
and $\mathrm{Hu}$ et al. [141] attempted to develop baseline DPMs for smaller areas), examining the height/floor number-structure type correlations is probably an important first step for applying the proposed integrated method in this type of area. The Br-LK review method is probably an effective method for solving this issue. As demonstrated previously, Br-LK reviews can help address many aspects of such correlations of a place. For example, (1) in terms of the Chinese mainland, Br-LK reviews can help by judging whether the overall height/floor number-structure type correlations in the residential and public office buildings of a specific area of interest are complex or not. Generally, the areas with good land and urban planning practices, mono-dwelling and architectural cultures, and relatively developed economies present relatively clear correlations, and vice versa; (2) For a specific Chinese mainland location, Br-LK reviews can further help check buildings for residential and public usages, for which the building heights may present complex relationships with structure types. In general, apart from a few exceptions that usually result from very old buildings, the residential and public office buildings on the Chinese mainland with seven or more floors in areas with a seismic fortification intensity of VIII should be R/C type buildings according to the relevant seismic building codes. However, varied relationships in such areas often exist for buildings with six or fewer floors. These relatively short buildings, especially those with one to three floors, were mainly built by the public by "acting on their own", and usually lacked unified planning and management. Consequently, wealthy families (even wealthy institutions) can build houses (or offices) that meet higher standards than poor families (institutions). As presented in the verification portion of this paper (Section 5.2), such variations in buildings with six or fewer floors also exist in the study area, but are not significant. Thus, building height or the number of floors are generally critical indicators of the buildings' seismic structural type, but not always and not all. (3) Br-LK reviews can considerably complement such indicators or references, such as building uses, ages, and so forth, as discussed in Section 4.2 of this paper. Systematically compiling and reviewing the Br-LKs of places characterized by varied or complex floor number-structure type relationships, and subsequently, carefully developing certain specific multi-indicator-based methods to better examine these relationships may strongly promote broader applications of the proposed integrated method.

For this particular issue, observations from remote sensing images could be very helpful. First, as mentioned previously, Hr-ORSIs can directly provide rudimentary, general and wide-reaching impressions if the correlations in a specific area are complex or simple (for examples, see Figure 7). More importantly, through careful analysis and data-mining, remote sensing images can also provide many of these multi-indicators for such correlation analyses. Apart from heights, these indicators include many other features of the buildings themselves and of the building environments that can be derived from remote sensing images. Regarding the issue of this aspect, Geiß et al. [35] recently conducted an enlightening attempt to determine how buildings' structure types could be statistically correlated with the various remote sensing features of these buildings themselves and of these buildings' surrounding environments. If this valuable attempt can further combine other useful information that can be derived from Br-LK reviews, including those of the buildings themselves (e.g., building archives and urban planning reports with recorded usage, age, and ownership, seismic building codes, and other relevant regulations and policies) and those of the buildings' context (e.g., local land and urban planning, local economy and local dwelling conventions that are contained in various local documents), developing certain multi-indicator-based methods (as an alternative to conventional 
earthquake engineering method) to rapidly examine building structure types may become more promising. This scenario may occur because some of the Br-LK-derived indicators could be boundary or controlling indicators, for example, seismic building codes of China clearly regulate that the residential and public office buildings with seven or more floors in areas where the seismic fortification criterion is intensity VIII should be R/C type on the Chinese mainland.

Because of the various economic conditions that are prevalent in various locations, the 2009 parameters we developed based on the central portion of the Tangshan administrative region for calculating monetary losses due to building damage may not be applicable to all of North China and its neighboring locations and are probably much less applicable for other areas of Mainland Chinese, especially the western areas. Among these locations and areas, some are wealthier, more industrialized, and more developed than other areas, resulting in variations in building contents and building replacement and/or repair costs. However, these economy-relevant parameters are easier to obtain from Br-LK reviews than are to obtain those regarding the physical buildings themselves (e.g., the height/floor number-structure type correlations and DPMs). Therefore, this aspect of analysis should not serve as a critical obstacle when applying this integrated method across the Chinese mainland.

Although the proposed integrated method was developed in the context of the Chinese mainland, its applicability is not restricted to the Chinese mainland. Rather, the general ideas and overall guidelines that closely and organically combine Hr-ORSIs and various Br-LKs to address the technical cores for quantitatively and specifically estimating seismic loss risks to buildings are likely universally applicable. However, except the worldwide applicability of the new algorithm developed herein for estimating the heights of buildings, all of the other key elements that underlie this integrated method are highly likely to vary, even sharply, from one location to another. These varied elements include the correlations between building heights and numbers of floors and between numbers of floors and structural types, DPMs, economic metrics for calculating monetary losses due to a buildings' damage, and the specific forms and contents of Br-LKs that serve as the bridging sources for determining these elements. To apply this integrated method to an area outside of the Chinese mainland, Br-LKs must be accumulated for the area first, and then using Br-LK reviews to carefully examine the associated elements specific to that area. This general integrated approach can be employed when addressing earthquake loss risks outside of China, where active seismic activities occur in areas with rapid socioeconomic developments. The overall guidelines of the integrated idea could also be tested in earthquake-prone areas outside of China, where socioeconomic changes are not as rapid. However, colleting and/or updating detailed building data through conventional methods remain a significant challenge.

\subsubsection{Applicability to a Range of Building Types}

The proposed integrated method is applicable to the first four types of buildings in Yin's structural vulnerability classification system [68]. These buildings primarily consist of residential buildings and public service offices. Our algorithm for estimating building heights using single Hr-ORSIs is applicable to the fifth (i.e., the last) type of building (i.e., specially structured buildings for commercial, industrial, or other special use). However, the DPMs, correlations, and parameters involving building heights, numbers of floors, structural types, and the economic metrics for calculating the monetary losses that were established in this study are not applicable to this fifth type of building. (1) The 
correlations of the building heights, numbers of floors, and structural types are significantly different for the fifth type of building relative to buildings used for residential purposes or public service offices; (2) Particularly, the DPMs of these specially structured buildings are unique. Moreover, inadequate DPMs exist for many of these special structures and inadequate baseline DPMs exist that could be used to analyze such buildings in groups; (3) Furthermore, the contents of such buildings differ substantially from those built for residential and public service purposes. These three aspects are beyond the scope of this paper and many of them may be difficult to resolve based on currently available science and technology knowledge and actual seismic damage experiences. Thus, it is still very difficult to determine specific seismic loss risks rapidly, accurately, and at a large scale for this fifth type of building relative to the first four types of buildings. As a result, the applicability of this integrated method inevitably decreases to a certain degree in certain modern urban centers or historic places, such as certain locations in Beijing and Tianjin, where many are specially structured buildings.

\subsubsection{Applicability to Various Scenarios}

From a disaster cycle perspective, the integrated method proposed in this study is primarily intended to serve during normal, or non-disaster times and may be referred to whenever needed during such a period. For example, we could use the method to yearly estimate the loss risks to residential and public office buildings in each Yearly Key Seismically Risky Area on the Chinese mainland (At the end of each year in China, the China Earthquake Administration (CEA) identifies a certain number of specific locations with relatively high levels of seismic activity as Key Seismically Risky Areas for the following year. Usually, several tens of locations are identified with spatial coverage of each location that usually spans several counties.) [146]. This type of analysis would be very helpful for making yearly adjustments to existing hazard mitigation and disaster preparedness plans in the areas or for developing new plans where necessary. Because of its speed, this new method could also play an important role before an imminent earthquake. The Law of the People's Republic of China on Protecting Against and Mitigating Earthquake Disasters (2008 edition) has clearly stipulated that "After the release of earthquake forecast opinions, the people's governments of relevant provinces, autonomous regions and municipalities directly under the Central Government may, in accordance with the earthquake situation forecasted, declare that the relevant areas enter an emergency period of an imminent earthquake; the relevant local people's governments shall, in accordance with the earthquake emergency plan, organize the relevant departments to do a good job in the emergency prevention and preparations for earthquake relief." This scenario is very rare due to the extreme difficulties of short-term and imminent predictions of actual earthquakes and the difficulty of officially issuing an earthquake forecast to the public. However, such forecasts have been made several times for the Chinese mainland. Among these, the most famous and most successful forecast involved the Ms 7.3 earthquake in Haicheng, Liaoning province, in 1975. Approximately nine hours before the earthquake, a timely official forecast and warning was broadcast $[147,148]$. It was reported that this well-timed forecast and warning saved over 100,000 lives [149]. If a similar situation occurs again in the future, we are certain that this integrated method could play a role in providing more timely and specific preparations. 
In addition to these two scenarios in a disaster cycle, the proposed integrated method can also be tested in the following two cases. (1) As in the particular simulation involving the Ms 7.8 Tangshan earthquake of 1976, this method can be used to simulate at least a portion of the modern effect scenarios of any historical earthquake if its ground motion intensities are available. This simulation helps form a conceivable and convincing reference for relevant areas to design more evidence-based seismic impact lessening strategies; (2) In addition, with the multi-temporal Hr-ORSIs and Br-LK, this method can serve as a tool for evaluating the year-to-year changes in seismic disaster risks and exploring their developmental mechanisms in different areas, thereby helping to adjust the corresponding disaster risk reduction strategies.

\subsubsection{Applicability to Larger Areas}

Theoretically, this integrated method is applicable to a level/flat location with any geographic size. However, this method likely cannot be applied to areas that are too large because Hr-ORSIs are currently expensive. Targeting areas with geographical sizes that are too large may be financially unrealistic. In this paper, the study area measured $456 \mathrm{~km}^{2}$, which exceeded (in most cases, greatly exceeded) the areas considered in each of the conventional earthquake loss estimation projects that we reviewed. The total expense for the method addressed in this paper was less than one-tenth of the mean cost of these projects conducted on the Chinese mainland, and nearly $90 \%$ of the total cost was for the GeoEye-1 images. In the economic context of the Chinese mainland, it may be financially feasible and acceptable to use GeoEye-1 images to provide coverage of areas measuring up to approximately $4560 \mathrm{~km}^{2}$ (i.e., approximately 10 times of our $456 \mathrm{~km}^{2}$ study area). Thus, from the perspectives of the current economic context of the Chinese mainland and the prices of Hr-ORSIs that are currently prevalent there, the proposed integrated method involving remote sensing images with meter or sub-meter resolutions may be applicable to flat portions of the Chinese mainland that cover up to several thousand square kilometers.

In the Chinese mainland, the application of this integrated method that employs remote sensing images with meter or sub-meter resolutions as underlying data to areas that are much larger than this limit is likely to be financially difficult. However, this integrated method may still play an important role in these cases. For example, this approach can be used to assess the risks to important but small sites in large target areas, thereby helping to optimize the allocation of risk reduction resources.

\subsection{Future Directions}

Obtaining timely, accurate and large-scale characterization of seismic loss risks and determining their changes in areas of rapid socioeconomic growth is a work in progress. Although many challenges await future solutions, we focus on the following four issues.

\subsubsection{Possible Methods for Estimating Building Heights in Hilly Areas}

The estimation of building heights using Hr-ORSIs is an important initial step in the proposed method. Building height is one key index for directly or indirectly obtaining data, including the number of floors, floor area, structural type, and DPM of a building. However, the algorithm we 
developed in this study for estimating building heights using single optical images alone is only reliable for buildings located on level/flat ground, such as plains, where the distortion of a building's image by the local topography is minimal. However, in mountainous or hilly areas, serious image distortions due to the local topography are highly likely (e.g., in images of buildings next to a steep hillside). To solve this problem, multi-source remote sensing data fusion techniques or stereo images could be introduced. However, these techniques may result in a greater monetary investment, which is a large problem when the area of interest is considerably large and contains a large number of packed buildings. Thus, the solution to this hilly area-focused issue may be to apply the proposed algorithm to buildings in the flat portions of the areas of interest. For buildings located in the portions with rugged topography, multi-source remote-sensing data-fusion techniques or stereo images should be applied.

\subsubsection{Accumulating Br-LKs of Other Earthquake-Prone Areas of China}

Except in North China and in some of its neighboring areas, correlations between parameters such as the heights, numbers of floors, and structural types of buildings; the DPMs; and the coefficients for calculating the monetary losses that developed in this study in Tangshan are unlikely to match those of other Chinese mainland regions, particularly those of rural and suburban locations. These differences from one region of China to another have evolved over many years due to either the diversities of local architectural styles and cultures or to the differences of local macro and micro economic conditions. However, the levels of seismic activity in certain regions, such as some regions of western China, can significantly exceed those in North China. Moreover, as in North China, nearly all of these regions have experienced and are experiencing rapid socioeconomic development. This situation implies that the work similar to this study that targets these places is even more urgent. Acquiring and accumulating such purpose and location-targeted sources of Br-LKs (1) to enable careful determination of required parameters; correlations, and coefficients and then (2) enabling timely and accurate large-scale assessments of seismic building loss risks and their changes in such regions will be one of our next efforts.

\subsubsection{Examining the Prospect of Using Images with Lower Resolutions in the Proposed Method}

The proposed integrated method employed remote-sensing images with meter or sub-meter resolutions (i.e., very high-resolution optical remote sensing images) as one source of input data. Currently, these very high resolution images are considerably expensive. Thus, it is worth considering the use of images with lower resolutions to decrease costs. The first priority of such a replacement should be that the images have a resolution that is exactly next to that of the highest resolution images, such as the Chinese-Brazil Earth Resources Satellite GF-1 (CBERS GF-1) images with a panchromatic resolution of $2 \mathrm{~m}$ and a multispectral resolution of $8 \mathrm{~m}$ [150], the SPOT-5 images recorded at a panchromatic resolution of $2.5 \mathrm{~m}$ [151], and the FORMOSAT-2 images with a panchromatic resolution of $2 \mathrm{~m}$ and a multispectral resolution of $8 \mathrm{~m}$ [152]. These images are the most promising for playing the same roles as those with meter or sub-meter resolutions. Particularly, these images are more easily available and cheaper (sometimes even free), thus possess the potential to allow the proposed integrated method to be more broadly applicable because covering a larger geographic area is less expensive and a more flexibility is allowed when using existing imagery resources. However, 
for assessing seismic loss risks to buildings, several uncertainties remain when using these images with slightly lower resolutions. The focus of these uncertainties is whether these images can ensure that the "revised" integrated method produces an assessment result with a similar level of accuracy. Specifically, focus is given to whether the buildings' heights and footprint areas can be extracted one by one from these images as accurately as expected when using the newly developed methods in this study (for assessing heights) or the already existing methods (for assessing footprint areas). If not, what could solve this problem? Thus, examining these pending uncertainties is an important future direction of our research.

\subsubsection{Testing the Applicability of this Hybrid Method to a Highway System}

Acquiring knowledge of building loss risks and their changes alone does not meet our goal of a comprehensively understanding earthquake loss risks and their rapidly changing scenarios in areas of rapid socioeconomic development. We hope that the hybrid approach and its general guidelines presented in this paper, which combine remote sensing imagery and local knowledge and employ a careful Br-LK review to bridge the gaps between remote sensing and technical cores of conventional seismic loss risk estimations, can address the many challenges posed by this goal. Next, we aim to test the applicability of this hybrid method to the seismic risks of highway systems. According to the basic logic of this integrated approach, the highway system is similar to buildings in several respects. (1) First, roads and bridges are clearly visible in high-resolution remote sensing images; (2) As building-relevant local knowledge (Br-LK) was used to assess, for example, building structural types, highway system-relevant local knowledge (HSr-LK) (e.g., transportation yearbooks) could be used to assess information regarding highway quality and quantity that is critical for estimating potential earthquake-induced highway damage; (3) Significant and rapid changes have occurred to the highway system on the Chinese mainland during previous decades [153,154]. This integrated approach is likely to play a role in the large-scale rapid estimation of seismic loss risks to highway transportation systems. Detailed and specific confirmation in this regard is worth careful examination in the future.

\section{Final Remarks}

Rapid socioeconomic growth in an earthquake-prone area can cause rapid seismic loss risk changes. These changes challenge seismic disaster risk reduction strategies in the area, which must be updated frequently to remain realistic, practical, and effective over time. The top priority for overcoming these difficulties is to capture ongoing rapid risk changes in a timely, definitive, and accurate manner. However, methods for rapidly and accurately characterizing such seismic disaster risks over a large area have been insufficiently explored. This current study developed an integrated or hybridized method that combines remote sensing data and local knowledge to resolve this issue. The focus of the proposed integrated method is not solely on remote sensing technology or independently on mainstream technical cores of LRC or DPM-based seismic loss risk estimates. Instead, this method focuses on how the large gaps between these two sides may be bridged properly and quickly at large scales. This bridging topic is an issue that has been insufficiently explored relative to the fast and significant progress of the two individual sides on their own. Thus, this method may be important for promoting deep and actual practice-aimed remote sensing applications as remote sensing data 
becomes more readily available and as remote sensing technology becomes more advanced for use in pressing seismic loss risk reduction battlefields of earthquake active areas with rapid socioeconomic development.

By focusing on the seismic loss risks to buildings, the proposed integrated method started with employing either the new algorithm developed herein or the old but actual practice-favorable method to accurately and quickly extract the heights and footprint areas of a large number of residential and public office buildings from single high-resolution optical remote sensing images (Hr-ORSIs). Based on these two beginning parameters, this integrated method adopted careful and comprehensive building-relevant local knowledge (Br-LK) reviews as a bridge to help quickly and accurately determine or estimate technical cores or key data for performing specific mainstream quantitative seismic loss risk calculations to these buildings, including their floor areas, structural types, damage probability matrixes (DPMs), and economic parameters for calculating monetary losses due to their structural and indoor content damage. In doing so, the conventional building inventory preparation and vulnerability analysis processes were properly replaced, thus the timeliness, definitiveness, and accuracy were all considerably enhanced when estimating earthquake-induced building loss risks across large areas with rapid socioeconomic development.

The proposed integrated method was demonstrated in Tangshan, China, an area that has experienced the severe impacts of the Ms 7.8 earthquake in 1976 and significant expansion of the population and economy since that event. The total floor area of the residential and public office buildings in central Tangshan in 2009, which was estimated using this integrated method employing GeoEye-1 images with meter and sub-meter resolutions, was 3.99\% lower than the corresponding number obtained by a conventional earthquake loss estimation project. Field-based verification indicated that the mean relative error of the method for estimating the floor areas of the addressed buildings was $2.99 \%$. In addition to being capable of offering an accuracy that is comparable to that of conventional and mainstream quantitative earthquake loss estimate methods based on conventional building inventory preparation methods, this integrated method presents the following advantages relative to conventional methods: noteworthy speed, substantial labor savings, much lower cost, and significant serviceability when facing issues defined by time (non-disaster $v s$. impending disaster time, historical vs. current issue, status quo vs. situation changes). However, the timely, accurate, and all-round large-scale characterization of seismic loss risks and their changes in areas with rapid socioeconomic growth is a work that contains many challenges. The integrated method presented in this study that focused on seismic loss risks to buildings is only a beginning and a small portion of the entire approach. Even for estimating loss risks to buildings, several weaknesses exist in this integrated approach that challenge its more broad application and require to be explored in the future, such as the uncertainty when dealing with buildings in mountainous and hilly areas, the incapability of addressing specially structured buildings, the financial infeasibility of covering very large geographic areas, and the uncertainness involved with using remote sensing images with lower resolutions as alternatives.

As a particular application of the proposed integrated method, a simulation of the modern impacts of the 1976 Ms 7.8 Tangshan earthquake was performed. The results indicated that if this earthquake had recurred in 2009, the total damaged floor area of the residential and public office buildings and associated direct monetary losses in the study area could have been 8.00 and 28.73 times greater, respectively, than in 1976. This simulated scenario is a strong warning to the residents of crowded 
earthquake-prone areas regarding the increasing challenges that they may face and provides concrete and solid evidence of what may accompany a booming economy of an area with active seismic activities. In earthquake active areas with rapid socioeconomic development, these hidden/latent troubles must be dealt with properly and timely when considering economic growth.

This integrated method was developed based on the Chinese mainland and only focused on the seismic loss risks of buildings. However, the general ideas and overall guidelines that employ careful and comprehensive local knowledge reviews to bridge the large gaps between what remote sensing can directly provide and what mainstream quantitative seismic loss risk estimates specifically require may be universally applicable, either across boundaries or across different seismic impact-susceptible human objects. The general ideas and overall guidelines can be tested either outside of the Chinese mainland or on structures other than buildings. However, the specific risk analysis cores, the specific remote sensing applications, and the specific local knowledge defined by these cores and applications in these tests likely vary, even sharply, from one location or type of seismic-susceptible human object to another. Exactly what these diversities may be, particularly the place or object-specific local knowledge, what the specific gaps are between such risk analysis cores and the involved remote sensing applications, and in what ways and how much these gaps can be bridged by comprehensively and carefully reviewing relevant local knowledge, are really attractive and worthwhile careful explorations.

\section{Acknowledgments}

This research was supported by the National Department Public Benefit Earthquake Research Foundation of China (Grant No. 201208018) and the National Natural Science Foundation of China (Grant No. 40971274 and 40771011). We extend our sincere thanks to Youpo Su and his team at Hebei United University, Tangshan, China, for providing us with their data regarding the losses due to the Ms 7.8 Tangshan earthquake in 1976. We are very grateful to Yifan Yuan, at the Institute of Engineering Mechanics, China Earthquake Administration, Harbin, and Dongming Wang, at the China Earthquake Disaster Prevention Center, Beijing, for their comments and advice on adjusting the DPMs of the study area. We would like to extend our heartfelt thanks to Yigang Li at the National Earthquake Response Support Service in Beijing, China, for sharing relevant data from his project titled "Earthquake Loss Estimation of Center Tangshan, China". Furthermore, we sincerely thank the four anonymous reviewers and associated editors for their constructive and detailed comments and suggestions.

\section{Author Contributions}

Guiwu $\mathrm{Su}$ designed the study. Guiwu $\mathrm{Su}$ and Wenhua Qi proposed the integrated method. Wenhua Qi, Xinsheng Liu, and Rui Sun developed the algorithm to estimate building height from single Hr-ORSIs. Guiwu Su, Wenhua Qi, Suling Zhang, Timothy Sim, Lei Sun, Yifan Jin, and Xinsheng Liu compiled the Br-LK. Suling Zhang and Wenhua Qi developed DPMs concerned. Guiwu Su and Wenhua Qi analyzed the accuracy and reliability of the integrated method. Wenhua Qi, Lei Sun, and Yifan Jin performed the fieldwork. Guiwu Su, Wenhua Qi, and Timothy Sim wrote the paper. 


\section{Conflicts of Interest}

The authors declare no conflict of interest.

\section{References}

1. National Bureau of Statistics of China (NBSC). National Data. 2013. Available online: http://data.stats.gov.cn/workspace/index;jsessionid=A239733E3890596C183080BE982052DB?m=h gnd (accessed on 15 November 2013). (In Chinese)

2. Su, G.W.; Zhu, L.; Ma, Z.J.; Wu, Q. A preliminary study on the changes of the regional scale macroscopic vulnerability to earthquake disasters of Beijing, Tianjin and Tangshan area-Spatial changes. Seismol. Geol. 2007, 29, 15-33. (In Chinese)

3. Su, G.W.; Ma, Z.J.; Zhu, L.; Wu, Q. Spatial differentiation changes of regional scale macroscopic vulnerability to earthquake disasters of Beijing, Tianjin and Tangshan area. Geol. Sci. Technol. Inf. 2008, 27, 1-11. (In Chinese)

4. Su, G.W.; Ma, Z.J.; Zhu, L.; Qi, W.H.; Deng, Y.; Li, M. Research on changes of regional macroscopic vulnerability to earthquake disasters in Beijing-Tianjin-Tangshan region. J. Catastrophol. 2010, 25, 1-12. (In Chinese)

5. United Nations International Strategy for Disaster Reduction (UN/ISDR). Definition of Disaster Risk. 2009. Available online: http://www.preventionweb.net/english/professional/terminology/ v.php?id=7818 (accessed on 15 November 2009).

6. United Nations Disaster Relief Organization (UNDRO). Natural Disasters and Vulnerability Analysis. 1980. Available online: http://www.unisdr.org/files/resolutions/NL800388.pdf (accessed on 19 July 2009).

7. Applied Technology Council (ATC). ATC-13-Earthquake Damage Evaluation Data for California. 1985. Available online: https://www.atcouncil.org/pdfs/atc13.pdf (accessed on 15 September 2009).

8. Applied Technology Council (ATC). ATC-25-Seismic Vulnerability and Impact of Disruption of Lifelines in the Conterminous United States, Redwood City, CA. 1991. Available online: https://www.atcouncil.org/component/mijoshop/?route=product/product\&path=2_14\&product_id=46 (accessed on 15 September 2009).

9. Grünthal, G. European Macroseismic Scale 1998. European Center of Geodynamics and Seismology. 1998. Available online: http://media.gfz-potsdam.de/gfz/sec26/resources/documents/ PDF/EMS-98_Original_englisch.pdf (accessed on 15 September 2009).

10. Gomes, A.; Gaspar, J.L.; Queiroz, G. Seismic vulnerability of dwellings at Sete Cidades Volcano (S. Miguel Island, Azores). Nat. Hazards Earth Syst. Sci. 2006, 6, 41-48.

11. Mouroux, P.; le Brun, B. Presentation of RISK-UE project. Bull. Earthq. Eng. 2006, 4, 323-339.

12. United Nations International Strategy for Disaster Reduction (UN/ISDR). RADIUS: Risk Assessment Tools for Diagnosis of Urban Areas against Seismic Disasters. 1999. Available online: http://www.unisdr.org/we/inform/publications/2752 (accessed on 15 September 2009). 
13. The Federal Emergency Management Agency (FEMA). Earthquake Loss Estimation Methodology_HAZUS 99. Washington, D.C. 1999. Available online: http://www.disastersrus.org/ emtools/earthquakes/FEMA366.pdf (accessed on 15 September 2009).

14. Inel, M.; Senel, S.M.; Toprak, S.; Manav, Y. Seismic risk assessment of buildings in urban areas: A case study for Denizli, Turkey. Nat. Hazards 2008, 46, 265-285.

15. Ploeger, S.K.; Atkinson, G.M.; Samson, C. Applying the HAZUS-MH software tool to assess seismic risk in downtown Ottawa, Canada. Nat. Hazards 2010, 53, 1-20.

16. Cutter, S.L.; Boruff, B.J.; Shirley, W.L. Social vulnerability to environmental hazards. Soc. Sci. Q. 2003, 84, 242-261.

17. Cutter, S.L.; Finch, C. Temporal and spatial changes in social vulnerability to natural hazards. Proc. Natl. Acad. Sci. USA 2008, 105, 2301-2306.

18. Carreño, M.L.; Cardona, O.D.; Barbat, A.H. A disaster risk management performance index. Nat. Hazards 2007, 41, 1-20.

19. Cardona, O.D.; Carreño, M.L. Updating the indicators of disaster risk and risk management for the Americas. J. Integr. Disaster Risk Manag. 2011, 1, 1-21.

20. Chen, Q.F.; Chen, Y.; Chen, L. Earthquake loss estimation with GDP and population data. Acta Seismol. Sin. 1997, 19, 640-649. (In Chinese)

21. Chen, Y.; Chen, Q.F.; Chen, L. Vulnerability analysis in earthquake loss estimate. Nat. Hazards 2001, 23, 349-364.

22. Dunbar, P.K.; Bilham, R.G.; Laituri, M.J. Earthquake loss estimation for India based on macroeconomic indicators. Risk Sci. Sustain. 2003, 112, 163-180.

23. Liu, J.F.; Chen, Y.; Shi, P.J.; Chen, J. On seismic risk assessment in mainland China. J. Beijing Norm. Univ. (Nat. Sci.) 2008, 44, 520-523. (In Chinese)

24. Ehrlich, D.; Guo, H.; Molch, K.; Ma, J.W.; Pesaresi, M. Identifying damage caused by the 2008 Wenchuan earthquake from VHR remote sensing data. Int. J. Digit. Earth 2009, 2, 309-326.

25. Brunner, D.; Lemoine, G.; Bruzzone, L. Earthquake damage assessment of buildings using VHR optical and SAR imagery. IEEE Trans. Geosci. Remote Sens. 2010, 48, 2403-2420.

26. Wang, X.Q.; Dou, A.X.; Ding, X. Study on quantitative earthquake damage of Dujiangyan city, caused by 2008 Ms 8.0 Wenchuan, China earthquake based on aerial imagery. In Proceedings of the IEEE Geoscience and Remote Sensing Symposium (IGARSS), Honolulu, HI, USA, 25-30 July 2010; pp. 2743-2746, doi:10.1109/IGARSS.2010.5653233.

27. Corbane, C.; Saito, K.; Dell'ro, L.; Gill, S.P.D.; Piard, B.E.; Huyck, C.K.; Kemper, T.; Lemoine, G.; Spence, R.J.S.; Shankar, R.; et al. A comprehensive analysis of building damage in the 12 January $2010 \mathrm{M}(\mathrm{W}) 7$ Haiti earthquake using high-resolution satellite- and aerial imagery. Photogramm. Eng. Remote Sens. 2011, 77, 997-1009.

28. Dell'Acqua, F.; Bignami, C.; Chini, M.; Lisini, G.; Polli, D.A.; Stramondo, S. Earthquake damage rapid mapping by satellite remote sensing data: L'Aquila April 6th, 2009 Event. IEEE J. Sel. Top. Appl. Earth Obs. Remote Sens. 2011, 4, 935-943.

29. Plank, S. Rapid damage assessment by means of multi-temporal SAR - A comprehensive review and outlook to Sentinel-1. Remote Sens. 2014, 6, 4870-4906.

30. Matsuoka, M.; Nojima, N. Building damage estimation by integration of seismic intensity information and satellite L-band SAR imagery. Remote Sens. 2010, 2, 2111-2126. 
31. Rezaeian, M.; Gruen, A. Automatic 3D building extraction from aerial and space images for earthquake risk management. Georisk Assess. Manag. Risk Eng. Syst. Geohazards 2011, 5, 77-96.

32. Dutta, D.; Serker, N.K.; Warnitchai, P. Use of VHR remote sensing imagery for urban building and infrastructure inventory database for disaster risk analysis. In Proceedings of the Map India 2005 and Geomatics 2005, Delhi, India, 7-9 February 2005.

33. Ehrlich, D.; Kemper, T.; Blaes, X.; Soille, P. Extracting building stock information from optical satellite imagery for mapping earthquake exposure and its vulnerability. Nat. Hazards 2013, 68, 79-95.

34. Geiß, C.; Taubenböck, H.; Tyagunov, S.; Tisch, A.; Post, J.; Lakes, T. Assessment of seismic building vulnerability from space. Earthq. Spectra 2013, 30, 1553-1583.

35. Geiß, C.; Pelizari, P.A.; Marconcini, M.; Sengara, W.; Edwards, M.; Tobia, L.; Taubenböck, H. Estimation of seismic building structural types using multi-sensor remote sensing and machine learning techniques. ISPRS J. Photogramm. Remote Sens. 2014, doi:10.1016/j.isprsjprs.2014.07.016.

36. Li, T.Z.; Zhai, Y.M. Research on application of remote sensing technique in prediction of earthquake damage of urban structures. J. Catastrophol. 2010, 25, 333-338. (In Chinese)

37. Miura, H.; Midorikawa, S.; Fujimoto, K. Automated building detection from high-resolution satellite image for updating GIS building inventory data. In Proceedings of the 13th World Conference on Earthquake Engineering, Vancouver, BC, Canada, 1-6 August 2004; Paper No. 678.

38. Miura, H.; Midorikawa, S. Updating GIS building inventory data using high-resolution satellite images for earthquake damage assessment: Application to Metro Manila, Philippines. Earthq. Spectra 2006, 22, 151-168.

39. Mück, M.; Taubenböck, H.; Post, J.; Wegscheider, S.; Strunz, G.; Sumaryono, S.; Ismail, F.A. Assessing building vulnerability to earthquake and tsunami hazard using remotely sensed data. Nat. Hazards 2013, 68, 97-114.

40. Panagiota, M.; Erwan, P.; Philippe, G.; Jocelyn, C. Seismic Vulnerability Assessment Using Support Vector Machine Classification for Remote Sensing and In-Situ Data. Available online: http://www.iitk.ac.in/nicee/wcee/article/WCEE2012_5147.pdf (accessed on 15 November 2009).

41. Panagiota, M.; Jocelyn, C.; Erwan, P.; Philippe, G. A support vector regression approach for building seismic vulnerability assessment and evaluation from remote sensing and in situ data. In Proceedings of the 2012 IEEE International Geoscience and Remote Sensing Symposium (IGARSS), Munich, Germany, 22-27 July 2012; pp. 7533-7536.

42. Pittore, M.; Wieland, M. Toward a rapid probabilistic seismic vulnerability assessment using satellite and ground-based remote sensing. Nat. Hazards 2013, 68, 115-145.

43. Wieland, M.; Pittore, M.; Parolai, S.; Zschau, J.; Moldobekov, B.; Begaliev, U. Estimating building inventory for rapid seismic vulnerability assessment: Towards an integrated approach based on multisource imaging. Soil Dyn. Earthq. Eng. 2012, 36, 78-83.

44. Sarabandi, P.; Kiremidjian, A. Development of Algorithms for Building Inventory Compilation through Remote Sensing and Statistical Inferencing; Report No. 158; The John A. Blume Earthquake Engineering Center, Department of Civil and Environmental Engineering, Stanford University: Stanford, CA, USA, 2007. 
45. Wu, H.; Cheng, Z.P.; Shi, W.Z.; Miao, Z.L.; Xu, C.C. An object-based image analysis for building seismic vulnerability assessment using high-resolution remote sensing imagery. Nat. Hazards 2014, 71, 151-174.

46. Yuan, Z.X.; Wang, L.M. Application of high-resolution satellite image for seismic risk assessment. In Proceedings of the 13th World Conference on Earthquake Engineering, Vancouver, BC, Canada, 1-6 August 2004; Paper No. 3454.

47. Zhang, G.F.; Shan, X.J.; Yin, J.Y.; Ma, Z.S.; Zhao, J.J. The method to extract urban buildings' height and location from single high resolution aerial imagery. Seismol. Geol. 2007, 29, 180-187. (In Chinese)

48. Zhang, G.F.; Shan, X.J.; Yin, J.Y. Application of high-resolution satellite remote sensing image in quick pre-estimate of seismic disaster. J. Geod. Geodyn. 2005, 25, 63-68. (In Chinese)

49. Yin, Z.Q. The Prediction Method of Earthquake Disasters and Losses; Seismological Press: Beijing, China, 1995. (In Chinese)

50. Zhao, Q.; Zhai, Y.M.; Li, T.Z. Study on application of high resolution remote sensing images in rapid prediction of earthquake disaster in urban area. J. Catastrophol. 2012, 27, 72-76. (In Chinese)

51. Borfecchia, F.; Pollino, M.; de Cecco, L.; Lugari, A.; Martini, S.; la Porta, L.; Ristoratore, E.; Pascale, C. Active and passive remote sensing for supporting the evaluation of the urban seismic vulnerability. Ital. J. Remote Sens. 2010, 42, 129-141.

52. Polli, D.; Dell'Acqua, F.; Gamba, P. Seismic vulnerability assessment in the framework of GEO: A case study on Messina, Italy. In Proceedings of the Gi4DM 2010 Conference, Geomatics for Crisis Management, Torino, Italy, 2-4 February 2010.

53. Polli, D.; Dell'Acqua, F. Fusion of optical and SAR data for seismic vulnerability mapping of buildings. Opt. Remote Sens. Augment. Vis. Real. 2011, 3, 329-341.

54. Mueller, M.; Segl, K.; Heiden, U.; Kaufmann, H. Potential of high-resolution satellite data in the context of vulnerability of buildings. Nat. Hazards 2006, 38, 247-258.

55. Gei $\beta$, C.; Taubenböck, H. Remote sensing contributing to assess earthquake risk: From a literature review towards a roadmap. Nat. Hazards 2013, 68, 7-48.

56. Taubenböck, H.; Post, J.; Roth, A.; Zosseder, K.; Strunz, G.; Dech, S. A conceptual vulnerability and risk framework as outline to identify capabilities of remote sensing. Nat. Hazards Earth Syst. Sci. 2008, 8, 409-420.

57. Ehrlich, D.; Tenerelli, P. Optical satellite imagery for quantifying spatio-temporal dimension of physical exposure in disaster risk assessments. Nat. Hazards 2013, 68, 1271-1289.

58. Dai, C.D.; Tang, L.L.; Cheng, G.; Wang, J.S.; Yang, Y.C. Monitoring of urban expansion and environment change using satellite remote sensing data. Remote Sens. Environ. (China) 1995, 10, 1-8. (In Chinese)

59. Yao, S.M.; Chen, S.; Wu, J.N.; Zhang, Y.; Chen, Z.G. Spatial expansion patterns of Chinese big cities-The case of Suzhou. Sci. Geogr. Sin. 2009, 29, 15-21. (In Chinese)

60. National Bureau of Statistics of China (NBSC). Tabulation on the 2010 Population Census of the People's Republic of China. 2012. Available online: http://www.stats.gov.cn/tjsj/pcsj/rkpc/6rp/ indexch.htm (accessed on 10 April 2013). (In Chinese) 
61. Ministry of Housing and Urban-Rural Development of the People's Republic of China (MOHURD). China Urban-Rural Construction Statistical Yearbook; China Planning Press: Beijing, China, 2012. (In Chinese)

62. Ministry of Housing and Urban-Rural Development of the People's Republic of China (MOHURD). China Urban Construction Statistical Yearbook; China Planning Press: Beijing, China, 2013. (In Chinese)

63. Goodchild, M. Citizens as sensors: the world of volunteered geography. GeoJournal 2007, 69, 211-221.

64. Schnebele, E.; Cervone, G. Improving remote sensing flood assessment using volunteered geographical data. Nat. Hazards Earth Syst. Sci. 2013, 13, 669-677.

65. Yang, X.L.; Wu, Z.L. Civilian monitoring video records for earthquake intensity: A potentially unbiased online information source of macro-seismology. Nat. Hazards 2013, 65, 1765-1781.

66. Middleton, S.E.; Middleton, L.; Modafferi, S. Real-time crisis mapping of natural disasters using social media. IEEE Intell. Syst. 2014, 29, 9-17.

67. Yang, Y.C.; Yang, L.; Gao, Y.X.; Yang, Y.L.; Lu, X.L.; Yang, G.Z. Method of damage prediction for existing multi-story brick buildings and its reliability. Earthq. Eng. Eng. Vib. 1982, 2, 75-86. (In Chinese)

68. Yin, Z.Q. A study for predicting earthquake disaster loss. Earthq. Eng. Eng. Vib. 1991, 11, 87-96. (In Chinese)

69. Chen, R.; Chen, X.L.; Fu, Z.X. Researches on Prediction of Chinese Earthquake Losses with Scale of Ten Years; Science Press: Beijing, China, 1995. (In Chinese)

70. Li, S.Z. Earthquake Disaster Assessment; Seismological Press: Beijing, China, 1996. (In Chinese)

71. Yin, Z.Q.; Yang, S.W. Earthquake Disaster Loss Analysis and Fortification Criterion; Seismological Press: Beijing, China, 2004. (In Chinese)

72. Standardization Administration of China (SAC). Chinese Standard GB/T 17742-2008: The Chinese Seismic Intensity Scale; Standards Press of China: Beijing, China, 2008. (In Chinese)

73. Li, S.Q. Study on the Comparison of Seismic Intensity Scales. Master's Thesis, Institute of Engineering Mechanics, China Earthquake Administration, Harbin, China, 2010. (In Chinese)

74. Li, W. Research on Macro Seismic Damages and Ground Motion Parameters for Seismic Intensity Scale. Ph.D. Thesis, Institute of Engineering Mechanics, China Earthquake Administration, Harbin, China, 2012. (In Chinese)

75. Xia, K.; Zhang, L.X.; Liu, J.P. Comparative study on the criteria "effects on humans" and "effects on objects" in the seismic intensity scales at home and abroad. J. Earthq. Eng. Eng. Vib. 2011, 31, 21-29. (In Chinese)

76. Standardization Administration of China (SAC). Chinese Standard GB 18306-XXXX: Seismic Ground Motion Parameters Zonation Map of China; 2012; pp. 1-15. Available online: http://www.cea.gov.cn/manage/_VHD/0a/1.pdf (accessed on 8 October 2014). (In Chinese)

77. Liu, X.S.; Sun, R.; Yang, Q.Y.; Su, G.W.; Qi, W.H. Simulating urban expansion using an improved SLEUTH model. J. Appl. Remote Sens. 2012, doi:10.1117/1.JRS.6.061709.

78. Liu, X.S.; Sun, R.; Su, G.W.; Qi, W.H. Improvement and validation of urban expansion model SLEUTH: Case of Tangshan. J. Beijing Norm. Univ. (Nat. Sci.) 2013, 49, 387-394. (In Chinese) 
79. The People's Government of Hebei Province. 2010 Hebei Economic Yearbook; China Statistics Press: Beijing, China, 2010. (In Chinese)

80. Fraser, C.S.; Baltsavias, E.; Gruen, A. Processing of IKONOS imagery for submetre 3D positioning and building extraction. ISPRS J. Photogramm. Remote Sens. 2002, 56, 177-194.

81. Shaker, I.F.; Abd-Elrahman, A.; Abdel-Gawad, A.K.; Sherief, M.A. Building extraction from high resolution space images in high density residential areas in the Great Cairo region. Remote Sens. 2011, 3, 781-791.

82. Tarantino, E.; Figorito, B. Extracting buildings from true color stereo aerial images using a decision making strategy. Remote Sens. 2011, 3, 1553-1567.

83. Dini, G.R.; Jacobsen, K.; Rottensteiner, F.; al Rajhi, M.; Heipke, C. 3D building change detection using high resolution stereo images and a GIS database. Int. Arch. Photogramm. Remote Sens. Spat. Inf. Sci. 2012, XXIX-B7, 299-304.

84. Poli, D.; Caravaggi, I. 3D modeling of large urban areas with stereo VHR satellite imagery: Lessons learned. Nat. Hazards 2013, 68, 53-78.

85. Tian, J.J.; Cui, S.Y.; Reinartz, P. Building change detection based on satellite stereo imagery and digital surface models. IEEE Trans. Geosci. Remote Sens. 2014, 52, 406-417.

86. Cheng, F.; Thiel, K.H. Delimiting the building heights in a city from the shadow in a panchromatic SPOT-image-Part 1: Test of forty-two buildings. Int. J. Remote Sens. 1995, 16, 409-415.

87. Xie, J.F.; Li, Y.M. The extraction of building distribution information of different heights in a city from the shadow in a IKONOS image. Remote Sens. Land Resour. 2004, 4, 4-6. (In Chinese)

88. Shao, Y.; Taff, G.N.; Walsha, S.J. Shadow detection and building height estimation using IKONOS data. Int. J. Remote Sens. 2011, 32, 6929-6944.

89. Irvin, R.B.; McKeown, D.M. Methods for exploiting the relationship between buildings and their shadows in aerial imagery. IEEE Trans. Man Cyber 1989, 19, 1564-1575.

90. Hartl, P.; Cheng, F. Delimiting the building heights in a city from the shadow on a panchromatic SPOT-image_-Part 2: Test of a complete city. Int. J. Remote Sens. 1995, 16, 2829-2842.

91. Shettigara, V.K.; Sumerling, G.M. Height determination of extended objects using shadow in SPOT images. Photogramm. Eng. Remote Sens. 1998, 64, 35-44.

92. Lin, C.G.; Nevatia, R. Building detection and description from a single intensity image. Comput. Vis. Image Underst. 1998, 72, 101-121.

93. Lee, D.S.; Shan, J.; Bethel, J.S. Class-guided building extraction from IKONOS imagery. Photogramm. Eng. Remote Sens. 2003, 69, 143-150.

94. Gianinetto, M. Updating large scale topographic databases in Italian urban areas with submeter QuickBird images. Int. J. Navig. Obs. 2008, doi:10.1155/2008/725429.

95. Shorter, N.; Kasparis, T. Automatic vegetation identification and building detection from a single nadir aerial image. Remote Sens. 2009, 1, 731-757.

96. Ahmadi, S.; Zoej, M.J.; Ebadi, H.; Moghaddam, H.A.; Mohammadzadeh, A. Automatic urban building boundary extraction from high resolution aerial images using an innovative model of active contours. Int. J. Appl. Earth Obs. Geoinf. 2010, 12, 150-157. 
97. Izadi, M.; Saeedi, P. Automatic building detection in aerial images using a hierarchical feature based images segmentation. In Proceedings of the 20th International Conference on Pattern Recognition (ICPR), Istanbul, Turkey, 23-26 August 2010; pp. 472-475.

98. Ouzounis, G.K.; Pesaresi, M.; Soille, P. Differential area profiles: Decomposition properties and efficient computation. IEEE Trans. Pattern Anal. Mach. Intell. 2012, 34, 1533-1548.

99. Jiang, L.W.; Ren, Q. The projection of population, households and housing demand in China. Mark. Demogr. Anal. 2005, 11, 20-29. (In Chinese)

100. Liu, Y.S.; Deng, X.S.; Gan, H. The state and optimization countermeasures of urban land-use in China. J. Chongqing Jianzhu Univ. 2005, 27, 1-4. (In Chinese)

101. Peng, C.; Du, N.R.; Liu, Y. Understanding residential expansion in big cities using MAS/RE. Geomat. Inf. Sci. Wuhan Univ. 2007, 32, 548-551. (In Chinese)

102. Sha, R. Research on the physical geographical background of the culture of traditional Chinese residential architecture. Sci. Geogr. Sin. 1998, 18, 58-64. (In Chinese)

103. Wang, G.F.; Hao, X.G. Character and development of Chinese residents. J. Jining Teachers' Coll. 2006, 29, 46-48. (In Chinese)

104. Li, Y.; Chen, L. Traditional Chinese Residences; China Architecture \& Building Press: Beijing, China, 2009; ISBN: 978-7-89475-028-0. (In Chinese)

105. Gu, D.N.; Zhou, J.S. Geographical distribution of residential housing and its evolution in China. Econ. Geogr. 2010, 30, 1344-1348. (In Chinese)

106. Wurm, M.; Taubenböck, H.; Schardt, M.; Esch, T.; Dech, S. Object-based image information fusion using multisensor earth observation data over urban areas. Int. J. Image Data Fusion 2011, 2, 121-147.

107. Ning, B.K.; Qu, G.S.; Zhang, N.; Li, Y.G. Application of IKONOS imagery to earthquake disaster reduction and damage assessment in urban area. Seismol. Geol. 2004, 26, 161-168. (In Chinese)

108. Liu, H.X. Seismic Damage of Tangshan Earthquake (the Second Fascicle); Seismological Press: Beijing, China, 1986. (In Chinese)

109. Liu, E.H.; Yu, J.K. Planning and construction of Tangshan-marking the tenth anniversary of the Tangshan earthquake. Arch. Technol. 1986, 17, 2-6. (In Chinese)

110. Wang, Z.P. The Moment and Ten Years: Beginning and End of the Tangshan Earthquake; Seismological Press: Beijing, China, 1986. (In Chinese)

111. Ma, C.Q.; Su, Y.P. Disaster Investigation Report of 1976 Tangshan Earthquake; Open Report; Hebei United University: Tangshan, China, 1992. (In Chinese)

112. Tangshan Urban Construction History Compilation Committee (TSUCHCC). Urban Construction History of Tangshan; Tianjin People's Publishing House: Tianjin, China, 1992. (In Chinese)

113. Zou, Q.J.; Wang, Z.P.; Chen, F.B.; Wang, S.Y. Research of Social Issues and Social Recovery in Tangshan Earthquake-Hit Areas; Seismological Press: Beijing, China, 1997. (In Chinese)

114. Tangshan Local Chronicles Compilation Committee (TSLCCC). Tangshan Local Chronicles; Publishing House of Local Records: Beijing, China, 1999. (In Chinese)

115. Yang, W.Z. The Tangshan Earthquake (1976) and Seismic Resistance of Buildings; Southwest Jiaotong University Press: Chengdu, China, 2003. (In Chinese) 
116. Shen, Q.J.; Ma, J.W. Retrospect, analysis and thinking on post-earthquake reconstruction planning of Tangshan city. Urban Plan. Forum 2008, 4, 17-28. (In Chinese)

117. Tangshan District Urban Planning Bureau (TSDUPB). The Master Plan of Tangshan City, China (2000); Open Report; Tangshan District Urban Planning Bureau: Tangshan, China, 1986. (In Chinese)

118. Tangshan District Urban Planning Bureau (TSDUPB). The Master Plan of Tangshan City, China (2003-2008); Open Report; Tangshan District Urban Planning Bureau: Tangshan, China, 2003. (In Chinese)

119. Tangshan District Urban Planning Bureau (TSDUPB). The Master Plan of Tangshan City, China (2008-2020); Open Report; Tangshan District Urban Planning Bureau: Tangshan, China, 2008. (In Chinese)

120. General Office of the People's Government of Hebei Province (GOPGHB). Hebei Rural Statistical Yearbook 2010; Statistics Press: Beijing, China, 2010. (In Chinese)

121. Tangshan Statistics Bureau (TSSB). 2010 Tangshan Statistical Yearbook; China Statistics Press: Beijing, China, 2010. (In Chinese)

122. Ministry of Construction of the People's Republic of China (MOC). Chinese Standard TJ 11-74: Code for Seismic Design of Industrial and Civil Construction; China Architecture \& Building Press: Beijing, China, 1974. (In Chinese)

123. Ministry of Construction of the People's Republic of China (MOC). Chinese Standard TJ 11-78: Code for Seismic Design of Industrial and Civil Construction; China Architecture \& Building Press: Beijing, China, 1978. (In Chinese)

124. Ministry of Construction of the People's Republic of China (MOC). Chinese Standard GBJ 11-89: Code for Seismic Design of Buildings; China Architecture \& Building Press: Beijing, China, 1989. (In Chinese)

125. Ministry of Construction of the People's Republic of China (MOC). Chinese Standard GB 50011-2001: Code for Seismic Design of Buildings; China Architecture \& Building Press: Beijing, China, 2001. (In Chinese)

126. Ministry of Housing and Urban-Rural Development of the People's Republic of China (MOHURD). Chinese Standard GB 50011-2010: Code for Seismic Design of Buildings; China Architecture \& Building Press: Beijing, China, 2010. (In Chinese)

127. China National Committee for Disaster Reduction (CNCDR). Integrated Assessment Model of Disaster Loss. In Comprehensive Analysis and Assessment of Wenchuan Earthquake Disaster; Science Press: Beijing, China, 2008; pp. 156-165. (In Chinese)

128. Zhang, S.L.; Ma, H.; Zhang, J.Y.; Yu, H.M.; Li, Y. The Report of Study on Earthquake Damage Prediction and Defensive Countermeasures in Nanyang City, Henan Province, China; Open Report; China Earthquake Networks Center: Beijing, China, 2006. (In Chinese)

129. Zhang, S.L.; Du, X.X.; Zhang, Y.; Xu, Y.; Shao, C.L.; Zhang, J.Y.; Zhou, J.; Zhu, J.Q. The Report of Seismic Hazard Assessment and Earthquake Damage Prediction in Handan City, Hebei Province, China; Open Report; China Earthquake Networks Center: Beijing, China, 2008. (In Chinese) 
130. Li, Y.G.; Zhang, Y.; Du, X.X.; Wang, J.P. The Report of Seismic Hazard Assessment and Earthquake Damage Prediction in Urban Tangshan, Hebei Province, China; Open Report; National Earthquake Response Support Service: Beijing, China, 2012. (In Chinese)

131. Standardization Administration of China (SAC). Chinese Standard GB/T 24335-2009: Classification of Earthquake Damage to Buildings and Special Structures; Standards Press of China: Beijing, China, 2009. (In Chinese)

132. The Federal Emergency Management Agency (FEMA). HAZUS: Multi-hazard Loss Estimation Methodology (HAZUS-MH-MR4); Technical Manual; FEMA: Washington, DC, USA, 2003. Available online: http://www.fema.gov/library/viewRecord.do?id=3731 (accessed on 15 September 2009).

133. China Earthquake Administration (CEA). Seismic Disaster Loss Assessment in China Mainland from 1996 to 2000; Seismological Press: Beijing, China, 2001. (In Chinese)

134. China Earthquake Administration (CEA). Seismic Disaster Loss Assessment in China Mainland from 2001 to 2005; Seismological Press: Beijing, China, 2010. (In Chinese)

135. China Earthquake Administration (CEA). Annual Earthquake Disasters. 2011. Available online: http://www.csi.ac.cn/publish/main/21/100640/index.html (accessed on 19 February 2011). (In Chinese)

136. Yuan, Y.F. Post-Earthquake Field Works-Part 4: Assessment of Direct Loss (GB/T 18208.4-2005); Seismological Press: Beijing, China, 2005. (In Chinese)

137. Project of Earthquake Prevention and Disaster Reduction in Chinese Large and Medium-Sized Cities (PEPDR). The Report of Study on Earthquake Damage Prediction and Defensive Countermeasures in Nan'an and Quanzhou City, Fujian Province, China; Open Report; Fujian Earthquake Administration: Fuzhou, China, 2000. (In Chinese)

138. Huang, Y.Q.; Li, J.; Cao, J.R. The Fundamental Research of Earthquake Disaster Prevention Planning in Kaifeng. In Urban Planning on Earthquake Resistance and Disaster Prevention in Kaifeng, Henan Province, China; Seismological Press: Beijing, China, 1998; pp. 51-176. (In Chinese)

139. Feng, Q.M.; Jiao, S.J.; Chen, J.H. Earthquake Damage Prediction in Longyan, Fujian Province, China; Seismological Press: Beijing, China, 2004. (In Chinese)

140. Li, Y.G.; Du, X.X.; Zhang, L.X.; Sun, M.X. The Report of Earthquake Damage Prediction and Preventing Strategies in Urban Nantong, Jiangsu Province, China; Open Report; National Earthquake Response Support Service: Beijing, China, 2009. (In Chinese)

141. Hu, S.Q.; Sun, B.T.; Zhang, Y.L. The approach on making empirical earthquake damage matrix complete using beta distribution. Key Eng. Mater. 2010, 452-453, 209-212.

142. Wei, B.W.; Xu, W.F.; Liu, X.X. Study on the architectural culture of human residence in northeast China. J. Jilin Inst. Arch. Civ. Eng. 2010, 27, 31-34. (In Chinese)

143. Yuan, C.X. Ecologic architecture and traditional dwellings of Western Regions. J. NW Inst. of Arch. Eng. (Nat. Sci.) 2002, 19, 34-37. (In Chinese)

144. China Earthquake Administration (CEA). The Disaster Assessment Report of the Yushu Ms. 7.1 Earthquake in 2010; Open Report; China Earthquake Administration: Beijing, China, 2010. (In Chinese) 
145. Jin, Y.; Jin, Y.B. Research and thinking on vernacular residential architectural in Western China. Arch. Cult. 2011, 5, 50-51.

146. China Earthquake Administration (CEA). Workshop for Predicating Yearly Key Seismic Risky Areas. 2010. Available online: http://www.cea.gov.cn/manage/html/8a8587881632fa5c0116674a 018300cf/_content/10_04/07/1127062929412.html (accessed on 10 April 2010). (In Chinese)

147. Jiang, F. Haicheng Earthquake; Seismological Press: Beijing, China, 1978. (In Chinese)

148. Zhu, F.M.; Wu, G. Haicheng Earthquake in 1975; Seismological Press: Beijing, China, 1982. (In Chinese)

149. Raleigh, C.B.; Bennett, G.; Craig, H.; Hanks, T.; Molnar, P.; Nur, A.; Savage, J.; Scholz, C.; Turner, R.; Wu, F.M.; et al. Prediction of the Haicheng earthquake. EOS Trans. Am. Geophys. Union 1977, 58, 236-272.

150. China Centre for Resources Satellite Data and Application (CRESDA). GF-1. Available online: http://www.cresda.com/n16/n1130/n188475/188494.html (accessed on 8 October 2014). (In Chinese)

151. Airbus Defence \& Space. SPOT 1 to SPOT 5. Available online: http://www.geoairbusds.com/en/4388-spot-1-to-spot-5-satellite-images (accessed on 8 October 2014).

152. National Space Organization (NSPO). FORMOSAT-2. Available online: http://www.nspo.org.tw/ 2008e/projects/project2/intro.htm (accessed on 8 October 2014).

153. Qiu, W. Simple analysis of the highway transportation development level in China. Highway 2009, 3, 116-120. (In Chinese)

154. Ministry of Transport of the People's Republic of China (MOT). The General Situation of Transportation Development in China. 2013. Available online: http://www.moc.gov.cn/ zhuzhan/jiaotonggaikuang/fazhanzongshu/jiaotongfazhan_GK/201306/t20130624_1437582.html (accessed on 14 July 2014). (In Chinese)

\section{Appendixes}

This appendix presents an example calculation of the proposed integrated method and describes what would occur and what would be different if the study area suffered a moderate seismic impact or a terrible seismic shock in 2009. We selected an intensity of VI on the Chinese Seismic Intensity Scale to represent a moderate impact and an intensity of $\mathrm{X}$ to represent a terrible shock. In addition, we assumed that the entire study area sustained an intensity of either VI or X without site-to-site variations. Based on the content in the main text of the paper, the calculated effect scenarios included building damage and direct monetary loss.

\section{A1. Equations}

We used Equations (A1) and (A2) to calculate the total potential damage to all residential and public office buildings in the study area in 2009 under two different intensity scenarios and used Equation (A3) to calculate the direct monetary loss due to damages to these buildings. Equations (A1)-(A3) are the same as Equations (8)-(10) in the main text of the paper respectively. For details regarding these equations, please see "Sections 4.3 and 4.4 " in the main text. 


$$
\begin{gathered}
A_{s}=B_{s} \times \sum_{j} P\left[D_{j} \mid I\right] \\
A=\sum_{s} A_{s} \\
L(I)=\sum_{s} \sum_{j} P\left[D_{j} \mid I\right] \times B_{s} \times b_{s} \times \varepsilon_{b j}+\sum_{s} \sum_{j} P\left[D_{j} \mid I\right] \times B_{s} \times a_{s} \times \varepsilon_{a j},
\end{gathered}
$$

\section{A2. Parameter Values}

Based on the findings of this study, the values of all relevant parameters in the above equations are as follows.

(1) $B_{S}$ : Total floor area of the $S$-type buildings. The specific numbers in 2009 are presented in the following table (Table A1).

Table A1. Total floor areas of each type of building in the study area and at different locations in $2009\left(B_{S}\right)$.

\begin{tabular}{ccccc}
\hline \multirow{2}{*}{ Place } & \multicolumn{4}{c}{ Floor Area $\left(\mathbf{m}^{\mathbf{2}}\right)$} \\
\cline { 2 - 5 } & S/B Building & B/C Building & R/C Building & Total \\
\hline Urban Center & 155,655 & $14,039,305$ & $5,453,503$ & $19,648,463$ \\
Dazhuangtuo & 746,774 & $1,494,957$ & 788,560 & $3,030,291$ \\
Xijiatao & 896,492 & 842,404 & 218,313 & $1,957,208$ \\
Wali & $1,636,137$ & 39,379 & 0 & $1,675,516$ \\
Kaiping & $3,142,172$ & $1,485,959$ & $1,274,413$ & $5,902,544$ \\
Yuehe & $1,573,173$ & 303,833 & $1,080,907$ & $2,957,914$ \\
Zhengzhuangzi & $1,065,284$ & 777,014 & 637,446 & $2,479,745$ \\
Guoyuan & $5,239,494$ & $4,673,749$ & $4,908,266$ & $14,821,509$ \\
Nvzhizhai & $4,930,949$ & $1,885,978$ & 344,287 & $7,161,214$ \\
Fengnan & $3,854,459$ & $5,091,162$ & $2,902,065$ & $11,847,685$ \\
Entire study area & $23,240,589$ & $30,633,740$ & $17,607,760$ & $71,482,089$ \\
\hline
\end{tabular}

(2) $P\left[D_{j} \mid I\right]$ : DPMs of the buildings. For specific values, please see Table 4 in Section 4.3 of the main body of the paper.

(3) I: Seismic intensity. As previously described in the appendix, we selected an intensity of VI to represent a moderate impact intensity and $\mathrm{X}$ to represent a heavy shock. The same intensity (VI or X) was maintained without any variations between the sites.

(4) $a_{s}$ : Mean monetary value of the building contents per unit floor area of the $S$-type buildings. The specific values for the study area in 2009 are provided in Table A2.

Table A2. Mean monetary values of the building contents per unit floor area for each type of building $\left(a_{s}\right)$.

\begin{tabular}{cccc}
\hline Structural Type & S/B Building & B/C Building & R/C Building \\
\hline $\boldsymbol{a}_{\boldsymbol{s}}\left(\mathrm{USD} / \mathbf{m}^{2}\right)$ & 23 & 60 & 60 \\
\hline
\end{tabular}


(5) $b_{s}$ : Replacement cost per unit floor area of the $S$-type buildings. Specific values for the study area in 2009 are provided in Table A3.

Table A3. Replacement costs of the per unit floor area of each type of building $\left(b_{s}\right)$.

\begin{tabular}{cccc}
\hline Structural Type & S/B Building & B/C Building & R/C Building \\
\hline $\boldsymbol{b}_{\boldsymbol{s}}\left(\mathrm{USD} / \mathbf{m}^{2}\right)$ & 75 & 120 & 180 \\
\hline
\end{tabular}

(6) $\varepsilon_{a j}$ Loss ratio of the building contents with the degree of building damage $(j)$. The specific values are presented in Table A4.

Table A4. Building content loss ratios $\left(\varepsilon_{a j}\right)$ under different damage degrees.

\begin{tabular}{ccccccc}
\hline & No Damage & Slight Damage & Moderate Damage & Major Damage & Collapse \\
\hline$\varepsilon_{a j}(\%)$ & 0 & 0 & 5 & 25 & 85 \\
\hline
\end{tabular}

(7): $\varepsilon_{b j}$ : Loss ratio of the $S$-type buildings with a damage degree of $j$. The specific values are presented in Table A5.

Table A5. Loss ratios of different types of buildings $\left(\varepsilon_{b j}\right)$ under different damage degrees.

\begin{tabular}{cccccc}
\hline & No Damage & Slight Damage & Moderate Damage & Major Damage & Collapse \\
\hline$\varepsilon_{b j}$ of S/B building (\%) & 0 & 6 & 19 & 55 & 85 \\
$\varepsilon_{b j}$ of B/C building (\%) & 0 & 8 & 20 & 60 & 90 \\
$\varepsilon_{b j}$ of R/C building (\%) & 0 & 8 & 20 & 60 & 90 \\
\hline
\end{tabular}
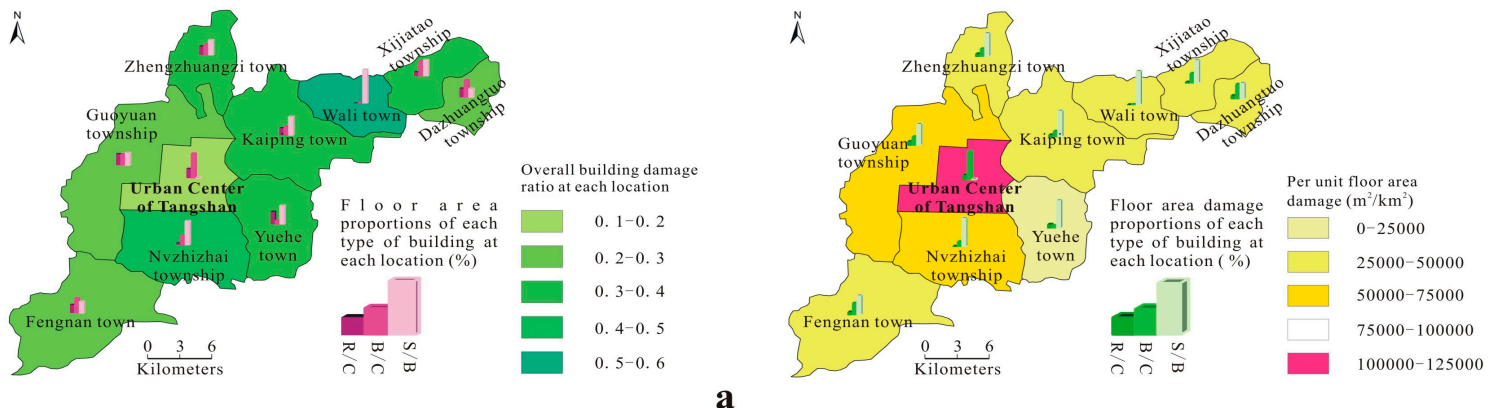

$\mathbf{a}$
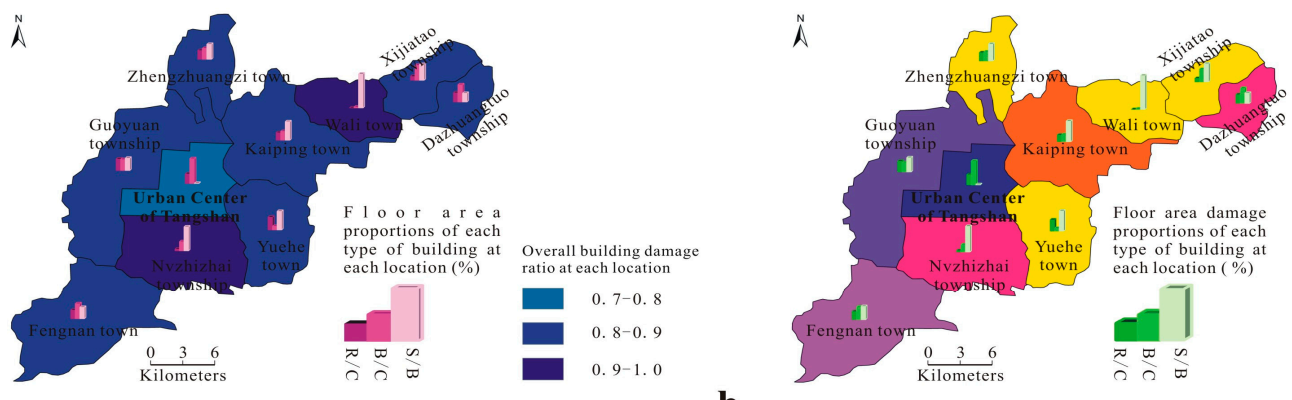

Per unit floor area
damage $\left(\mathrm{m}^{2} / \mathrm{km}^{2}\right)$

damage $\left(\mathrm{m}^{2} / \mathrm{km}^{2}\right)$
$50000-75000$

75000-100000

100000-125000

$125000-150000$
$150000-175000$

b

Figure A1. Building damage scenarios in the study area in 2009 based on scenario intensities of VI and X. (a) Damage scenarios under intensity VI; (b) Damage scenarios under intensity $\mathrm{X}$. 


\section{A3. Results}

\section{A3.1. Building Damage Scenarios}

If the study area suffered a seismic intensity of VI in 2009 , only the S/B buildings would have sustained significant/substantial damage. The damage of many of these buildings could reach the Moderate degree of damage, and some could reach the Major degree of damage. However, the B/C and $\mathrm{R} / \mathrm{C}$ buildings would only sustain a light impact (i.e., Slight degree of damage). The spatial distributions of the damages throughout the study area when subjected to the same impact intensity of VI indicated that the locations with larger building damage ratios would mainly be rural (Figure Ala), where S/B buildings were dominant in 2009 (Table A1 and Figure 8a in the main body). However, if a seismic intensity of $\mathrm{X}$ affected the area in 2009, the residential and public office use buildings sustaining serious damage and destruction would have included all of the $\mathrm{S} / \mathrm{B}, \mathrm{B} / \mathrm{C}$ and $\mathrm{R} / \mathrm{C}$ buildings. In this scenario, few places in the study area would be free of heavy impacts (Figure A1b).
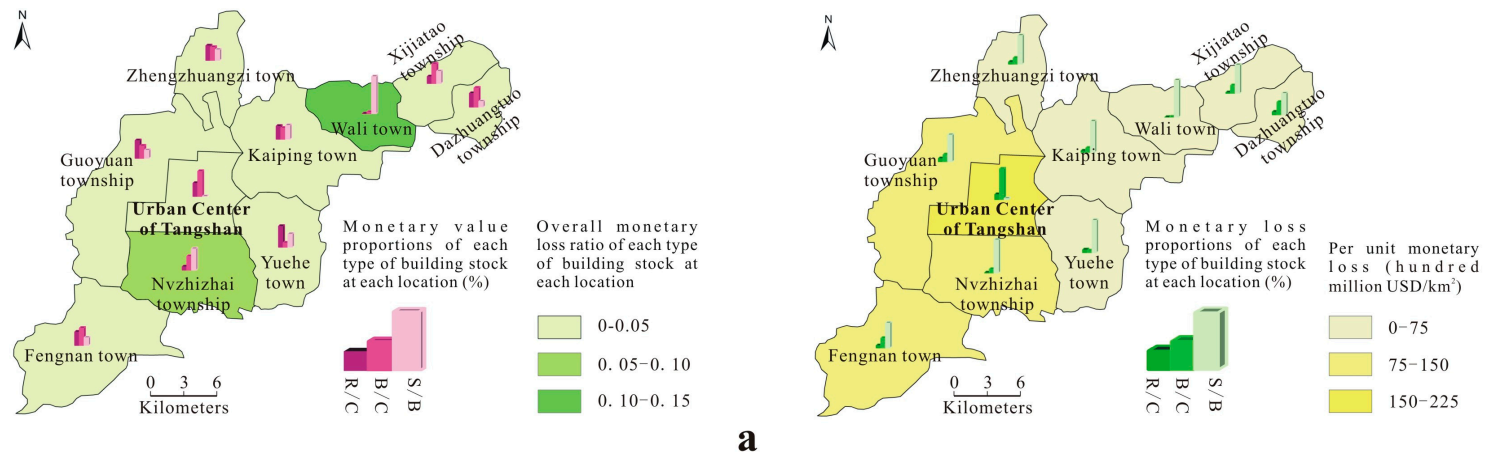

a
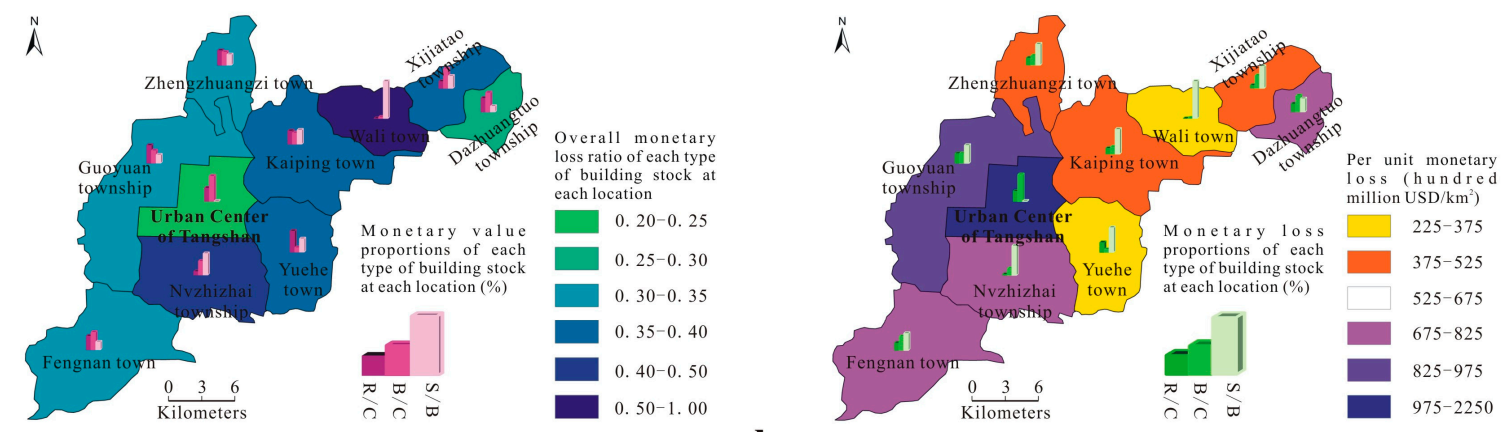

b

Figure A2. Direct monetary loss scenarios of the study area in 2009 by setting hypothetical intensities as VI and X, respectively. (a) Loss scenarios under intensity VI; (b) Loss scenarios under intensity $\mathrm{X}$.

\section{A3.2. Direct Monetary Loss Scenarios}

If a seismic intensity of VI was encountered in 2009, the direct monetary losses in the study area would mostly have resulted from the damage to the S/B buildings. In terms of spatial appearance, the places with larger loss ratios would be rural locations (Figure A2a) where most of the buildings were S/B in 2009 (Table A1 and Figure 8a in the main body). However, if an intensity of X occurred, the direct monetary losses of the study area would have resulted from severe and heavy damages of all 
of the $\mathrm{S} / \mathrm{B}, \mathrm{B} / \mathrm{C}$ and $\mathrm{R} / \mathrm{C}$ buildings. In terms of spatial differences in this impact case, urban centers and some periurban regions would sustain the heaviest monetary losses within the study area (Figure A2b). This significant feature is a combined product of the following factors: (1) Greater building densities occur and more good/high standard buildings exist in the urban and periurban locations (Table A1 and Figure 8a in the main body); (2) Good/high standard buildings require higher replacement and repair costs; and (3) The building contents in these locations are usually greater and more expensive relative to other locations in the study area.

(C) 2015 by the authors; licensee MDPI, Basel, Switzerland. This article is an open access article distributed under the terms and conditions of the Creative Commons Attribution license (http://creativecommons.org/licenses/by/4.0/). 